\title{
Hematopoietic stem cell transplantation: ASBMT/CIBMTR 2010 tandem meeting highlights and discussion
}

\author{
Noelle V. Frey and David L. Porter*
}

The American Society for Blood and Marrow Transplantation (ASBMT) and the Center for International Blood and Marrow Transplantation Research (CIBMTR) held their 12th Annual Tandem Meeting this February in Orlando, Florida. This International Transplant Meeting brought together a record 2,570 attendees from 45 countries, and included the state of the art educational and plenary sessions and 478 oral and poster presentations. Recently, the American Journal of Hematology published a series of articles reviewing the "Top 10 clinically oriented abstracts" presented at the 2009 American Society of Hematology meeting [1]. Given how well this series was received, we believed it would be worthwhile providing a similar review of relevant abstracts from this year's BMT meetings. There has been dramatic progress in this field that we believe is of great interest and importance to the hematology/oncology community. There was an incredible body of work presented and it is misleading to suggest that there is a "top 10" list. Many more abstracts than can be presented here are worthy of discussion and recognition and any exclusion of important studies is solely a reflection of space limitation rather than quality of work. We tried to pick abstracts that were important, novel, biologically interesting, and that address either changing or controversial areas in the field. All 10 abstracts are published in full in the February 2010 issue of Biology of Blood and Marrow Transplantation (volume 16, No. 2) and are identified here by their abstract number.

Frequency of CD4 ${ }^{+} \mathrm{CD}_{25} 5^{\mathrm{hi}} \mathrm{FOXP}^{+}$Regulatory T Cells Has Diagnostic and Prognostic Value As a Biomarker for Acute Graft-Versus-Host-Disease (\#5)

Abstract Summary

The diagnosis and severity of acute graft versus host disease (GVHD) is typically based on clinical and laboratory observations that are often subjective or inconclusive. For instance, a skin rash may be graded as GVHD by one observer and attributed to an allergic drug reaction by a second observer. Biopsies of involved organs may be useful but can be associated with significant risk and may also return conflicting or inconclusive results. For many years investigators have attempted to identify biomarkers to predict and diagnose GVHD [2,3] and ideally herald the onset and severity before clinical symptoms develop allowing for early intervention and better, more effective, and targeted immunosuppressive therapies. To date, however there are no validated diagnostic or prognostic noninvasive tests for acute GVHD.

Regulatory T cells (Tregs) have been found to be important mediators of tolerance after experimental hematopoietic SCT, and have been used to prevent and treat GVHD in murine models [4]. While there is great interest in using Tregs therapeutically in clinical transplantation, just the presence and number of Tregs could serve as a useful biomarker for GVHD. The study by Magenau et al. uses flow cytometry to measure CD4+/CD25hi/FOXP3+ Tregs in 215 patients with $(n=60)$ and without $(n=155)$ GVHD.

Patients with GVHD $(N=60)$ had a Treg frequency that was $40 \%$ less $(0.66 \% \pm 0.07, P<0.001)$ than those without GVHD and Treg frequency was identified as a significant independent biomarker of GVHD. Furthermore, Treg frequency correlated with the maximum overall grade of GVHD $(r=-0.33 ; P<0.001)$, suggesting Treg values could predict severity and potential prognosis of GVHD.

To test this they then divided patients according to the median Treg frequency. Patients with Treg frequency below the median had significantly higher nonrelapse mortality (largely attributable to GVHD) compared to patients with Treg frequency above the median $41 \%$ vs. $8 \%, P=0.03$. This translated into inferior 2 year survival of $38 \%$ versus $63 \%(P=0.03)$. There was no difference in relapse mortality according to Treg frequency.

This analysis shows that the frequency of $\mathrm{CD} 4{ }^{+} \mathrm{CD} 25^{\mathrm{hi}} \mathrm{FOXP}^{+}{ }^{+}$Tregs at the onset of GVHD correlates with ultimate severity, nonrelapse mortality, and overall survival. It will be of interest to determine whether Tregs can predict the onset of GVHD and whether therapy can be targeted depending on the frequency of regulatory T cells identified at GVHD onset. This relatively simple and rapid flow cytometry assay may have important diagnostic and prognostic value in patients developing clinical findings consistent with graftversus-host disease after hematopoietic SCT.

CCR5 Expression on Circulating Blood DC Post Allogeneic Hematopoietic Cell Transplant is Highly Predictive for the Development of Clinically Significant Acute Graft versus Host Disease (\#23)

\section{Abstract Summary}

GVHD affects $20-70 \%$ of allogeneic SCT recipients and can result in significant transplant-related morbidity and mortality due to tissue injury and opportunistic infections from intensive and chronic immunosuppressive therapy [5-7]. GVHD is initiated by both host and donor antigen presenting cells [including dendritic cells (DC)] and mediated by memory and effector T cells of donor origin. A better understanding of the pathogenesis of GVHD is needed and could lead to more effective preventative or therapeutic interventions and better outcomes from SCT.

Sartor and colleagues report results of their investigations into the relationship between the severity of acute GVHD and the expression of the chemokine receptors CCR5 and CCR7 on dendritic cells, which are critical molecules for mediating DC trafficking into tissues. They evaluated serial peripheral blood samples from 32 patients after allogeneic SCT and 11 developed grade II-IV GVHD. The percentage of DC expressing either CCR5 or CCR7 was calculated and correlated with the development of acute GVHD. CCR7 expression showed no association with GVHD. In contrast, higher CCR5 expression was detected on DC in patients developing grade II-IV GVHD compared to DC in patients with grade 0 -I GVHD $(P<0.0001)$. All 11 patients with grade II-IV GVHD expressed CCR5 in over $35 \%$ of their DCs while only 2 of 21 patients with grade $0-1$ GVHD expressed CCR5 at this high a percentage. Most importantly, the expression of CCR5 on DC preceded the development of moderate to severe GVHD by a median of 19 days (range 2-47 days; samples drawn twice weekly).

This is an exciting study which identifies a biologic marker which predicts for the development of GVHD; if verified, this could result in preventative modulation of immunosuppressive therapy for certain patients found to be at higher and lower risk for GVHD. In addition this study highlights a specific potential target for GVHD intervention (the CCR5 receptor), which has gained notoriety as the site of entry for HIV into lymphocytes. Other studies have suggested that CCR5 is important for development of GVHD [8,9]. For this reason CCR5 antagonists such as maraviroc may be potential mediators of GVHD and should be studied in clinical trials.

\section{Common Cold Viruses Early After HSCT Are Associated With} Life Threatening Alloimmune Lung Syndromes (\#36)

\section{Abstract Summary}

Alloimmune lung syndromes after allogeneic SCT include Idiopathic Pneumonia Syndrome (IPS) and bronchiolitis obliterans (BO), and are major causes of morbidity and mortality. The incidence appears higher after allogeneic stem cell transplant compared to autologous stem cell transplant suggesting pulmonary toxicity is not solely related to high dose conditioning therapy. Inflammatory cytokines have been implicated in the pathogenesis of IPS and the risk of BO is higher in patients with chronic GVHD $[10,11]$ Nevertheless the precise etiology of pulmonary toxicity after transplant is not well defined. 
Early infection with common respiratory viruses (RV) after lung transplant has been associated with both acute and chronic rejection. To determine if an infection with RVs was associated with alloimmune lung syndromes after hematopoietic SCT, Versluys et al. performed a prospective trial in 110 pediatric patients receiving a variety of graft sources for both malignant and nonmalignant diseases and conditions with either TBI (33) or chemotherapy based (77) conditioning regimens. They used quantitative PCR of nasopharyngeal aspirates to monitor for the most common RVs and found that $50 \%$ of patients had evidence of infection at a median of day +16 after transplant (range: 7-100). The most frequent infection was Rhinovirus (28), followed by Parainfluenzavirus 1-3, Coronavirus, Influenza A virus and Adenovirus. They reported that clinical symptoms were mild and all patients recovered spontaneously.

During this time, patients were monitored for pulmonary toxicity and $16 \%$ were diagnosed with IPS and 11\% ultimately diagnosed with BO. Multivariable analysis showed that any RV infection was associated with subsequent development of an alloimmune lung syndrome $(P<0.0001)$ independent of the type of viral infection. Interestingly the development of acute GVHD was associated with a lower risk of an alloimmune lung syndrome $(P=0.004)$, perhaps related to the protective effects of prolonged immunosuppression. Most striking was the finding that development of an alloimmune lung syndrome was the only predictor for mortality $(P=0.04)$. Overall survival was $73 \%$ for all patients but $53 \%$ for patients who developed pulmonary toxicity.

Although tissue damage, inflammatory cytokines, and an allogeneic "graft vs. lung" effect have all been implicated in the development of IPS and BO, the precise etiology of these syndromes is not well-defined. This study implicated common RV as a major risk factor for alloimmune lung syndromes. It is possible that these infections enhance local inflammation or changes that make the lung a target for allogeneic recognition. This is supported by the protective effects of acute graft vs. host disease perhaps related to the prolonged use of immunosuppression. This study is important for several reasons. The high incidence of respiratory virus infection (50\%) is concerning in itself and may support the use of reverse isolation precautions so common in many transplant centers. This study suggests a possible mechanism of pulmonary toxicity after allogeneic transplant and should lead to further prospective studies for early monitoring, protection, and intervention of patients undergoing transplant. It would also be of interest to determine if early common RV infections occur with this frequency and are associated with pulmonary toxicity and adult patients undergoing HSCT.

Prochymal Improves Response Rates in Patients with SteroidRefractory Acute Graft Versus Host Disease (SR-GVHD) Involving the Liver and Gut: Results of a Randomized, Placebo-Controlled, Multicenter Phase III Trial in GVHD (41)

\section{Abstract Summary}

Treatment options for steroid-refractory GVHD (SR-GVHD) are unsatisfactory and prognosis is poor. The use of conventional intensive therapies to inhibit T-cells and inflammatory cytokines often result in high response rates ranging between 30 and $70 \%$, but consistently long-term survival is limited ranging between 5 and $30 \%$ [12,13]. Available therapies are limited both by lack of response as well as by high mortality from infectious complications related to intensive immunosuppression. There is immediate need to develop effective and safe therapies for SR-GVHD.

Martin et al. presented promising results of a phase III study comparing institutionally selected second line therapy with or without the addition of Prochymal, a mesenchymal stem cell (MSC) product derived from unrelated volunteer adult donors.

This was a large study enrolling 244 patients. Most patients have advanced GVHD; IBMTR severity index grade for Prochymal vs. placebo treated patients was B in 22 vs. $26 \%$, C in 51 vs. $58 \%$, and D in $27 \%$ vs. $16 \%$. The groups were well matched and randomized in a 2: 1 fashion. Although the intention to treat analysis showed no difference in durable complete response (DCR) rates (35 vs. $30 \%, P=0.3$ ), there was a trend toward better DCR in the treated population at $40 \%$ vs. $28 \%(P=0.08)$. For the 22 patients with involvement of three organs, the rate of CR/PR at day 28 was $63 \%$ for the treatment group compared to $0 \%$ for the placebo group ( $P<$ $0.05)$. Importantly there was no significant difference in infections, relapse ( $9 \%$ vs. $8 \%$ ) or adverse events.

Various case reports and phase II trials have demonstrated potential efficacy with a good safety profile of MSCs for GVHD. This study can be com- mended simply for completing a randomized study in a large group of patients with SR-GVHD. Response rates in the MSC-treated patients were reasonable, and higher than placebo-treated patients. Nevertheless, despite including such a large number of patients, many questions remain unanswered. Would MSCs be most effective combined with a specific consistent second-line therapy? Numerous trials of SR-GVHD show high response rates but ultimately limited survival due to recurrent GVHD, infections, and even relapse; long-term outcomes beyond day 100 from this trial will be important to report for the transplant community. Finally, given the suggestion of important activity, further studying the role of MSCs for GVHD therapy earlier in the course of the disease will be important.

\section{Second Solid Cancers After Allogeneic Hematopoietic-Cell Transplantation Using Busulfan-Cyclophosphamide Conditioning (\#59)}

\section{Abstract Summary}

The number of patients undergoing autologous and allogeneic SCT has continued to increase over time. This, in combination with improvements in short-term treatment-related mortality rates has led to an increased prevalence of SCT recipients in the population who have unique long-term health care needs related to their survivorship. A potentially devastating long-term complication of SCT is the development of secondary malignancies [14]. Secondary myelodysplastic syndrome or acute myeloid leukemia usually occur within the first 7 years after SCT [15]. The risk of developing solid tumors however continues to increase with time and patients are often no longer under the care of a transplant physician at the time of increased risk. Secondary solid tumors predominantly occur in the upper Gl tract, oral cavity, brain, soft tissues and skin. A clear dose response has been found with the use of total body radiation and the incidence of solid tumors after SCT $[16,17]$. In addition to increased risk from the direct cytotoxic effects of the conditioning regimen, chronic inflammation (as in the setting of GVHD), chronic immunosuppression (with increase risk of viral infection and decreased tumor surveillance) and increased genetic susceptibility may also play roles in the pathogenesis of these secondary tumors after allogeneic SCT $[14,17]$.

The authors in this study report the incidence and risk factors associated with the development of solid tumors in 4349 pediatric and adult patients who underwent allogeneic stem cell transplant (SCT) for acute myelogenous leukemia $(A M L)$ in $C R 1$ or chronic myelogenous leukemia $(C M L)$ in first chronic phase. All subjects received chemotherapy only conditioning regimens with busulfan and cyclophosphamide. The median time of follow-up for survivors was 8.2 years; $47 \%$ of patients were alive and evaluable at 5 years after SCT and $18 \%$ were alive and evaluable at 10 years after SCT. Sixty-six solid cancers were reported; the cumulative incidence of solid tumors at 3, 5 and 10 years after SCT were $0.7,0.9$, and $2.0 \%$ for AML patients and 0.5, 1.1 , and $3.4 \%$ for $C M L$ patients. These rates were higher than expected rates in the general population. Significantly higher rates of solid tumors were found [reported as observed to expected ratio $(\mathrm{O} / \mathrm{E})$ ] for cancers of the lip $(\mathrm{O} / \mathrm{E}=25.7)$, tongue $(\mathrm{O} / \mathrm{E}=9.1)$, mouth $(\mathrm{O} / \mathrm{E}=7.2)$, esophagus $(\mathrm{O} / \mathrm{E}$ $=10.3)$, lung $(\mathrm{O} / \mathrm{E}=2.6)$, soft tissue $(\mathrm{O} / \mathrm{E}=7.1)$ and brain $(\mathrm{O} / \mathrm{E}=4.7)$. On Cox-regression analysis, risk factors for developing solid tumors included older age, chronic GVHD and use of peripheral blood (as opposed to bone marrow) as a stem cell source.

This study supports the fact that SCT recipients are at significant longterm risk for the development of secondary solid tumors. Further longer term reports from larger cohorts of SCT recipients are needed to better define overall risk over time. It is important for patients and their physicians to be aware of these risks to modify screening and preventative techniques in this patient population.

\section{Pre-Transplant Consolidation Chemotherapy Does Not Improve Rates of Relapse Following Reduced Intensity Conditioning (RIC) Hematopoietic Stem Cell Transplantation (HCT) for AML in CR1 (\#63) \\ Abstract Summary}

Post remission chemotherapy with cytarabine before myeloablative allogeneic SCT has not been shown to affect outcomes for patients with AML $[18,19]$. Transplants using a reduced intensity conditioning regimen (RIC$\mathrm{SCT}$ ) are being used more frequently as post remission therapy for $\mathrm{AML}$ in 
an effort to limit transplant related toxicity and broaden potential treatment options for older and sicker patient populations. The role of pretransplant consolidative chemotherapy may be different in the RIC-SCT setting than the myeloablative setting. One could hypothesize that with less intensive conditioning therapy, additional rounds of cytarabine-based consolidation chemotherapy before RIC-SCT would result in lower relapse rates by minimizing residual disease. Alternatively, RIC-SCT recipients tend to be older and sicker than myeloablative SCT recipients and increased rounds of therapy before SCT may contribute to more treatment-related mortality.

In this report, McCormack and colleagues retrospectively reviewed outcomes of 61 patients at their institution who underwent nonmyeloablative SCT and evaluated the impact of pretransplant consolidation chemotherapy on outcome. All patients had AML in $\mathrm{CR} 1$ at time of transplant and received either HLA matched sibling $(n=18)$, cord blood $(n=42)$ or unrelated $(n=1)$ donor grafts. Of these patients, 26 received pretransplant consolidation $(73 \%$ received 1 round; range $1-3$ ) and 35 received none: $58 \%$ and $40 \%$ in each group respectively had high-risk cytogenetics. In univariate analysis, exposure to pre-SCT consolidation therapy had no impact on 2 year OS or relapse rates and did not increase treatment related mortality rates (See Table I). In multivariate analysis (variables tested: comorbidity score, number of induction cycles to achieve $\mathrm{CR}$, high risk cytogenetics) exposure to consolidation therapy still had no effect on relapse. The only variable significantly associated with treatment related mortality was comorbidity score.

This study suggests that in the RIC-SCT setting, pre transplant consolidation may not impact outcomes. It also further validates the value of the pretransplant comorbidity score on predicting treatment-related mortality. It is important to point out that the numbers of patients evaluated in this study are small and composed mostly of cord blood recipients. The study is likely underpowered to detect a significant difference in outcomes and outcomes from RIC-SCT cord recipients are likely different from recipients of RIC sibling or unrelated SCTs. Nevertheless, this is an important topic that warrants further investigation in the cord blood, sibling and unrelated setting using larger cohorts of patients.

\section{Multi Tumor Antigen Specific Cytotoxic T Lymphocytes for Therapy of Hematologic Malignancies (\#64) \\ Abstract Summary}

Tumor-specific immunotherapy holds great promise, but in most cases tumor-specific antigens are not well defined and numerous strategies have been limited in part by the inability to generate functional tumor-specific $T$ cells. In some cases this is due to the low frequency of tumor-reactive $T$ cells. Furthermore, even when they can be isolated they may be anergized, tolerized, or after allogeneic SCT, they may be senescent and unable to expand [20]. The most successful use of targeted cellular therapy has been with the generation of viral-specific $T$ cells to treat viral-associated malignancies such as EBV-associated Hodgkin's disease or post-transplant lymphoproliferative disorders [21].

Gerdemann et al. reported on an important technical advance in the ability to generate tumor-specific $T$ cells. T cells are activated in the presence of autologous dendritic cells (DCs) transfected with plasmids encod-

TABLE I. Two-Year Outcomes: Univariate Analysis

\begin{tabular}{lccr}
\hline & No Pre-HCT & Pre-HCT & \\
& consolidation $n=35$ & consolidation $N=26$ & $P$-Value \\
\hline OS & $48 \%(30-64 \%, 95 \% \mathrm{Cl})$ & $35 \%(12-59 \%, 965 \% \mathrm{Cl})$ & 0.74 \\
Relapse & $29 \%(14-45 \%, 95 \% \mathrm{Cl})$ & $43 \%(23-62 \%, 95 \% \mathrm{Cl})$ & 0.23 \\
TRM & $27 \%(30-64 \%, 95 \% \mathrm{Cl})$ & $6 \%(30-64 \%, 95 \% \mathrm{Cl})$ & 0.05 \\
\hline
\end{tabular}

ing multiple potential tumor-associated antigens or pulsed with tumor-associated antigen peptides. This permits generation of $\mathrm{T}$ cells specific for multiple antigens and multiple epitopes. Antigens and epitopes would not be restricted to a specific HLA polymorphism as occurs when tumor-specific T cells are generated against only 1 specific peptide that is expressed in an HLA-restricted manner. Polyclonal T cell activation occurs by exposure to a potent cocktail of cytokines developed to promote generation of Th1 cells (IL12), inhibit expansion of Tregs (IL-6) and provide enhanced survival and proliferative signals (IL15). To target lymphoma, they combined three potential lymphoma associated antigens, SSX2, Survivin, and MAGEA4 and generated "multi-tumor associated antigen cytotoxic T cells" (multiTAA CTL) against all three antigens from six healthy donors. They showed that these cells had activity against autologous antigen pulsed targets and whole antigen expressing fibroblasts and were not reactive against control targets. Similarly to target myeloid leukemia they combined WT1, Prame, PR3, and Survivin and generated multispecific $T$ cells against all antigens from two healthy donors.

To date, tumor-specific cellular therapy has been successful primarily when well-defined viral associated antigens can be defined and targeted. Multiple potential tumor-associated antigens have been identified but development of targeted cellular therapy has been limited by inability to generate sufficient, HLA-restricted $\mathrm{T}$ cells, and in the case of patients who have had prior allogeneic SCT, donor T cell senescence has limited ability to expand tumor-specific $T$ cells [20]. This technical advance is important since it permits generation of CTLs against multiple tumorassociated antigens and therefore may reduce the risk of tumor escape; it is likely that multiple antigens will need to be targeted for maximal efficacy. Furthermore, the ability to generate CTLs with multiple specificities markedly increases the efficiency of this approach and eliminates the need for specific polymorphic HLA-restriction. It will be of interest to see if activation by this method can reverse functional tolerance or senescence in patients with primary disease or after allogeneic stem cell transplantation.

\section{Autologous Stem Cell Transplantation (ASCT) for HIV-Related Lymphomas in the HAART Era: A Meta-Analysis of Response and Survival Post Transplant (\#114) \\ Abstract Summary}

The prognosis for HIV-infected patients with non-Hodgkin lymphoma $(\mathrm{NHL})$ has improved dramatically since the consistent use of highly-active anti-retroviral therapy (HAART) and conventional chemotherapy. Despite initial reports showing lower responses and higher mortality from combination chemotherapy in HIV-infected patients, in the modern era HAART-treated patients with diffuse large B-cell lymphoma treated with $\mathrm{CHOP}$ or rituximabCHOP have similar outcomes to patients without HIV infection [22]. Nevertheless, many patients relapse and lymphoma remains a significant cause of death for patients with HIV-related lymphoma. In the past, HIV infection was felt to be a contraindication to autologous SCT out of concern for excessive toxicity and poor response rates. Currently, several reports suggest that HIVinfected patients may tolerate autologous SCT similar to non-HIV-infected patients [23].

Sunil et al. performed a meta-analysis that ultimately included five studies and abstracts dealing with autologous SCT for patients with HIV related lymphoma. They were 35 patients with Hodgkin lymphoma and 83 with NHL. Outcomes were as impressive as would be anticipated in a similar non-HIV infected population. After transplant, $71 \%$ of patients $(95 \% \mathrm{Cl} 60-80)$ achieved complete remission (CR) and 2 year overall survival was $71 \%$ (95\% Cl 61-79). A CR before transplant was highly predictive of a CR after transplant in 2 year overall survival. Overall this meta-analysis confirms the

TABLE II. Response Rates to Mycophenolate Based on MPA Levels

\begin{tabular}{|c|c|c|c|c|c|}
\hline & All patients & $\begin{array}{c}\text { Mean MPA } \\
\text { trough weeks } 1 \\
\text { and } 2>0.5 \mathrm{mg} / \mathrm{mL}\end{array}$ & $\begin{array}{c}\text { Mean MPA } \\
\text { trough weeks } 1 \\
\text { and } 2<0.5 \mathrm{mg} / \mathrm{mL}\end{array}$ & $\begin{array}{c}\text { Mean unbound } \\
\text { MPA trough }>0.015 \mathrm{mcg} / \mathrm{mL} \\
\text { trough weeks } 1 \text { and } 2\end{array}$ & $\begin{array}{c}\text { Mean unbound MPA } \\
\text { trough }<0.015 \mathrm{mcg} / \mathrm{mL} \\
\text { trough weeks } 1 \text { and } 2\end{array}$ \\
\hline Day 28 CR/PR & $\begin{array}{c}21(65.6 \%) / 5 \\
(15.6 \%)\end{array}$ & $19 / 19(100 \%)$ & $\begin{array}{l}7 / 13(54 \%) \\
(P=0.002\end{array}$ & $15 / 15(100 \%)$ & $\begin{array}{c}11 / 17(65 \%) \\
\quad(P=0.02)\end{array}$ \\
\hline
\end{tabular}

Notably there was no association between drug measurement and risk of infection by day 90 or overall survival at day 180 . 
community opinion that autologous SCT for HIV infected patients should not be contraindicated and is likely to result in comparable outcomes compared to a non-HIV-infected group of patients.

There are caveats to this report as there are in any meta-analysis. This is a retrospective analysis combining results of several case series. In addition there is likely to be significant reporting bias in this field. However the review of five studies including 111 patients support the conclusion that autologous transplant should be offered to HIV-infected patients as clinically appropriate and is not contraindicated. The authors appropriately conclude that prospective trials are necessary (and these data confirm that they are appropriate) and the community should anxiously await results from a planned multicenter prospective trial of autologous SCT in HIV-related lymphoma patients in development by the Blood and Marrow Transplant Clinical Trials Network (BMT CTN).

\section{The Graft-Versus-Myeloma Effect Using Nonmyeloablative or Reduced Intensity Allogeneic Hematopoietic Stem Cell Transplantation (HSCT) (\#204) \\ Abstract Summary}

A graft vs. myeloma (GVM) effect has been suggested in transplant studies and has been demonstrated as a "proof of principle" concept using DLI to treat relapsed myeloma [24]. However outcomes after DLI for relapsed myeloma have been disappointing [25] calling in to question the potential efficacy of nonmyeloablative allogeneic stem cell transplantation. Large series of allogeneic SCT are not available to guide treatment decisions.

Dr. Ringden for the CIBMTR reported on outcomes for 177 recipients of matched sibling allogeneic SCT conditioned with a nonmyeloablative or reduced intensity conditioning $(\mathrm{RIC})$ regimen for myeloma. The median age of patients was 50 (range 24-69) and 105 patients received a planned tandem autologous transplant followed by allogeneic SCT. With a median follow-up of 55 months (range 3-98) for all patients, and 25 months (range 376) for recipients of tandem autologous/allogeneic SCT, 3 year overall survival was quite reasonable at $45 \%(95 \% \mathrm{Cl} 33-58)$ for recipients of a single allogeneic SCT and 64\% (53-75) for recipients of tandem autologous/allogeneic SCT. Treatment related mortality (TRM) at 3 years was 27 (17-38)\% and $16(10-25) \%$ respectively and relapse rates were $48(36-60) \%$ and 41 (29-54)\%. The 3 year progression free survival (PFS) was $25(15-37) \%$ and $42(20-43) \%$ demonstrating that long-term control was possible in some patients. The multivariate analysis showed that chronic GVHD decreased the probability of relapse (RR $0.43, P=0.012$ ), though this effect was limited to patients without IgG myeloma for reasons that are difficult to explain. In addition, PFS was better with autologous + allogeneic HSCT compared to allogeneic SCT (RR 3.6, $P=0.001$ ), suggesting that dose intensive chemotherapy still has a major role in care of these patients.

This report has many limitations. In particular it is a retrospective study and it is not known how patients were selected for specific therapies. Some findings are not easily explained, such as a benefit of chronic GVHD in terms of relapse noted only in patients without IgG myeloma. Nevertheless, it is a large study using available registry data demonstrating that at least in some patients, a GVM effect can be generated and long-term disease control achieved. Defining the proper patient population, timing of transplant, and the role for autologous/allogeneic SCT before RIC allogeneic SCT remain important subjects for future studies that hopefully will someday harness the GVM effect for maximal benefit.

\section{Mycophenolate Pharmacokinetics and Association with Response to Acute Graft vs. Host Disease (GVHD) Treatment (\#385)}

\section{Abstract Summary}

Mycophenolate mofetil (MMF) is commonly used for GVHD prophylaxis, particularly in the setting of nonmyeloablative allogeneic SCT. It is also being used with increasing frequency to treat GVHD and may be more effective in combination with steroids than other therapies [26]. However, increasing evidence suggests that variable pharmacokinetics may be critical to efficacy of MMF.

As part of a randomized phase II trial from the Bone Marrow Transplant Clinical Trials Network (BMT-CTN), MMF $1 \mathrm{~g}$ twice daily plus corticosteroids was given as 1 of 4 possible therapies; MMF pharmacokinetics were studied in the context of acute GVHD response. This cohort included 32 patients and
MMF pharmacokinetic sampling occurred in weeks 1 and 2. Targets for therapeutic concentration of the active metabolite mycophenolic acid (MPA) were set at $0.5 \mathrm{mg} / \mathrm{mL}$ or unbound MPA at $0.015 \mathrm{mcg} / \mathrm{mL}$. One of the most significant findings was that approximately half of the patients did not achieve these drug levels, and drug levels had a direct impact on response rates.

The overall response rate of acute GVHD at day 28 and day 56 for all patients was impressive at 65.6 and $78 \%$ respectively as shown below. Single mycophenolic acid (MPA) pharmacokinetic measurements during weeks 1 and 2 after treatment did not correlate with $\mathrm{CR}$ at either day 28 or $56(P>$ 0.07). However, as shown in Table II, if the mean of weeks 1 and 2 are taken together and the MPA trough was above the thresholds noted, more patients achieved CR + PR compared to cases where the MPA trough was low.

There is increasing use of MMF for the prevention and treatment of acute GVHD. Although direct comparative data is limited, there is an expectation that this drug has significant activity and a favorable toxicity profile compared to other immunosuppressive therapies for GVHD. However, the pharmacokinetics have not been well defined in this setting. This analysis from Jacobson and colleagues for the BMT-CTN is important since it shows that obtaining therapeutic levels is important to optimize response rates for acute GVHD without resulting in increased risk of infection or limited survival at least by day 180 . This should directly impact how transplant physicians use MMF. Further pharmacokinetic studies will be needed to define the optimal dose and schedule, but consideration should be given to either close drug monitoring and/or altering dosing from 2 to $3 \mathrm{~g} /$ day or body weight dosing.

Director, Blood and Marrow Transplantation, Division of Hematology-Oncology, University of Pennsylvania Medical Center, Philadelphia, Pennsylvania Grant sponsor: NIH; Grant number: 5K24CA117879-04

${ }^{*}$ Correspondence to: David L. Porter, Director, Blood and Marrow Transplantation, Division of Hematology-Oncology, University of Pennsylvania Medical Center, 3400 Civic Center Boulevard, PCAM 2 West Pavilion, Philadelphia, PA 19104 E-mail: David.porter@uphs.upenn.edu Conflict of interest: Nothing to report. Published online 27 April 2010 in Wiley InterScience (www.interscience.wiley.com). DOI: 10.1002/ajh.21744

\section{References}

1. Porter D. ASH 2009 meeting report: The top 10 clinically-oriented abstracts in hematopoietic stem cell transplantation. Am J Hematol 2009;85:193-196.

2. Mathias C, Mick R, Grupp S, et al. Soluble interleukin-2 receptor concentration as a biochemical indicator for acute graft-versus-host disease after allogeneic bone marrow transplantation. J Hematotherapy Stem Cell Res 2000;9: 393-400.

3. Paczesny S, Levine J, Braun T, Ferrara J. Plasma biomarkers in graft-versushost disease: A new era? Biology of blood and marrow transplantation. J Am Soc Blood Marrow Transplant 2009;15:33-38.

4. June C, Blazar B. Clinical application of expanded CD4+25+ cells. Seminars Immunol 2006;18:78-88.

5. Flowers ME, Parker PM, Johnston LJ, et al. Comparison of chronic graft-versus-host disease after transplantation of peripheral blood stem cells versus bone marrow in allogeneic recipients: Long-term follow-up of a randomized trial. Blood 2002;100:415-419.

6. Shlomchik WD. Graft-versus-host disease. Nat Rev Immunol 2007;7:340352.

7. Socie G, Stone JV, Wingard JR, et al. Long-term survival and late deaths after allogeneic bone marrow transplantation. Late effects working committee of the international bone marrow transplant registry. N Engl J Med 1999;341: 14-21.

8. Ma Q, Palmer $L$, Balogun $\mathrm{J}$, et al $\mathrm{CCR} 5+\mathrm{T}$ cells mediate alloimmune responses in human graft versus host disease. Biology of blood and marrow transplantation. J Am Soc Blood Marrow Transplant 2010;16:S300-S301.

9. Ma Q, Gooley TA, Storb R. CCR5 Expression on cells from HLA-matched unrelated marrow donors and graft-versus-host disease. Biology of blood and marrow transplantation. J Am Soc Blood Marrow Transplant 2010;16:132-133.

10. Cooke KR, Yanik G. Acute lung injury after allogeneic stem cell transplantation: Is the lung a target of acute graft-versus-host disease? Bone Marrow Transplant 2004:34:753-765.

11. Yanik G, Cooke KR, Yanik G, Cooke KR. The lung as a target organ of graftversus-host disease. Seminars Hematol 2006;43:42-52.

12. Deeg $\mathrm{HJ}$, Blazar BR, Bolwell $\mathrm{BJ}$, et al. Treatment of steroid-refractory acute graft-versus-host disease with anti-CD147 monoclonal antibody ABX-CBL. Blood 2001;98:2052-2058.

13. Khoury H, Kashyap A, Adkins DR, et al. Treatment of steroid-resistant acute graft-versus-host disease with anti-thymocyte globulin. Bone Marrow Transplant 2001;27:1059-1064.

14. Appelbaum FR, editor.Thomas' Hematopoietic Cell Transplantation, Secondary Malignancies after Hematopoitic Cell Transplantation: 1638. Wiley-Blackwell: Chichester, UK; 2009. 
15. Karp JE, Sarkodee-Adoo CB. Therapy-related acute leukemia. Clin Lab Med 2000;20:71-81.

16. Curtis RE, Rowlings PA, Deeg $\mathrm{HJ}$, et al. Solid cancers after bone marrow transplantation. N Engl J Med 1997;336:897-904.

17. Rizzo JD, Curtis RE, Socie G, et al. Solid cancers after allogeneic hematopoietic cell transplantation. Blood 2009;113:1175-1183.

18. Tallman MS, Rowlings PA, Milone G, et al. Effect of postremission chemotherapy before human leukocyte antigen-identical sibling transplantation for acute myelogenous leukemia in first complete remission. Blood 2000;96:12541258.

19. Cahn JY, Labopin M, Sierra J, et al. No impact of high-dose cytarabine on the outcome of patients transplanted for acute myeloblastic leukaemia in first remission. Acute leukaemia working party of the European group for blood and marrow transplantation (EBMT). Brit J Haematol 2000;110:308-314.

20. Beatty G, Smith J, Reshef R, et al. Functional unresponsiveness and replicative senescence of myeloid leukemia antigen-specific CD8+ T cells after allogeneic stem cell transplantation. Clin Cancer Res 2009;15:49444953.
21. Rooney $\mathrm{C}$, Smith $\mathrm{C}, \mathrm{Ng} \mathrm{C}$, et al. Infusion of cytoxic $\mathrm{T}$ cells for the prevention and treatment of Epstein-Barr virus-induced lymphoma in allogeneic transplant recipients. Blood 1998;92:1549-1555.

22. Boue F, Gabarre J, Gisselbrecht $\mathrm{C}$, et al. Phase II trial of $\mathrm{CHOP}$ plus rituximab in patients with HIV-associated non-Hodgkin's lymphoma. J Clin Oncol 2006;24:4123-4128.

23. Ambinder RF. The same but different: autologous hematopoietic stem cell transplantation for patients with lymphoma and HIV infection. Bone Marrow Transplant 2009;44:1-5.

24. Lokhorst HM, Schattenberg A, Cornelissen JJ, et al. Donor lymphocyte infusions for relapsed multiple myeloma after allogeneic stem-cell transplantation: Predictive factors for response and long-term outcome. J Clin Oncol 2000;18:3031-3037.

25. Salama M, Nevill T, Marcellus D, et al. Donor leukocyte infusions for multiple myeloma. Bone Marrow Transplant 2000;26:1179-1184.

26. Alousi AM, Weisdorf DJ, Logan BR, et al. Etanercept, mycophenolate, denileukin, or pentostatin plus corticosteroids for acute graft-versus-host disease: A randomized phase 2 trial from the blood and marrow transplant clinical trials network. Blood 2009;114:511-517.

\title{
Primary pulmonary non-Hodgkin's lymphoma: A retrospective analysis of 29 cases in a Chinese population
}

\author{
Jiajia Huang, ${ }^{1,2}$ Tongyu Lin, ${ }^{1,2}$ Zhi-Ming Li, ${ }^{1,2 *}$ Ruihua Xu, ${ }^{1,2}$ Huiqiang Huang, ${ }^{1,2}$ and Wenqi Jiang ${ }^{1,2}$
}

Primary pulmonary non-Hodgkin's lymphoma (PPL) is a rare extranodal lymphoid neoplasm. The present knowledge of this entity is vague and minimal. A total of 29 patients diagnosed with PPL at Sun Yat-Sen University Cancer Center in China were retrospectively analyzed. Nineteen patients had mucosa-associated lymphoid tissue (MALT) lymphoma, nine had diffuse large B-cell lymphoma (DLBCL), and one had plasmacytic lymphoma. Six patients received PET/CT scans before treatment, and mean maximum standardized uptake values (mSUVs) were much higher in the DLBCL cases $(n=3)$ than in the MALT lymphoma cases $(n=3)$. The 3-year overall survival (OS) rate was $79.3 \%$. Cox regression analysis showed that hilar/mediastinal lymphadenopathy (LAP) was an independent predictor of survival $(P=0.029)$. The mean survival time (MST) was $\mathbf{7 5 . 5}$ months for patients who underwent surgery and 65.7 months for those who didn't $(P=0.38)$. The MST was 77.4 months for patients treated with rituximab and $\mathbf{5 4 . 1}$ months for those not treated with rituximab $(P=0.101)$. Clinical characteristics in our study were partly similar to those previously reported. However, we found that hilar/mediastinal LAP seemed to be an effective prognostic factor in Chinese PPL patients. The role of surgery and rituximab in the management of PPL warrants further investigation.

PPL is quite rare and it is defined as clonal lymphoid proliferation involving the lung parenchyma and/or bronchi but without extrathoracic extension at the time of diagnosis or within the subsequent 3 months [1,2]. Patients diagnosed with PPL may present with hilar or mediastinal LAP, but most of the tumor burden is in the lung [1]. PPL represents only $0.4 \%$ of all lymphomas, and less than $1 \%$ of NHL [2-4]. The treatment for primary pulmonary lymphomas (whether surgery, radiotherapy, chemotherapy, or targeted therapy alone or in combination) has not been clearly established. The role of rituximab in the treatment of PPL remains controversial [5].

In this study, we retrospectively reviewed 29 cases of newly diagnosed PPL in the Sun Yat-Sen University Cancer Center in China from January 2001 to December 2008 to identify prognostic factors of PPL and optimal treatment for PPL in the rituximab era. The clinical features of all patients are presented in Table I. Nineteen patients $(65.5 \%)$ had MALT Iymphoma, nine $(31.0 \%)$ had DLBCL, and one $(3.4 \%)$ had plasmacytic lymphoma. In most of the patients in this series, surgery provided a definite diagnosis, whereas bronchoscopic biopsy had a low-diagnostic yield. Of the 16 patients with PPL who underwent bronchoscopic examination, only four had positive results. Prior to treatment, all 29 patients were evaluated by CT scans, and six patients underwent integrated ${ }^{18} \mathrm{~F}-\mathrm{FDG}$-PET/CT scanning. The radiological findings for all patients are listed in Table I. Twenty patients (69.0\%) had unilateral lung involvement and nine $(31.0 \%)$ had hilar/mediastinal LAP. Of the six patients who underwent integrated ${ }^{18} \mathrm{~F}$-FDG-PET/CT scanning, three had DLBCL and three had MALT lymphoma. The maximal standardized uptake values (mSUVs) ranged from 2.0 to 7.6 (mean mSUV, $3.9 \pm 1.72$ ) in the three MALT lymphoma cases and from 10.5 to 16.9 (mean mSUV, 13.5 $\pm 2.74)$ in the three DLBCL cases.

Clinical characteristics of PPL (MALT vs non-MALT) are shown in Table I. Patients with MALT Iymphoma had a higher frequency of elevated LDH level at diagnosis $(15.8 \%$ vs $70.0 \%, P=0.011)$ and $B$ symptoms $(21.1 \%$ vs $70.0 \%, P=0.017)$. Moreover, a significant difference in the rate of hilar/ mediastinal LAP was found between the MALT type lymphoma group and non-MALT lymphoma group ( $10.5 \%$ vs $70.0 \%, P=0.002$ )

The primary treatment modalities of all patients were: (a) surgery alone (5 cases); (b) chemotherapy alone (6 cases); (c) surgery followed by chemotherapy ( 8 cases); (d) chemotherapy followed by radiotherapy (10 cases). A total of 13 patients received surgery, including two patients by VATS, one by wedge resection thoracotomy, and 10 by lobectomy. Twenty-four patients treated with chemotherapy (median: 5 cycles, range: 2-9 cycles). The most frequently used first-line treatment were CHOP (cyclophosphamide, doxorubicin, vincris-

TABLE I. Baseline Characteristics of 29 Chinese Patients with PPL

\begin{tabular}{|c|c|c|c|}
\hline Characteristics & $\begin{array}{c}\text { MALT } \\
\text { lymphoma } \\
(n=19)\end{array}$ & $\begin{array}{c}\text { non-MALT } \\
\text { lymphoma } \\
(n=10)\end{array}$ & Total (\%) \\
\hline \multicolumn{4}{|l|}{ Age (years) } \\
\hline Median (range) & 50 & 40.5 & $50(17-76)$ \\
\hline$\geq 60$ & 6 & 1 & $7(24.1)$ \\
\hline \multicolumn{4}{|l|}{ Sex } \\
\hline Male & 7 & 5 & $12(41.4)$ \\
\hline Female & 12 & 5 & $17(58.6)$ \\
\hline History of smoking & 4 & 3 & $7(24.1)$ \\
\hline \multicolumn{4}{|l|}{ Presenting symptoms } \\
\hline None & 9 & 2 & $11(37.9)$ \\
\hline Respiratory symptoms & 10 & 8 & $18(62.1)$ \\
\hline B symptoms & 4 & 7 & $11(37.9)$ \\
\hline $\mathrm{PS} \geq 2$ & 1 & 2 & $3(10.3)$ \\
\hline \multicolumn{4}{|l|}{ Radiological findings at diagnosis } \\
\hline Unilateral & 13 & 7 & $20(69.0)$ \\
\hline Bilateral & 6 & 3 & $9(31.0)$ \\
\hline Lung nodule/mass & 11 & 5 & $16(55.2)$ \\
\hline Infiltrates/consolidation & 8 & 4 & $12(41.4)$ \\
\hline Hilar/mediastinal lymphadenopathy & 2 & 7 & $9(31.0)$ \\
\hline Pleural effusion & 2 & 3 & $5(17.2)$ \\
\hline High-LDH level & 3 & 7 & $10(34.5)$ \\
\hline \multicolumn{4}{|l|}{ Ann Arbor Stage } \\
\hline IE-IIE & 16 & 7 & $23(79.3)$ \\
\hline IIIE-IVE & 3 & 3 & $6(20.7)$ \\
\hline \multicolumn{4}{|l|}{ IPI scores } \\
\hline $0-2$ & 17 & 8 & $25(86.2)$ \\
\hline $3-5$ & 2 & 2 & $4(13.8)$ \\
\hline
\end{tabular}




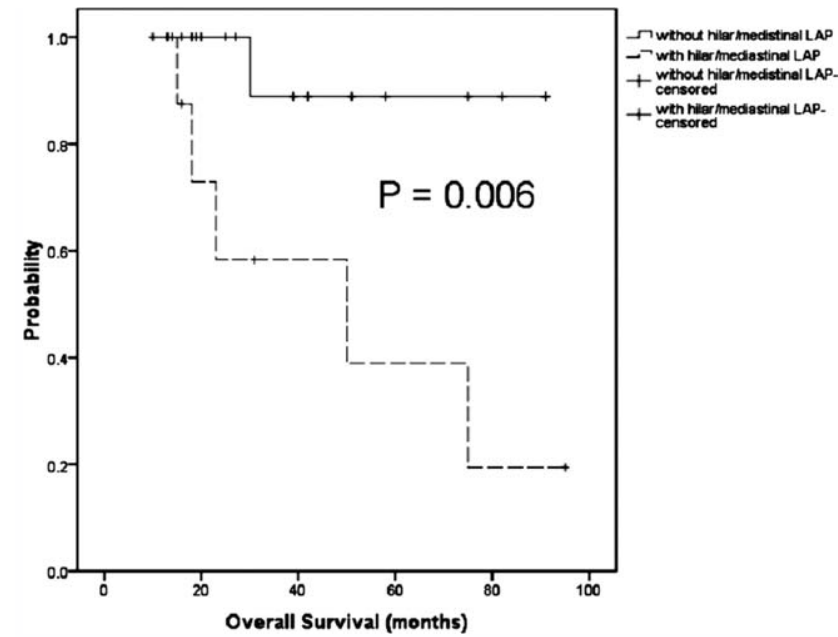

Figure 1. Overall survival of patients with or without hilar/mediastinal lymphadenopathy (LAP).

tine, and prednisone) or $\mathrm{CHOP}$-like regimens. Thirteen patients received rituximab (median: 5 cycles, range: 2-9 cycles) in combination with chemotherapy: seven had MALT lymphoma, five had DLBCL, and one had plasmacytic lymphoma. The overall response rate to initial chemotherapy was $81 \%$, including complete remission in four cases and partial response in nine cases. Ten patients underwent radiation. The total dose of radiotherapy ranged from 30 to 46 Gy. Pneumonia related to radiation was observed in one case.

In a median follow-up of 35 months (range: 5-95 months), 6 of 29 patients $(20.7 \%)$ died due to disease progression (3 cases), pneumonia related to bone marrow suppression after chemotherapy (1 case), renal failure (1 case), and unknown causes ( 1 case). OS at 3 years was $79.3 \%$ and MST was 73.7 months (95\% confidence interval, Cl 59.4-88.0). MST was shorter in patients with hilar/mediastinal LAP than in those without hilar/mediastinal LAP (50.6 months vs 84.2 months, $P=0.006$ ) (Fig. 1) and in patients with non-MALT Iymphoma than in those with MALT Iymphoma (48.8 months vs 83.1 months; $P=0.009)$. Univariate analysis identified non-MALT type ( $P=$ 0.009), B symptoms $(P=0.012)$, high-LDH level $(P=0.011)$, advanced Ann Arbor Stage (IIIE-IVE) $(P=0.012)$, International Prognostic Index scores (IPI) $=3-5(P=0.040)$, and hilar/mediastinal LAP $(P=0.006)$ as indicators of poor prognosis. Multivariate Cox regression analysis identified only hilar/mediastinal LAP as an independent predictor of OS $(\mathrm{RR}=11.0$, 95\% Cl: 1.29-94.4, $P=0.029)$. The MST was 75.5 months for patients who underwent surgery initially and 65.7 months for those who did not undergo surgery $(P=0.38)$. The MST was 77.4 months for patients treated with rituximab and 54.1 months for those not treated with rituximab $(P=0.101)$.

PPL is a very rare entity accounting for only $3.6 \%$ of all extranodal lymphoma cases [2]. The predominant pathologic subtype in our study was MALT lymphoma, followed by DLBCL, confirming previous data $[6,7]$. PET/ CT imaging is a highly sensitive and specific tool for detection and localization of $\mathrm{HL}$ and aggressive $\mathrm{NHL}$, and it also superior to $\mathrm{CT}$ in differentiating immunophenotypes of lymphoma [5,8-10]. PET scans may be able to reliably distinguish between indolent and aggressive subtypes in lymphoma patients. In our study, the mSUVs were much higher in DLBCL cases than MALT lymphoma cases. DLBCL in contrast to MALT lymphoma often shows aggressive growth, which may increase FDG uptake by the lesions. Further clinical trials are warranted to determine whether the effectiveness of PET/ CT in PPL depends on the histological subtype.

MALT and non-MALT PPLs are reported to differ in clinical behavior and prognosis [7,11-13]. In this series, hilar/mediastinal LAP, high-LDH elevation, and B symptoms were more frequent in non-MALT Iymphoma. Our data demonstrated that hilar/mediastinal LAP was the only independent prognostic factor in PPL in multivariate analysis. Previous studies have presented little evidence indicating the prognostic significance of hilar/mediastinal LAP in PPL [6]. Previous reports focused mainly on MALT Iymphoma and some studies did not include patients with hilar/mediastinal LAP $[7,14,15]$. Until now, no risk factors have been clearly identified in PPL. Our findings showed that patients with MALT type PPL survived longer than those with non-MALT PPL, but unlike other authors $[11-13,16]$.
The optimal modality for the management of PPL has not been established so far [16-18]. In patients with MALT primary lung non-Hodgkin's lymphomas $(\mathrm{NHL})$, surgical resection is commonly preferred for localized tumors. A review of 17 primary pulmonary B-cell lymphoma cases by Fadel and coworkers suggested that surgery was the treatment of choice in localized PPL cases [13]. However, in our study, the difference in survival between surgically treated and untreated groups did not reach statistical significance, similar to some of the previous reports $[6,19]$.

Although the results of rituximab (a chimeric anti-CD20 antibody) plus chemotherapy for a wide variety of B-cell lymphomas, including DLBCL and MALT lymphoma, have been encouraging $[20,21]$, the role of rituximab in PPL treatment is unclear. In this study, we did a preliminary evaluation of the efficacy of rituximab in the management of primary pulmonary B-cell lymphoma. Patients treated with rituximab tended to have better outcomes, but no statistical difference. Most patients in our study were in early stages. The impact of rituximab could not be demonstrated, possibly because the results of surgery and conventional chemotherapy for early-stage disease were excellent. Multicenter clinical trials will be needed to define the best therapeutic strategies.

In conclusion, the clinical characteristics of Chinese patients with PPL in our study were partly similar to those previously reported. PET/CT scan may be helpful in differentiating immunophenotypes and clinical behaviors. Furthermore, we found that hilar/mediastinal LAP could identify patients with significantly worse outcomes in Chinese PPL patients. The role of surgery and rituximab in the management of PPL patients warrants further investigation.

\section{Methods}

Patients and staging. The data from 29 patients with newly diagnosed PPL in the Sun Yat-Sen University Cancer Center in China from January 2001 to December 2008 were retrospectively analyzed. The study protocol was approved by the Institutional Review Board of the Sun Yat-Sen University Cancer Center. All patients consented to have their medical records reviewed for research purposes. The diagnosis of PPL was based on the following criteria $[2,11]$ : unilateral or bilateral lung involvement of $\mathrm{NHL}$; no history of lymphoma; no evidence of extrathoracic lymphoma at the time of diagnosis by clinical staging workup. No extrathoracic lymphoma was detectable within 3 months after the initial diagnosis. Cases with hilar/mediastinal adenopathy or adjacent chest wall invasion were also included in our study, as described in previous reports $[6,11]$. All patients were staged according to the Ann Arbor staging system [22]. IPI scores were also measured [23].

All hematoxylin and eosin stained and immunohistochemically stained slides were reviewed, and pathological subtypes were identified according to the World Health Organization criteria by histopathologists [24]. Antibodies to the following antigens were used to confirm the diagnosis in suspected subtypes: leukocyte common antigen, cluster designation (CD)3, CD5, CD10, CD19, CD20, CD30, CD45, CD79a, Ki-67, Cyclin D1, kappa and lambda immunoglobulin, and anaplastic lymphoma kinase. For the cases with inconclusive morphological features and immunophenotypic findings, molecular genetic analysis was performed to detect rearrangements of immunoglobulin heavy chain genes and T-cell receptor gamma chain genes. Response criteria and statistical analysis. Response to treatment was assessed according to the International Working Group Recommendations for Response Criteria for NHL $[25,26]$. OS was calculated from the date of diagnosis to the date of death from any cause or to the date of last followup. Clinical characteristics of PPL cases were summarized by means, medians, and percentages, and were compared using the $\gamma^{2}$ or Fisher's exact test. The primary endpoint of our analysis was OS. Survival curves were analyzed using the Kaplan-Meier method. The prognostic importance of different variables in OS was estimated by multivariate analysis using the Cox regression model. A two-tailed $P<0.05$ assessed by the log-rank test was considered statistically significant. Statistical analysis was performed using SPSS 16.0 for Windows.

${ }^{1}$ State Key Laboratory of Oncology in Southern China, Sun Yat-sen University, Guangzhou, Guangdong, People's Republic of China; ' 2 Department of Medical Oncology, Cancer Center, Sun Yat-sen University, Guangzhou, Guangdong, People's Republic of China *Correspondence to: Zhi-Ming Li, State Key Laboratory of Oncology in Southern China, Department of Medical Oncology, Sun Yat-Sen University Cancer Center, 651 Dong Feng Rd East, Guangzhou 510060, People's Republic of China E-mail: Izmlzmlzm@yahoo.com 
Conflict of interest: Nothing to report. Published online 24 March 2010 in Wiley InterScience (www.interscience.wiley.com). DOI: 10.1002/ajh.21720

\section{References}

1. Chilosi M, Zinzani PL, Poletti V. Lymphoproliferative lung disorders. Semin Respir Crit Care Med 2005;26:490-501.

2. Freeman C, Berg JW, Cutler SJ. Occurrence and prognosis of extranodal lymphomas. Cancer 1972;29:252-260.

3. Clagett OT, Allen TH, Payne WS, et al. The surgical treatment of pulmonary neoplasms: A 10-year experience. J Thorac Cardiovasc Surg 1964;48:391400.

4. L'hoste RJ, Filippa DA, Lieberman $\mathrm{PH}$, et al. Primary pulmonary lymphomas. A clinicopathologic analysis of 36 cases. Cancer 1984;54:1397-1406.

5. Zinzani PL, Martelli M, Poletti V, et al. Practice guidelines for the management of extranodal non-Hodgkin's lymphomas of adult non-immunodeficient patients. I. primary lung and mediastinal lymphomas. A project of the Italian Society of Hematology, the Italian Society of Experimental Hematology and the Italian Group for Bone Marrow Transplantation. Haematologica 2008;93: 1364-1371.

6. Hu YH, Hsiao LT, Yang CF, et al. Prognostic factors of Chinese patients with primary pulmonary non-Hodgkin's lymphoma: The single-institute experience in Taiwan. Ann Hematol 2009;88:839-846.

7. Kim JH, Lee SH, Park J, et al. Primary pulmonary non-Hodgkin's lymphoma. Jpn J Clin Oncol 2004;34:510-514.

8. Bae YA, Lee KS, Han J, et al. Marginal zone B-cell lymphoma of bronchusassociated lymphoid tissue: Imaging findings in 21 patients. Chest $2008 ; 133$ 433-440.

9. Ngeow JY, Quek RH, Ng DC, et al. High SUV uptake on FDG-PET/CT predicts for an aggressive B-cell lymphoma in a prospective study of primary FDG-PET/CT staging in lymphoma. Ann Oncol 2009;20:1543-1547.

10. Yang $D H$, Min JJ, Jeong YY, et al. The combined evaluation of interim contrast-enhanced computerized tomography (CT) and FDG-PET/CT predicts the clinical outcomes and may impact on the therapeutic plans in patients with aggressive non-Hodgkin's lymphoma. Ann Hematol 2009;88:425-432.

11. Ferraro $\mathrm{P}$, Trastek VF, Adlakha $\mathrm{H}$, et al. Primary non-Hodgkin's Iymphoma of the lung. Ann Thorac Surg 2000;69:993-997.
12. Cordier JF, Chailleux $E$, Lauque $D$, et al. Primary pulmonary lymphomas. A clinical study of 70 cases in nonimmunocompromised patients. Chest 1993; 103:201-208.

13. Vanden Eynden $F$, Fadel $E$, de Perrot $M$, et al. Role of surgery in the treatment of primary pulmonary B-cell lymphoma. Ann Thorac Surg 2007;83:236-240.

14. Tamura A, Komatsu $\mathrm{H}$, Yanai N, et al. Primary pulmonary lymphoma: Relationship between clinical features and pathologic findings in 24 cases. The Japan National Chest Hospital Study Group for Lung Cancer. Jpn J Clin Oncol 1995;25:140-152.

15. Zinzani PL, Tani M, Gabriele A, et al. Extranodal marginal zone B-cell lymphoma of MALT-type of the lung: Single-center experience with 12 patients. Leuk Lymphoma 2003;44:821-824.

16. Wannesson L, Cavalli F, Zucca E. Primary pulmonary lymphoma: Current status. Clin Lymphoma Myeloma 2005;6:220-227.

17. Cadranel J, Wislez M, Antoine M. Primary pulmonary lymphoma. Eur Respir J 2002;20:750-762.

18. Zinzani PL, Poletti V, Zompatori M, et al. Bronchus-associated lymphoid tissue lymphomas: An update of a rare extranodal maltoma. Clin Lymphoma Myeloma 2007;7:566-572.

19. Zucca E, Conconi A, Pedrinis E, et al. Nongastric marginal zone B-cell lymphoma of mucosa-associated lymphoid tissue. Blood 2003:101:2489-2495.

20. Migkou M, Dimopoulos MA, Gavriatopoulou M, et al. Applications of monoclonal antibodies for the treatment of hematological malignancies. Expert Opin Biol Ther 2009;9:207-220.

21. Zhou X, Hu W, Qin X. The role of complement in the mechanism of action of rituximab for B-cell lymphoma: Implications for therapy. Oncologist 2008;13: 954-966.

22. Carbone PP, Kaplan HS, Musshoff K, et al. Report of the committee on Hodgkin's disease staging classification. Cancer Res 1971;31:1860-1861.

23. The International Non-Hodgkin's Lymphoma Prognostic Factors Project. A predictive model for aggressive non-Hodgkin's lymphoma. $\mathrm{N}$ Engl $\mathrm{J}$ Med 1993:329:987-994.

24. Chan JK. The new World Health Organization classification of lymphomas: The past, the present and the future. Hematol Oncol 2001;19:129-150.

25. Cheson BD, Horning SJ, Coiffier B, et al. Report of an international workshop to standardize response criteria for non-Hodgkin's lymphomas. $\mathrm{NCl} \mathrm{Spon-}$ sored International Working Group. J Clin Oncol 1999;17:1244

26. Grillo-Lopez AJ, Cheson BD, Horning SJ, et al. Response criteria for NHL: Importance of 'normal' lymph node size and correlations with response rates. Ann Oncol 2000;11:399-408.

\title{
The assessment of human organic cation transporter 1 (hOCT1) mRNA expression in patients with chronic myelogenous leukemia is affected by the proportion of different cells types in the analyzed cell population
}

\author{
Zdenek Racil, ${ }^{1 \star}$ Filip Razga, ${ }^{1}$ Lucie Buresova, ${ }^{2}$ Tomas Jurcek, ${ }^{1}$ Dana Dvorakova, ${ }^{1}$ Daniela Zackova, ${ }^{1}$ \\ Shira Timilsina, ${ }^{3}$ Petr Cetkovsky, ${ }^{4}$ and Jiri Mayer ${ }^{1}$
}

The monitoring of hOCT1 mRNA expression in patients with chronic myelogenous leukemia (CML) was used for predicting the response to imatinib treatment. However, different cell populations from patients who received various degrees of pretreatment were used for this analysis. Therefore, several biases in the results and their interpretation may arise. We investigated hOCT1 mRNA expression in different cell populations of peripheral blood (PB) from healthy volunteers and in imatinib naïve de novo CML patients by analyzing changes in hOCT1 mRNA expression during the first 6 months of imatinib therapy. The hOCT1 mRNA expression was significantly higher in PB polymorphonuclears compared to mononuclears. The hOCT1 mRNA expression in total PB leukocytes is, therefore, preferentially determined by the percentage of polymorphonuclears. Expression in each analyzed group of cells was always significantly lower in imatinib naïve de novo CML patients compared to healthy volunteers. This difference disappeared after the initiation of imatinib therapy, suggesting that CML tumor burden and the degree of pretreatment at the time of monitoring were both influencing factors.

Imatinib (IMA) uptake is predominantly mediated by human organic cation transporter 1 (hOCT1) [1]. Decreased expression or function of this protein can lead to a reduction of the intracellular concentration of IMA and, there- fore, lead to pharmacokinetic resistance to the drug [1,2]. There are several data suggesting a correlation between hOCT1 activity/expression and the therapeutic outcome of CML patients treated with IMA [3-5]. Unfortunately, this issue has several uncertainties in the literature that may lead to the misinterpretation of previously reported data and the interpretation of future studies. First, hOCT1 activity, which is measured by a functional assay [1,2], must be clearly differentiated from mRNA expression monitoring [1,3-5]. Second, the cell populations used for analysis vary widely in cell type, especially in studies that monitor mRNA hOCT1 expression [1,3-5]. Furthermore, while some studies have monitored a well-defined group of patients with de novo chronic phase CML [3], others make analyses on heterogeneous study populations that contain pretreated patients $[4,5]$.

We investigated differences in hOCT1 mRNA expression in different cell populations of PB leukocytes (LEU) from healthy volunteers and patients with de novo CML, a change in hOCT1 mRNA expression during the first 6 months of IMA treatment, and the relationship between hOCT1 mRNA expression and the percentage of immature myeloid cells as well as $B C R$ / $A B L$ transcript levels in PB (as indirect markers of disease burden).

The hOCT1 mRNA expression was measured in PB LEU $(n=66)$, PB PMNC $(n=35)$, and PB MNC $(n=33)$ from 66 healthy volunteers. Figure 1 summarizes these results and clearly shows a wide range of hOCT 1 
mRNA expression in total LEU as well as in PMNC and MNC. The hOCT1 mRNA expression was significantly higher in PMNC compared to MNC. Therefore, the total LEU hOCT1 mRNA expression was preferentially determined by the percentage of PMNC in the total LEU.

Analogous measurements were performed in 23 patients with IMA naïve de novo CML. Similarly, a large distribution of expression was seen from individual groups of cells (Fig. 1). Total hOCT1 mRNA expression in PB LEU was again significantly influenced by the PMNC hOCT1 mRNA expression and PMNC percentage. The large variability in the percentage of PMNC from total LEU in patients with IMA naïve de novo CML (median: $75 \%$; range: $33-93 \%$ ) is, therefore, an important factor in the marked variability seen in hOCT1 mRNA expression in total LEU at the time of CML diagnosis. In addition, the hOCT1 mRNA expression from each analyzed group of cells was always significantly lower in IMA naïve de novo CML patients compared to healthy volunteers (Fig. 1). This suggested that CML cells have an additional effect on the observed hOCT1 mRNA expression level.

The hOCT1 mRNA expression was detected in total LEU and in MNC at monthly intervals from IMA naïve de novo CML patients from the time of diagnosis until the 6th month of IMA therapy. The median hOCT1 mRNA

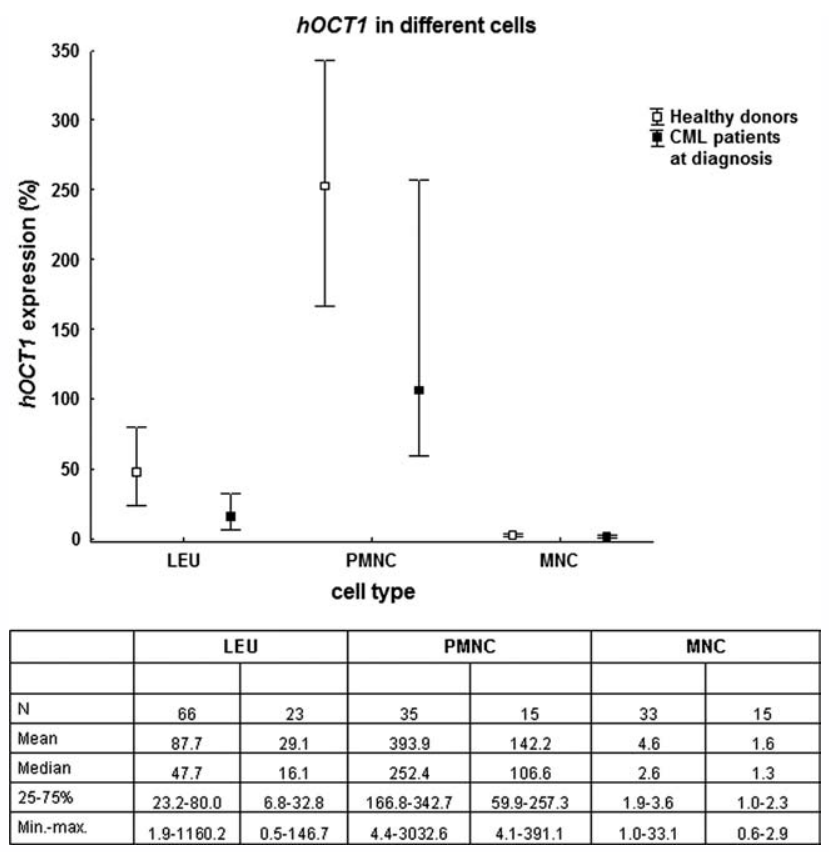

Figure 1. The hOCT1 mRNA expressions (median, 25-75\% quartiles) in total leukocytes (LEU), polymorphonuclear cells (PMNC), and mononuclear cells (MNC) in healthy volunteers and in imatinib naïve de novo CML patients.

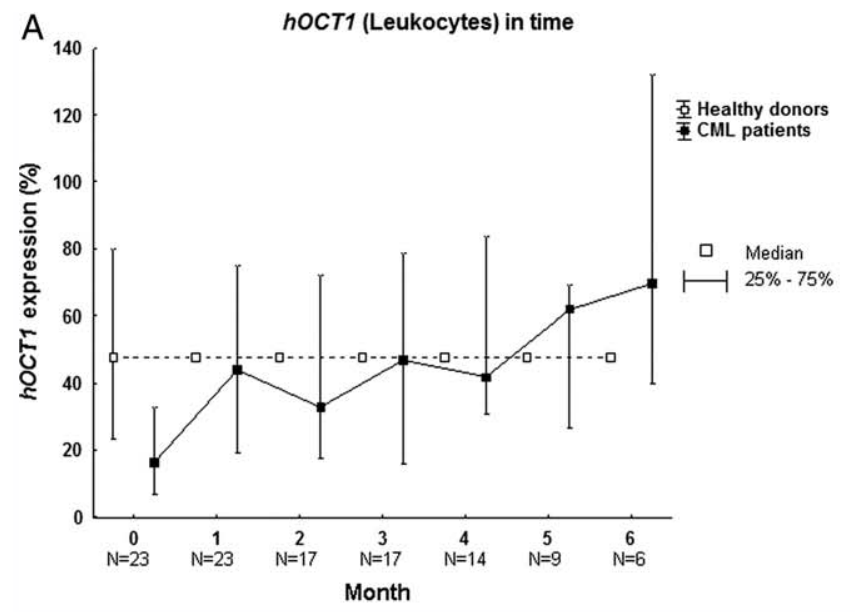

expression level from total LEU was significantly lower in the CML patients at the time of diagnosis compared to median expression levels in healthy individuals ( Fig. 1; $P<0.001$; nonparametric Mann Whitney test). However, after 1 month of IMA treatment, the median hOCT1 mRNA expression level in total LEU significantly increased $(P=0.031$; nonparametric Wilcoxon test) and reached the expression levels from healthy volunteers. Therefore, the previously described difference in expression level disappeared during this observation period ( $P=0.769$; nonparametric Mann Whitney test) (Fig. 2A). The same finding of hOCT1 mRNA expression was seen in the MNC samples from patients under the same criteria (Figs. 1 and 2B).

The lower hOCT1 mRNA expression level in LEU from IMA naïve de novo CML patients compared to healthy volunteers as well as its progressive increase after the start of IMA therapy could be explained by the initial presence and subsequent gradual disappearance of tumor cells from the measured cell population. To confirm this hypothesis, we performed an analysis on the relationship of hOCT1 expression with the percentage of immature myeloid cells in the LEU samples (as a marker of disease burden) obtained from IMA naïve de novo CML patients. In addition, because of the fact that a majority of patients did not have immature myeloid cells present in PB LEU samples after the first month of IMA therapy, we analyzed the dependence of LEU hOCT1 mRNA expression on the amount of BCR /ABL transcripts from these samples. We found a statistically significant relationship between hOCT1 mRNA expression level and the percentage of immature myeloid cells at the time of diagnosis as well as the $B C R / A B L$ transcript level at the first month after the start of IMA treatment (Fig. 3A,B).

Very limited data concerning hOCT1 mRNA expression in different cell populations exist to date [6-8]. Bazeos et al. reported a higher hOCT1 mRNA expression level in PB PMNC compared to MNC from healthy individuals [6]. In this study, we have enhanced these findings and described the difference in expression level in IMA naïve de novo CML patients as well.

Our finding of lower hOCT1 mRNA expression in total LEU from IMA naïve de novo CML patients that quickly reached the expression levels of healthy volunteers is in accordance with observations from Bazeos et al. [6]. However, the authors from that study assumed that this finding was related to the achievement of a complete cytogenetic response. According to our findings, the increase in hOCT1 mRNA expression after the start of IMA treatment was not caused by the suppression of inhibitory effects of the $B C R / A B L$ oncogene, as suggested by Bazeos et al., but rather was due to a significant effect of the lower hOCT1 mRNA expression in immature myeloid cells (mostly CML tumor cells), which rapidly disappeared from the PB within the first month of IMA therapy.

Several studies have monitored hOCT1 mRNA expression in the MNC fraction of the leukocytes [3,9]. However, the MNC is composed of several types of cells (including immature myeloid precursors, mostly tumor cells in CML patients). Although not analyzed, because of a low number of available samples for hOCT mRNA measurement in MNC (required for statistical significance), we expected that the impact of the cell composition found in total leukocytes on the hOCT mRNA expression results would be similar when measured in MNC. Therefore, it is not surprising that Labussiere et al. and White et al. did not dem-

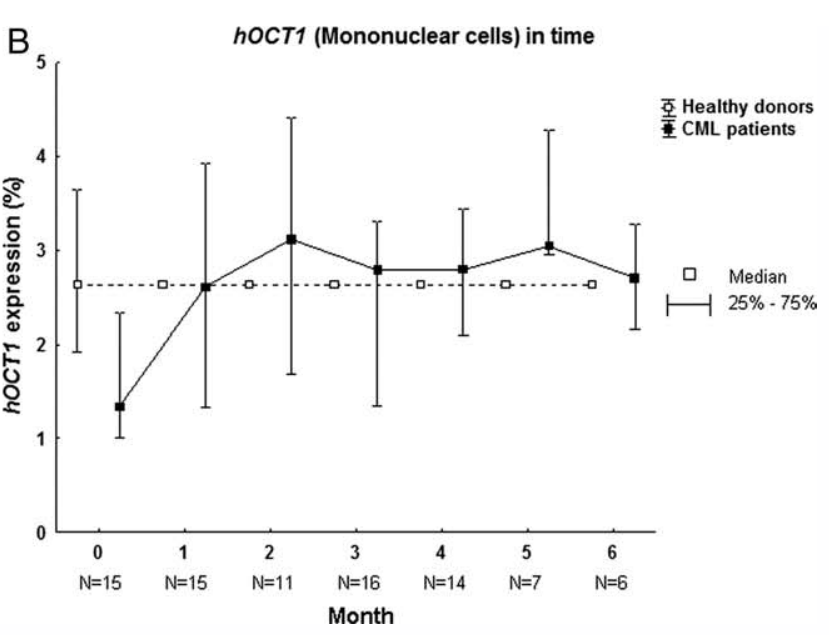

Figure 2. The hOCT1 mRNA expression level in total leukocytes (A) and mononuclear cells (B) in IMA naïve de novo CML patients before the start of IMA treatment (month 0 ) and during the first 6 months of IMA therapy as well as a comparison of hOCT1 expression in analogous cell populations in healthy volunteers. 

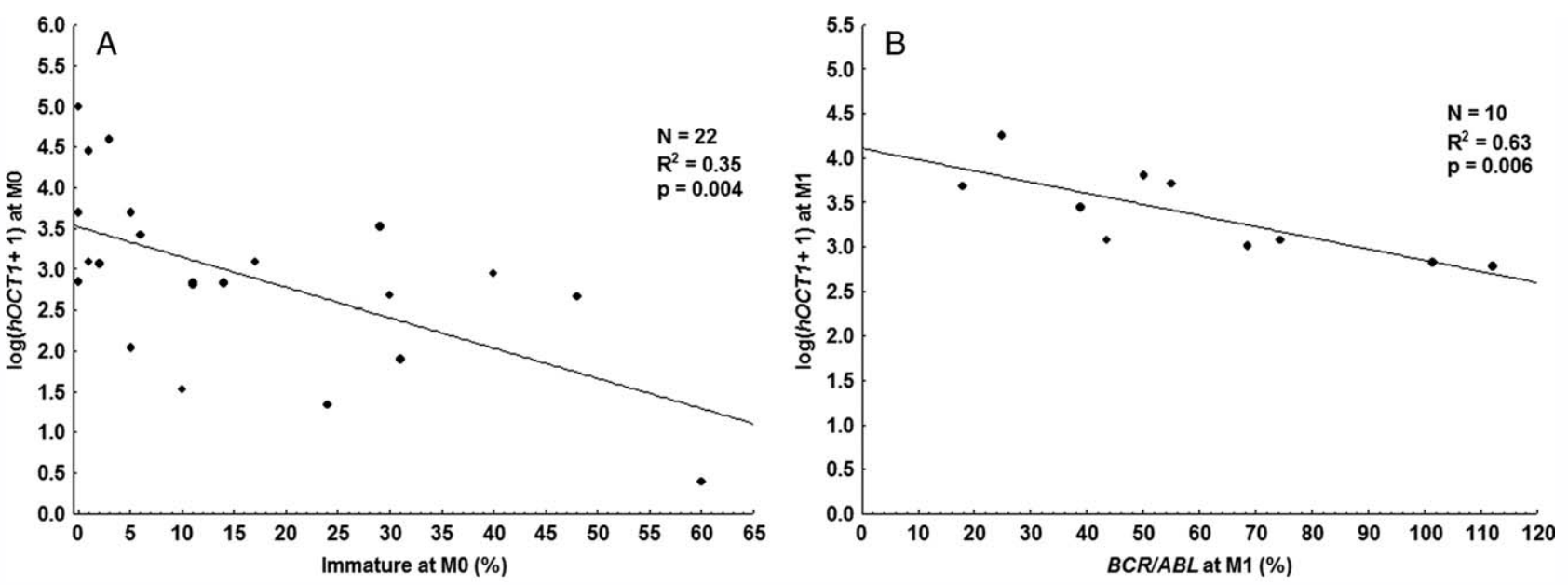

Figure 3. Linear regression fit of hOCT1 mRNA expression and the percentage of immature myeloid cells at the time of diagnosis (M0) (A) and $B C R / A B L$ transcript level at the 1st month after the start of IMA (M1) (B). In the regression analysis, hOCT1 was transformed by adding one and taking the natural logarithm (log denotes natural logarithm).

onstrate a relationship between hOCT1 expression measured in IMA naïve de novo CML patients and the future therapeutic response [3,9]. Although Wang et al. [5] was able to show this relationship, only 16 of the $70 \mathrm{CML}$ patients from this study were not pretreated. Thus, it is unknown whether the high hOCT1 mRNA expression level seen in Wang et al. could be a real predictor of therapeutic response in the future, or whether patients with a high hOCT1 mRNA expression level had a differential leukocyte and mononuclear count (due to pretreatment) that was close to that of healthy individuals and therefore higher than other patients in the study. In addition, Wang et al. did not clearly define the cell population in which measurements was carried out, which creates additional uncertainty in their results. Similarly, Crossman et al. demonstrated a relationship between of hOCT1 mRNA expression and the achievement of a complete cytogenetic response [4]. However, all patients in that study were pretreated and this fact could explain why there was no observed difference between expression of hOCT1 mRNA in CML patients and healthy donors. Furthermore, Crossman et al. used bone marrow MNC for monitoring hOCT1 mRNA expression. The influence from the higher percentage of different myeloid precursors in these samples, as well as the greater heterogeneity in hOCT1 mRNA expression, is likely to exceed the influence of the immature cells in the PB samples that we have described in the present study.

In summary, our study has shown that monitoring hOCT1 mRNA expression in total PB leukocytes is controversial. However, we have shown that this level corresponds to the current differential count of leukocytes and the quantity of tumor cells at the time of testing, rather than being a prognostic factor that correlates with the future therapeutic response of patients with CML. Although we did not assess enough patients in this study for unequivocal evidence, it can be assumed that an analogous situation exists in monitoring the hOCT1 mRNA expression level in PB mononuclear cells, as it is also a mixture of cells (although less heterogeneous than the total leukocytes) with different expression levels of hOCT1 mRNA. Finally, the question remains of whether or not the dependencies of hOCT1 mRNA expression in total leukocytes described in this study also apply to functional assays that analyze the activity of the hOCT1 transporter. It would be of great interest to perform analogous analyses to those in this study for monitoring the activity of the hOCT1 transporter. These data would be essential for the evaluation of all studies that assess the importance of this parameter as a marker of therapeutic response to IMA in de novo CML patients.

\section{Methods}

A total volume of $10 \mathrm{~mL}$ of $\mathrm{PB}$ in ethylenediaminetetraacetic acid was obtained from 66 healthy volunteers and from a cohort of 23 IMA naïve de novo CML patients (month $0=\mathrm{MO}$ samples). CML patients were investigated monthly for a period of 6 months from the start of IMA treatment (M1M6 samples). All volunteers and patients signed an informed consent form and the study was approved by the institutional review board.
The total volume of PB was used for the leukocyte (LEU) separation and for fractionation into polymorphonuclear cells (PMNCs) and mononuclear cells (MNCs) using gradient centrifugation Histopaque ${ }^{\mathbb{R}}$ 1077/1119 (Sigma Diagnostics, St. Louis, USA). The fractionation was performed according to the manufacturer's recommendations. For verification of the composition of leukocyte fractions obtained by separation, microscopic analysis of individual cell groups (PMNC and MNC) was performed. Smears were processed using May-Grünwald and Giemsa-Romanowski solutions. Interestingly, the MNC fraction from CML patients whose $\mathrm{PB}$ was collected at the time of diagnosis also contained immature cells (e.g. myelocytes, promyelocytes, and metamyelocytes).

Extraction of total RNA from all selected cell fractions (LEU, PMNC, and $\mathrm{MNC}$ ) was performed using the RNeasy Mini Kit (Qiagen, Hilden, Germany) according to the manufacturer's manual. A cDNA synthesis was performed using random hexamers and MuLV reverse transcriptase (Applied Biosystems, Foster City, USA).

To detect the expression level of hOCT1, GUS, BCR/ABL, and $A B L$ mRNA from selected fractions at different time points of IMA therapy, the TaqMan based real-time reverse transcription PCR (RQ-RT-PCR) with absolute quantification was carried out on an ABI PRISM 7300 (Applied Biosystems Inc, Foster City, USA). The RQ-RT-PCR using the Absolute $Q$ PCR Mix (ABgene, Epsom, UK) was performed at $95^{\circ} \mathrm{C}$ for 15 min followed by 50 cycles of denaturation at $95^{\circ} \mathrm{C}$ for $15 \mathrm{~s}$ and extension at $60^{\circ} \mathrm{C}$ for $1 \mathrm{~min}$.

For hOCT1 cDNA amplification, a TaqMan Gene Expression Assay (serial number Hs00427552_m1) (Applied Biosystems Inc, Foster City, USA) was used according to the manufacturer's recommendations. The final hOCT1 mRNA expression level was then calculated using the following formula: hOCT1 $1^{\text {(absolute copies) }} /$ GUS $^{\text {(absolute copies) }} \times 100 \%$. To detect the expression of the control gene GUS in all selected cell fractions, the primer set and probe from Beillard et al. were used [10].

The $B C R / A B L$ quantification was performed in LEU using standard methodologies with the primer set and probe previously published by Gabert et al. [11]. The final $B C R / A B L$ expression was calculated according to $B C R /$

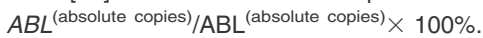

The RQ-RT-PCR product obtained from the hOCT1 TaqMan Gene Expression Assay (Hs00427552_m1; Applied Biosystems Inc, Foster City, USA) was purified using the QIAquick PCR Purification Kit (Qiagen, Hilden, Germany) and ligated into pCR 2.1 vector using the TA Cloning Kit (Invitrogen, Carlsbad, USA). Recombinant plasmids were subsequently used for Escherichia coli transformation. Plasmid DNA was isolated using the QIAprep Spin Miniprep Kit (Qiagen, Hilden, Germany) and used as the standard for hOCT1 absolute copy number quantification in 10-fold dilutions (range $10^{6}-10^{1}$ copies). Standards for GUS, $B C R / A B L$, and $A B L$ with serial numbers CGRS-03, FGRS-10, and CGRS-01, respectively (FusionQuant ${ }^{\mathbb{R}}$ Standards Kit, Ipsogen, Marseille, France), were used for the absolute quantification of these particular genes. 
To ensure reproducibility, all samples were performed and analyzed in duplicate. To obtain robust results, a cDNA from the KCL-22 cell line (DSMZ, Braunschweig, Germany), which has low hOCT1 mRNA expression, was used as an internal control for hOCT1 and GUS assessment. In addition, cDNA from the K562 cell line (DSMZ, Braunschweig, Germany) was used as an internal control $B C R / A B L$ quantification.

For all statistical analyses, the software Statistica, version 9.0 (StatSoft, Tulsa, USA) and R (R Development Core Team, Auckland, New Zealand) were used.

${ }^{1}$ Department of Internal Medicine Hemato-Oncology, Masaryk University and University Hospital Brno, Brno, Czech Republic; ${ }^{2}$ Institute of Biostatistics and Analyses, Masaryk University, Brno, Czech Republic; ${ }^{3}$ School of Medicine, Masaryk University, Brno, Czech Republic; ${ }^{4}$ Institute of Hematology and Blood Transfusion, Prague, Czech Republic; Zdenek Racil and Filip Razga contributed equally to this work. Contract grant sponsor: CELL - The CzEch Leukemia Study Group for Life Contract grant number: MSM0021622430. ${ }^{*}$ Correspondence to: Zdenek Racil, Department of Internal Medicine Hemato-Oncology, University Hospital Brno, Jihlavska 20, Brno 62500 Czech Republic

E-mail: zracil@fnbrno.cz Conflict of interest: Nothing to report. Published online 24 March 2010 in Wiley InterScience (www.interscience.wiley.com). DOI: 10.1002/ajh.21722

\section{References}

1. Thomas J, Wang L, Clark RE, Pirmohamed M. Active transport of imatinib into and out of cells: Implications for drug resistance. Blood 2004;104:37393745 .
2. White DL, Saunders VA, Dang P, et al. OCT-1-mediated influx is a key determinant of the intracellular uptake of imatinib but not nilotinib (AMN107) Reduced OCT-1 activity is the cause of low in vitro sensitivity to imatinib. Blood 2006:108:697-704.

3. White DL, Saunders VA, Dang P, et al. Most CML patients who have a suboptimal response to imatinib have low OCT-1 activity: Higher doses of imatinib may overcome the negative impact of low OCT-1 activity. Blood 2007;110:4064-4072.

4. Crossman LC, Druker BJ, Deininger MW, et al. hOCT 1 and resistance to imatinib. Blood 2005;106:1133-1134.

5. Wang L, Giannoudis A, Lane S, et al. Expression of the uptake drug transporter hOCT1 is an important clinical determinant of the response to imatinib in chronic myeloid leukemia. Clin Pharmacol Ther 2008:83:258-264.

6. Bazeos A, Marin D, Gerrard G, et al. BCR-ABL1 Oncogene Down-regulates the Expression of OCT1 in CML. ASH Annu Meet Abstr 2009;114:3248.

7. Engler JR, Frede A, Zannettino ACW, et al. Reduced Activity of the OCT-1 Protein in Primitive CML Cells: A Likely Determinant of Stem Cell Resistance in Imatinib Treated CML Patients. ASH Annu Meet Abstr 2008;112:196.

8. Jiang $X$, Zhao $Y$, Smith $C$, et al. Chronic myeloid leukemia stem cells possess multiple unique features of resistance to BCR-ABL targeted therapies. Leukemia 2007;21:926-935.

9. Labussiere H, Hayette $\mathrm{S}$, Chabane K, et al. Pharmacogenomic Factors Such as the Expression of Imatinib Transporters (OCT-1, ABCB-1 and ABCG-2) a Diagnosis, OCT-1 SNPs, and Steady-State Imatinib and Desmethyl-Imatinib Trough Plasma Levels in De Novo Chronic Phase Chronic Myelogenous Leukemia, May Influence Disease Response to Imatinib. ASH Annu Meet Abstr 2008;112:2643.

10. Beillard $\mathrm{E}$, Pallisgaard $\mathrm{N}$, van der Velden $\mathrm{VH}$, Bi W, Dee $\mathrm{R}$, van der Schoot $\mathrm{E}$ Delabesse E, Macintyre E, Gottardi E, Saglio G, Watzinger F, Lion T, van Dongen JJ, Hokland P, Gabert J. Evaluation of candidate control genes for diagnosis and residual disease detection in leukemic patients using 'real-time' quantitative reverse-transcriptase polymerase chain reaction (RQ-PCR) - a Europe against cancer program. Leukemia 2003;17:2474-2486.

11. Gabert J, Beillard E, Van Der Velden VH, et al. Standardization and quality control studies of 'real-time' quantitative reverse transcriptase polymerase chain reaction of fusion gene transcripts for residual disease detection in leukemia—A Europe Against Cancer program. Leukemia 2003;17:2318-2357.

\title{
Informational needs assessment of non-Hodgkin lymphoma survivors and their physicians
}

\author{
Daphne R. Friedman, ${ }^{1 *}$ April D. Coan, ${ }^{2}$ Sophia K. Smith, ${ }^{3}$ James E. Herndon II, ${ }^{4}$ and Amy P. Abernethy ${ }^{5}$
}

Cancer Survivorship Care Plans (SCPs) are a recommended part of medical care for cancer survivors. We sought to identify the medical and psychosocial informational needs of non-Hodgkin lymphoma survivors and their physicians in cancer survivorship care to be included in SCPs. Questionnaires were mailed to eligible lymphoma survivors and their physicians, querying their preferences about informational needs in SCPs. The survivor cohort had a median age at diagnosis of 62, with $57 \%$ Female, $87 \%$ White, and $76 \%$ from North Carolina. The physician cohort was comprised of oncologists $(27 \%)$ and nononcologists $(73 \%)$, and $86 \%$ practiced in North Carolina. Greater than $60 \%$ of both survivors and physicians preferred an oncologist and primary care provider comanage cancer survivorship care. The most highly rated informational needs were medical issues, although there were differences between survivors and physicians for many of the informational needs queried. There was higher concordance between patient and physician responses for medical issues (63 to 100\%) compared to psychosocial issues (25 to $63 \%$ ). Important components of SCPs for lymphoma survivors and their physicians may go unrecognized. Tailoring SCPs to patient or physician users may better accommodate the differences in need for particular cancer survivorship care information.

As cancer is becoming more treatable and curable, the numbers of cancer survivors is increasing [1]. Medical complications, long-term and late effects of therapy, and psychosocial difficulties are among the issues with which cancer survivors must live [2-4].

In recognition of this, SCPs were recommended, in the first comprehensive manner, by the Institute of Medicine [5]. Several templates exist (e.g. American Society of Clinical Oncology [6], Lance Armstrong Foundation/ OncoLink [7], and Journey Forward [8]), but patients criticize these tem- plates as being too technical, lacking personalization, and being deficient in resource and wellness guides [2,9]. Barriers to development and implementation of these care plans include difficulty in identifying evidence-based components [10], insufficient reimbursement for record abstraction [11], lack of specific medical knowledge by primary care physicians (particularly regarding hematologic malignancies) [12], and poor communication between oncologists and primary care physicians $[5,13]$.

Despite a growing body of literature regarding SCPs, the oncology community has not fully recognized that cancer survivors, oncologists, and primary care providers have varying levels of knowledge and different experiences, and thus may have different informational needs regarding cancer survivorship care [2]. By focusing survivorship care based on prioritized needs, cancer survivors may be more receptive to receiving continued medical care in all areas.

To address these issues, we focused on a group of survivors who are treated in a standardized manner, but who are often left out of the SCP development discussions, specifically survivors of diffuse large B-cell lymphoma, the most common type of non-Hodgkin lymphoma. We aimed to (1) identify the most important informational needs of survivors and their treating physicians responsible for cancer survivorship care, (2) define the effect of demographic factors on informational needs, and (3) assess how closely the informational needs of individual survivors link to that of their physicians.

A total of 178 surveys were mailed to cancer survivors. Fourteen were excluded because of death (4) or returned mail (10). Sixty-seven of the 164 potential respondents responded, resulting in an overall response rate of $41 \%$. Seventy-eight surveys were mailed to physicians. Two were excluded because of returned mail. Twenty-two of the 76 potential participants responded, resulting in an overall response rate of $29 \%$. Baseline character- 


\begin{tabular}{|c|c|c|c|c|c|}
\hline \multirow[b]{3}{*}{ Survivor cohort } & \multicolumn{2}{|c|}{ Nonresponder } & \multicolumn{2}{|c|}{ Responder } & \multirow[b]{3}{*}{$P$ value } \\
\hline & $N$ & $\%$ & $N$ & $\%$ & \\
\hline & 97 & 59 & 67 & 41 & \\
\hline \multicolumn{6}{|l|}{ Age at diagnosis (years) } \\
\hline Mean (SD) & $54.3(15.7)$ & & $59.6(12.8)$ & & 0.024 \\
\hline Median (Range) & $57(19-86)$ & & $62(29-86)$ & & \\
\hline \multicolumn{6}{|c|}{ Age at survey completion (years) } \\
\hline Mean (SD) & NA & & $64.2(12.3)$ & & \\
\hline Median (Range) & NA & & $65(37-88)$ & & \\
\hline \multicolumn{6}{|l|}{ Time since diagnosis (years) } \\
\hline Mean (SD) & & & $4.7(2.9)$ & & \\
\hline Median (Range) & & & $3.9(0.9-12.6)$ & & \\
\hline \multicolumn{6}{|l|}{ Gender } \\
\hline Female & 41 & 42 & 38 & 57 & NS \\
\hline Male & 56 & 58 & 29 & 43 & \\
\hline \multicolumn{6}{|l|}{ Race } \\
\hline White & 81 & 84 & 58 & 87 & NS \\
\hline Black & 12 & 12 & 7 & 10 & \\
\hline Other & 4 & 4 & 2 & 3 & \\
\hline \multicolumn{6}{|l|}{ Location of residence } \\
\hline In state, local & 35 & 36 & 22 & 33 & NS \\
\hline In state, not local & 42 & 43 & 29 & 43 & \\
\hline Not in state & 20 & 21 & 16 & 24 & \\
\hline \multicolumn{6}{|c|}{ Ann Arbor stage of cancer at diagnosis } \\
\hline 1 & 25 & 26 & 15 & 22 & NS \\
\hline 2 & 26 & 27 & 10 & 15 & \\
\hline 3 & 21 & 22 & 15 & 22 & \\
\hline 4 & 25 & 26 & 27 & 40 & \\
\hline \multicolumn{6}{|c|}{ Received bone marrow transplant } \\
\hline No & 79 & 81 & 58 & 87 & NS \\
\hline mYes & 18 & 19 & 9 & 13 & \\
\hline Physician Cohort & 54 & 71 & 22 & 29 & \\
\hline \multicolumn{6}{|l|}{ Location of practice } \\
\hline In state, local & 21 & 39 & 9 & 41 & NS \\
\hline In state, not local & 17 & 31 & 10 & 45 & \\
\hline Not in state & 16 & 30 & 3 & 14 & \\
\hline \multicolumn{6}{|l|}{ Specialty } \\
\hline Oncology & 12 & 22 & 6 & 27 & NS \\
\hline Non-oncology & 42 & 78 & 16 & 73 & \\
\hline Primary Care & 37 & 88 & 13 & 81 & \\
\hline Cardiology & 0 & 0 & 1 & 6 & \\
\hline Dermatology & 1 & 2 & 0 & 0 & \\
\hline Nephrology & 2 & 5 & 0 & 0 & \\
\hline Neurology & 1 & 2 & 0 & 0 & \\
\hline Orthopedic Surgery & 0 & 0 & 1 & 6 & \\
\hline Rheumatology & 0 & 0 & 1 & 6 & \\
\hline Unknown & 1 & 2 & 0 & 0 & \\
\hline
\end{tabular}

NS, not significant; NA, not applicable.

istics for survivor and physician cohorts are summarized in Table I. Survivor responders were older at diagnosis than nonresponders $(P=0.024)$; otherwise responders did not differ significantly from nonresponders with respect to baseline characteristics. Thirteen survivors (19\%) completed the survey less than 2 years since their diagnosis, 26 (39\%) completed the survey 2 to 5 years since their diagnosis, and $28(42 \%)$ completed the survey more than 5 years since their diagnosis.

The majority of survivors (63\%) and physicians (64\%) preferred an oncologist and primary care provider to comanage cancer survivorship care. Among survivors, there was no association between having a primary care physician and the preference of type of physician(s) to manage cancer survivorship care $(P=0.143)$.

The queried components of SCPs and their ratings for survivors and physicians are presented in Table II. Compared to physicians, survivors were more interested in having a plan for screening of recurrence $(P=$ $0.012)$ and late effects of therapy $(P=0.018)$ and a summary of treatments given $(P=0.044)$, whereas physicians thought summaries of the treatment complications $(P=0.005)$ were more essential parts of the SCP than survivors. Additionally, a plan to monitor overall health was a more important component of cancer survivorship care for survivors than for physicians ( $P=$ 0.0002). Overall, physicians and survivors rated psychosocial issues as less important in SCPs than medical issues. However, comparing the responses obtained from survivors and physicians, survivors identified nutrition and exercise $(P=0.002)$, insurance $(P<0.0001)$, and payment for providing cancer survivorship care $(P=0.0006)$ as more important than physicians did.
There were no differences among the survivor subgroups with regards to who should provide cancer survivorship care, having a primary care physician or having an oncologist outside of our tertiary referral hospital. Male survivors rated sexuality and fertility as more important than women $(P=$ 0.004); otherwise there were no significant differences based on gender. Survivors who were younger than 60 years old at time of diagnosis identified a plan for monitoring overall health problems $(P=0.03)$, sexuality and fertility $(P=0.007)$, mental health services $(P=0.044)$, and financial issues $(P=0.042)$ as more important than survivors who were older than 60 years old at diagnosis. There were no differences in responses obtained from survivors greater than 5 years compared to those less than 5 years from the time of diagnosis.

Physicians of different specialties were equally likely to prefer both oncologists and primary care physicians comanage cancer survivorship care. Nononcologists thought that having a plan to screen for cancer relapse was more important than oncologists $(P=0.004)$, whereas oncologists were more likely to find that providing insurance information and help with resolving financial issues were important components of cancer survivorship care compared to nononcologists $(P=0.021$ and 0.035 , respectively).

There were 24 matched survivor physician survey pairs. One survivor had two physicians and one physician had three survivors; thus one survivor and one physician contributed more than once to the analyses. As seen in Fig. 1 , there was higher concordance between survivors and their physicians with regards to medical issues (62.5 to 100\%) than for psychosocial issues (25 to $62.5 \%$ ). 


\begin{tabular}{|c|c|c|c|c|c|c|c|c|c|c|}
\hline \multicolumn{5}{|l|}{ Survivors } & \multicolumn{5}{|l|}{ Physicians } & \multirow[b]{2}{*}{$P$ value } \\
\hline & $N$ & Mean & $S D$ & Rank & & $N$ & Mean & $S D$ & Rank & \\
\hline \multicolumn{11}{|l|}{ Components pertaining to medical issues } \\
\hline $\begin{array}{l}\text { Q1. Your type of cancer and its stage } \\
\text { (how far advanced it is) }\end{array}$ & 66 & 8.8 & 2.3 & 8 & $\begin{array}{l}\text { Q1. The patient's type of cancer and } \\
\text { its stage (how far advanced it was) }\end{array}$ & 22 & 9.0 & 1.7 & 2 & NS \\
\hline $\begin{array}{l}\text { Q2. Specific information about your cancer } \\
\text { that might influence whether your } \\
\text { cancer stays away or returns }\end{array}$ & 66 & 9.4 & 1.6 & 4 & $\begin{array}{l}\text { Q2. Specific information about the } \\
\text { patient's cancer that might influence } \\
\text { whether the cancer relapses (risk factors } \\
\text { or other markers such as tumor grade) }\end{array}$ & 22 & 8.5 & 2.2 & 6 & NS \\
\hline $\begin{array}{l}\text { Q3. The anti-cancer treatments you had } \\
\text { (surgery, chemotherapy, hormone, } \\
\text { and/or radiation therapy) }\end{array}$ & 64 & 9.5 & 1.3 & 3 & $\begin{array}{l}\text { Q3. The particular cancer therapy given } \\
\text { (surgery, chemotherapy, hormone, } \\
\text { and/or radiation therapy) }\end{array}$ & 22 & 8.5 & 1.9 & 7 & 0.044 \\
\hline $\begin{array}{l}\text { Q4. Your treatment success and/or } \\
\text { complications you experienced }\end{array}$ & 66 & 9.3 & 1.6 & 5 & $\begin{array}{l}\text { Q4. Summary of the patient's treatment } \\
\text { success and/or complications } \\
\text { experienced }\end{array}$ & 22 & 9.1 & 1.0 & 1 & NS \\
\hline $\begin{array}{l}\text { Q5. The treatment side effects you } \\
\text { experienced or still experience }\end{array}$ & 66 & 7.7 & 2.8 & 13 & $\begin{array}{l}\text { Q5. The treatment side effects the patient } \\
\text { experienced or still experiences }\end{array}$ & 22 & 8.9 & 1.2 & 4 & 0.005 \\
\hline $\begin{array}{l}\text { Q6. The risk of future health problems } \\
\text { from your cancer treatment }\end{array}$ & 66 & 9.0 & 1.9 & 7 & $\begin{array}{l}\text { Q6. The risk of future health problems } \\
\text { that could occur due to the patient's } \\
\text { cancer treatment }\end{array}$ & 22 & 9.0 & 1.5 & 3 & NS \\
\hline $\begin{array}{l}\text { Q7. A plan to screen for possible return } \\
\text { of your cancer }\end{array}$ & 66 & 9.7 & 1.0 & 1 & $\begin{array}{l}\text { Q7. A plan to screen for possible cancer } \\
\text { relapse }\end{array}$ & 22 & 8.5 & 1.9 & 8 & 0.012 \\
\hline $\begin{array}{l}\text { Q8. A plan to screen for possible future } \\
\text { health problems due to your } \\
\text { cancer treatment }\end{array}$ & 66 & 9.5 & 1.0 & 2 & $\begin{array}{l}\text { Q8. A plan to screen for possible future } \\
\text { health problems due to cancer therapy }\end{array}$ & 22 & 8.6 & 1.5 & 5 & 0.018 \\
\hline $\begin{array}{l}\text { Q9. A plan for monitoring your other medical } \\
\text { problems and your overall health }\end{array}$ & 66 & 9.2 & 1.7 & 6 & $\begin{array}{l}\text { Q9. A plan for monitoring other medical } \\
\text { problems and overall health (not } \\
\text { otherwise related to the patient's } \\
\text { cancer or therapy) }\end{array}$ & 22 & 6.7 & 2.6 & 13 & 0.0002 \\
\hline \multicolumn{11}{|l|}{ Components pertaining to psychosocial issues } \\
\hline Q10. Nutrition and exercise & 67 & 8.8 & 1.8 & 9 & $\begin{array}{l}\text { Q10. Information about nutrition } \\
\text { and exercise }\end{array}$ & 22 & 6.7 & 2.7 & 12 & 0.002 \\
\hline Q11. Sexuality and fertility & 66 & 5.7 & 3.5 & 17 & $\begin{array}{l}\text { Q11. Information about sexuality } \\
\text { and fertility }\end{array}$ & 22 & 6.8 & 2.4 & 11 & NS \\
\hline $\begin{array}{l}\text { Q12. Alternative medicine techniques } \\
\text { (for example: herbs and supplements, } \\
\text { chiropractic, massage, acupuncture) }\end{array}$ & 67 & 5.4 & 3.4 & 19 & $\begin{array}{l}\text { Q12. Alternative medicine techniques } \\
\text { (for example: herbs and supplements, } \\
\text { chiropractic massage, acupuncture) }\end{array}$ & 22 & 4.6 & 2.6 & 19 & NS \\
\hline $\begin{array}{l}\text { Q13. Mental health services (for example: } \\
\text { care available for depression or anxiety) }\end{array}$ & 66 & 6.0 & 3.6 & 16 & Q13. Mental health services & 22 & 7.2 & 2.1 & 10 & NS \\
\hline Q14. Insurance (health, life or disability) & 67 & 8.7 & 2.7 & 10 & $\begin{array}{l}\text { Q14. Insurance information (health, } \\
\text { life, or disability) }\end{array}$ & 22 & 5.6 & 2.6 & 18 & $<0.0001$ \\
\hline $\begin{array}{l}\text { Q15. Resolving financial issues (employment, } \\
\text { disability/SSI, retirement) }\end{array}$ & 67 & 7.0 & 3.5 & 15 & $\begin{array}{l}\text { Q15. Resolving financial issues } \\
\text { (employment, disability/SSI, retirement) }\end{array}$ & 22 & 6.2 & 2.9 & 16 & NS \\
\hline $\begin{array}{l}\text { Q16. Social Support (support groups, therapy, } \\
\text { resources in the community) }\end{array}$ & 67 & 5.5 & 3.2 & 18 & $\begin{array}{l}\text { Q16. Social support (support groups, } \\
\text { therapy, resources in the community) }\end{array}$ & 22 & 6.7 & 2.5 & 14 & NS \\
\hline $\begin{array}{l}\text { Q17. Information for family members and } \\
\text { caregivers about cancer and your health }\end{array}$ & 67 & 8.3 & 2.5 & 12 & $\begin{array}{l}\text { Q17. Information for family members } \\
\text { and caregivers about cancer and health }\end{array}$ & 22 & 7.3 & 2.4 & 9 & NS \\
\hline $\begin{array}{l}\text { Q18. Legal issues (for example: power of } \\
\text { attorney, advanced directives, living wills) }\end{array}$ & 67 & 7.1 & 3.3 & 14 & $\begin{array}{l}\text { Q18. Legal issues (for example: power of } \\
\text { attorney, advanced directives, living wills) }\end{array}$ & 22 & 6.4 & 2.3 & 15 & NS \\
\hline $\begin{array}{l}\text { Q19. Physician payment for providing cancer } \\
\text { survivorship care }\end{array}$ & 67 & 8.4 & 2.7 & 11 & $\begin{array}{l}\text { Q19. Physician reimbursement for providing } \\
\text { cancer survivorship care }\end{array}$ & 22 & 6.0 & 2.9 & 17 & 0.0006 \\
\hline
\end{tabular}

Your type of cancer and its stage Specific information about your cancer that might influence whether your cancer stays away or returns The anti-cancer treatments you had Your treatment success and/or complications you experienced The treatment side effects you experienced or still experience The risk of future health problems from your cancer treatment A plan to screen for possible return of your cancer A plan to screen for possible future health problems due to your cancer treatment A plan for monitoring your other medical problems and your overall health
Nutrition and exercise Sexuality and fertility Alternative medicine techniques Mental health services Insurance
Resolving financial issues Social Support Information for family members and caregivers about cancer and your health Legal issues Physician payment for providing cancer survivorship care

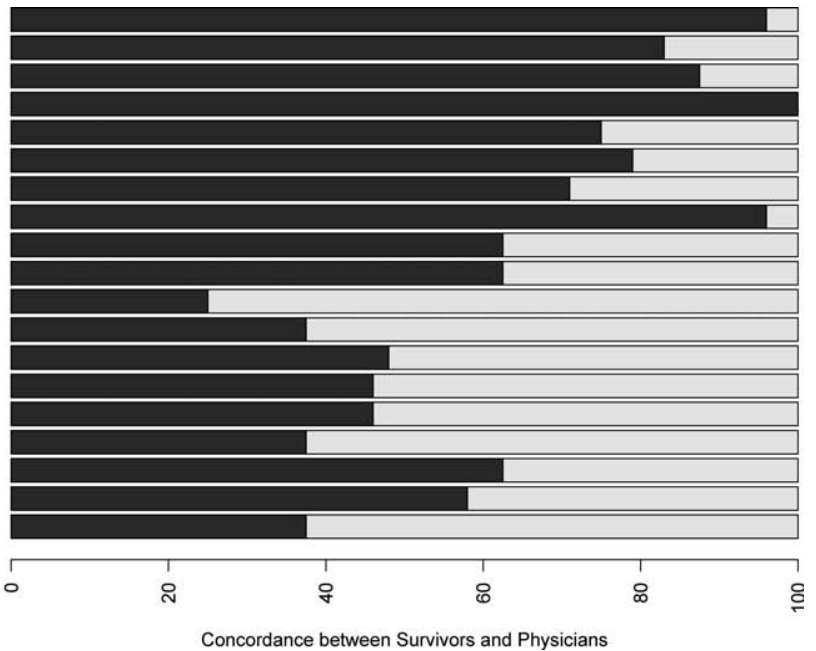

Figure 1. Concordance of survivors and their physicians for the nineteen survey questions (in order found in the questionnaire) regarding importance of components of cancer survivorship care plans. Dark bars in the bar graph reflect concordances. 
The number of cancer survivors is increasing, and the burden of their diseases and late or long-term effects of cancer therapy has medical, psychosocial, and economic effects on the survivors themselves and society at large $[3,4,14]$. Providing comprehensive and efficient medical care to this population would help to address these problems. But, what should constitute this medical care?

Instead of moving directly into implementing a "one-size-fits-all" approach, we decided to query a defined subgroup of non-Hodgkin lymphoma survivors and their physicians, to identify who should provide cancer survivorship care and to determine the important components of such care. We chose this group of cancer survivors and their physicians because they have been evaluated in a limited fashion [12,15,16], and not as thoroughly as breast cancer, childhood cancer, or Hodgkin lymphoma survivors. In addition, we wanted to begin our analyses with a homogeneous group of survivors with regards to curative intent and treatment regimens. Survivors with incurable malignancies or with cancers treated with a variety of different chemotherapy regimens or therapeutic modalities might have varying opinions about cancer survivorship care.

Using our mailed questionnaire, we confirmed prior studies' findings that survivors and physicians prefer cancer survivorship care coordinated by both the oncologist and the primary care physician $[3,13,17]$. We also found that medical issues were also highly rated as important components in cancer survivorship care for both survivor and physician groups. Psychosocial, alternative medicine, and fertility issues have been noted to be important to cancer survivors, particularly breast cancer survivors, and are increasingly being studied in the lymphoma survivor population $[4,18]$. However, our results suggest that survivors of diffuse large B-cell lymphoma believe medical content is a more important component of SCPs.

We found that survivors thought that a plan to monitor overall health was a more important part of SCPs than physicians. This might imply that survivors view cancer survivorship care as part of their general health maintenance, whereas physicians compartmentalize survivorship care and noncancer related care.

Survivors rated nutrition, exercise, and insurance SCP components higher than their physicians. Whereas physicians might be more comfortable discussing a survivor's general health, they may have less immediate information and the resources to address these other issues. Notably, the results found in this cohort vary from those found in other studies, in which there was more agreement between physicians and a heterogeneous survivor cohort in expectations for cancer survivorship care [19].

Our findings of differences between physicians and survivors regarding the relative importance of different cancer survivorship care issues confirmed our hypothesis that the different "target audiences" might need different SCPs. While providing the maximum available information to everyone might seem optimal, this approach risks overloading the user and diluting the impact of the most important content. Developing personalized SCPS could address these barriers and adjust the type, level, and amount of information for the end user's needs.

Limitations of this study include the small sample size, low response rate, exclusion of survivors with $>1.5$ years since last contact, and inclusion of survivors from a single institution. The questionnaire was not formally tested in a pilot cohort, and the wording of the questions varied slightly between physician and survivor questionnaires. Because many of our findings echo results obtained by other studies performed in other survivor groups, we feel that major improvements in the response rates would unlikely influence our findings.

In contrast to the currently available templates containing standardized information by cancer type, our findings indicate that SCPs should be individually tailored to reflect the prioritized needs of survivors, primary care physicians, and oncologists. Our findings should be confirmed and compared to other larger cohorts or cohorts of other cancer subtypes. Comparative effectiveness research is needed to evaluate whether the implementation of personalized survivorship care plans provide higher levels of survivor and/or physician satisfaction, knowledge, and quality of life than the use of a single standardized survivorship care plan.

\section{Methods}

Participants. Survivors were identified through the Duke Comprehensive Cancer Center (DCCC) Tumor Registry. Eligible participants seen at Duke for treatment or for consultation, were treated with curative intent, and had no evidence of lymphoma at their last visit at Duke. We further limited our cohort to lymphoma patients with a diagnosis of diffuse large B-cell lymphoma as treatment is more standardized, homogenous, and aggressive than for all subtypes of lymphoma taken together. To reduce the chance of questionnaires mailed to survivors who had died, moved, or otherwise lost to follow up, eligible patients were included in this study only if they had been seen within the Duke University Medical system within 1.5 years prior to the chart review.

Physicians were identified in two ways. The Duke oncologists' names were obtained from the DCCC registry. Local oncologists' and primary care physicians' names were obtained from survivors' questionnaires responses.

Questionnaires. The mailed questionnaires for survivors and for physicians were developed by the investigators. The questionnaires were designed after reviewing available SCP templates, exploring literature regarding medical and psychosocial issues relevant to cancer survivors and their physicians, and querying oncologists and internists. Questionnaires for survivors and physicians included the same components, but the wording was not identical. Participants rated the importance of each item in a set of medical and psychosocial informational needs (listed in Table I) using a numeric scale of 1 to 10 for each question. A letter explaining the study was mailed to each survivor with the questionnaire. After 6 months, a reminder card was mailed to nonresponders. Following receipt of identified physicians from survivor questionnaires, survey packages were mailed to the identified physicians. Survivor surveys were received between June and December 2008. Physician surveys were received between November 2008 and January 2009. Informed consent was inferred by a response, per the Duke University School of Medicine Institutional Review Board (Duke IRB) mailed questionnaire policy. This study was approved by the Duke IRB.

Patient characteristics. Demographic information was obtained from the DCCC registry and chart review. Specifics regarding stage of disease, therapies received, and treatment outcomes were obtained from chart review.

Statistical analysis. Baseline demographics and characteristics for the survivor and physician cohorts were summarized by descriptive statistics. Within these cohorts, the characteristics of responders and nonresponders were compared using two-sample t-tests (for continuous variables) and Fisher's exact tests, Chi-square tests, or Cochran-Armitage Trend tests (for categorical variables) to assess selection bias.

Descriptive statistics (mean and standard deviation) were computed for survivor and physician ratings of individual informational needs. Two-sample t-tests and exact chi-square tests were used to assess the relationship between outcome (e.g., informational needs or type of health care provider) and survivor/physician subgroups. Gender, age at diagnosis ( $<60$ years, $=60$ years), and time since diagnosis $(<5$ years, $=5$ years $)$ were used as survivor subgroups and specialty (oncology, nononcology) was considered for physicians. Sixty years was chosen as the age cut-off, consistent with the International Prognostic Index [20]. Likewise, 5 years since diagnosis was chosen as a cut-off, as the 5 -year time horizon from diagnosis often signifies "cure" from cancer.

Initially the survivor and physician cohort were treated as independent groups and two-sample t-tests were used to detect differences in mean ratings of each individual item between survivors and physicians. Survey responses from survivors were also matched with their self-identified primary care physician and/or oncologist to form survivor physician pairs. A physician may have cared for more than one survivor and a survivor may have had more than one physician. Thus, in all paired analyses, a survivor or physician may have contributed more than once to the analyses. Agreement in ratings of issues concerning survivorship care was assessed between survivors and their physicians using concordance. Concordance was defined as complete agreement in response categories. For this analysis, ratings were categorized as follows: 1-3 (low importance), 4-6 (moderate importance), and 7-10 (high importance) [19].

All statistical analyses were conducted with SAS version 9.2 (SAS Institute, Cary, NC). A significance level of 0.05 was used for all statistical tests. $P$-values are presented for descriptive purposes.

${ }^{1}$ Department of Medicine, Duke University Medical Center, Durham, NC; ${ }^{2}$ Cancer Biostatistics, Duke Comprehensive Cancer Center, Durham, NC; ${ }^{3}$ Duke Comprehensive Cancer Center, Durham, NC, and Gillings School of Global Public Health, University of North Carolina, Chapel Hill, NC; ${ }^{4}$ Department of Biostatistics and Bioinformatics, Duke University, and Cancer Biostatistics, Duke

Comprehensive Cancer Center, Durham, NC, ${ }^{5}$ Duke Comprehensive Cancer Center and Department of Medicine, Duke University Medical Center, Durham, NC 
${ }^{*}$ Correspondence to: Dr. Daphne Friedman, Duke University Medical Center DUMC 3382 Durham, NC 27705

E-mail: daphne.friedman@duke.edu Received for publication 29 January 2010; Revised 23 March 2010; Accepted 24 March 2010 Conflict of interest: Nothing to report. Published online 29 March 2010 in Wiley InterScience (www.interscience.wiley.com). DOI: 10.1002/ajh.21725

\section{References}

1. Centers for disease control and prevention. Cancer survivorship-United States, 1971-2001. MMWR 2004;53:526-529.

2. Hewitt ME, Bamundo A, Day R, Harvey C. Perspectives on post-treatment cancer care: Qualitative research with survivors, nurses, and physicians. $\mathrm{J}$ Clin Oncol 2007;25:2270-2273.

3. Oeffinger KC, McCabe MS. Models for delivering survivorship care. J Clin Oncol 2006;24:5117-5124

4. Stanton AL. Psychosocial concerns and interventions for cancer survivors. $\mathrm{J}$ Clin Oncol 2006;24:5132-5137.

5. Hewitt M, Greenfield S, Stovall E. From cancer patient to cancer survivor: Lost in transition. Washington, DC:National Academies Press; 2005.

6. Cancer.Net. ASCO Cancer Treatment Summaries [cited 2010 January 7]; Available from: http://www.cancer.net/patient/Survivorship/ASCO+Cancer+ Treatment+Summaries.

7. Livestrong. Livestrong Care Plan [cited 2010 January 7]; Available from: http://www.livestrongcareplan.org/.

8. Journey Forward. Survivorship Care Plan Builder [cited 2010 January 7]; Available from: http://www.journeyforward.org/professionals/survivorshipcare-plan-builder.htm.
9. Burg MA, Lopez ED, Dailey A, et al. The potential of survivorship care plans in primary care follow-up of minority breast cancer patients. J Gen Intern Med 2009;24 (Suppl 2):S467-S471.

10. Carver JR, Shapiro CL, Ng A, et al. American society of clinical oncology clinical evidence review on the ongoing care of adult cancer survivors: Cardiac and pulmonary late effects. J Clin Oncol 2007;25:3991-4008.

11. Earle CC. Failing to plan is planning to fail: Improving the quality of care with survivorship care plans. J Clin Oncol 2006;24:5112-5116.

12. Rosen PJ, Wender RC, Kadkhoda H, Kober SL. Measuring the ability of primary-care physicians to diagnose and manage patients with hematologic malignancies. ASH annual meeting abstracts 2007;110:3312.

13. Wood ML, McWilliam CL. Cancer in remission. Challenge in collaboration for family physicians and oncologists. Canadian family physician Medecin de famille canadien 1996;42:899-904;907-910.

14. Short PF, Vargo MM. Responding to employment concerns of cancer survivors. J Clin Oncol 2006;24:5138-5141.

15. Arora NK, Hamilton AS, Potosky AL, et al. Population-based survivorship research using cancer registries: A study of non-Hodgkin's lymphoma survivors. J Cancer Surviv 2007:1:49-63.

16. Soloe $\mathrm{C}$, Bandel K, Jarblum M, et al. Information needs of hematologic cancer survivors. J Clin Oncol (Meeting Abstracts) 2006;24:18547.

17. Sisler JJ, Brown JB, Stewart M. Family physicians' roles in cancer care. Survey of patients on a provincial cancer registry. Canadian family physician Medecin de famille canadien 2004;50:889-896.

18. Habermann TM, Thompson CA, LaPlant BR, et al. Complementary and alternative medicine use among long-term lymphoma survivors: A pilot study. Am J Hematol 2009;84:795-798.

19. Cheung WY, Neville BA, Cameron DB, et al. Comparisons of patient and physician expectations for cancer survivorship care. J Clin Oncol 2009;27: 2489-2495.

20. A predictive model for aggressive non-Hodgkin's lymphoma. The international non-Hodgkin's lymphoma prognostic factors project. N Engl J Med 1993;329: 987-994.

\title{
Pain rate and social circumstances rather than cumulative organ damage determine the quality of life in adults with sickle cell disease
}

\author{
Charlotte F.J. van Tuijn, ${ }^{1}$ Eduard J. van Beers, ${ }^{1}$ John-John B. Schnog, ${ }^{2}$ and Bart J. Biemond ${ }^{1 *}$
}

Due to the significant morbidity associated with sickle cell disease (SCD), sickle cell patients have a reduced quality of life (QoL). Even though pain is considered an important determinant of QoL in sickle cell patients, factors such as organ damage and socioeconomic circumstances may also be important. Therefore, we determined the contribution of chronic organ damage and sickle cell-related complications to QoL and also analyzed the effect of vaso-occlusive crises and socioeconomic circumstances on QoL. Consecutive adult sickle cell patients were included. QoL was represented in a physical component scale (PCS) and a mental component scale (MCS) and assessed with SF-36 forms. Higher pain rates were related to lower QoL scores. Both occupation and the level of education were significantly related to PCS while no relation with MCS or pain rate was found. Thirty-five percent of the patients were unemployed when compared with $6 \%$ of the general population and $16 \%$ of immigrants without SCD. Neither genotype nor the presence of chronic organ damage were significantly related to QoL. In conclusion, a reduced QoL was mainly determined by pain rate, occupation, and educational level. Chronic organ damage, although a major factor determining life expectancy in SCD, was not a determinant of QoL.

SCD is a hereditary hemoglobinopathy characterized by recurrent microvascular vaso-occlusion and chronic hemolytic anemia resulting in progressive organ damage and reduced life expectancy [1,2]. Given the chronic nature of SCD and the severity of its complications, patients are likely to have a significantly reduced QoL. Intuitively and historically, pain is widely regarded as the major factor in determining QoL in SCD. However, even though previous studies have indeed demonstrated a reduced QoL of sickle cell patients, this was often not or not only attributable to pain [2]. Factors such as anxiety, depression, and socioeconomic circumstances may also contribute to the reduced QoL of sickle cell patients [3-5].
Sickle cell patients develop organ damage irrespective of their frequency of acute painful events, which has been related to significant morbidity and increased mortality, and it seems likely that SCD-related organ damage negatively impacts QoL of sickle cell patients [6]. However, to our knowledge, the impact of chronic organ damage on QoL in SCD has not been previously assessed. Therefore, we prospectively assessed the QoL in a cohort of consecutive sickle cell patients in whom chronic organ damage, pain rate, and the history of sickle cell-related complications in the last 5 years was systematically analyzed. In addition, the impact of occupation and educational level on QoL of these patients was studied.

One hundred seventeen adult patients with SCD $\left(\mathrm{HbSS}, \mathrm{HbS}^{\circ}, \mathrm{HbSC}\right.$, and $\mathrm{HbS}^{+}$) were eligible for our study. Twenty-three patients were excluded from analysis because they were not able to fill in the SF-36 questionnaire for different reasons (illiterate persons, mental retardation or repeated no show at their appointments). These excluded patients did not differ from the study population concerning outcome variables (pain, disease severity, education, and occupation). QoL was assessed in 51 patients with HbSS, 5 with $\mathrm{HbS} \beta^{0}, 11$ with $\mathrm{HbS} \beta^{+}$, and 27 patients with $\mathrm{HbSC}$.

The QoL data of our population are presented in Table I. As expected, our patient group scored lower on QoL compared with the healthy Dutch population [7] (see Supporting Information Table IV). No correlation between the MCS and PCS was found in the sickle cell population (spearman $r=0.14$; $P>0.20)$. When comparing male to female sickle cell patients, the overall PCS appeared to be significantly higher in males when compared with females $(P=0.015)$. We found no significant difference in the overall MCS between males and females. Older patients scored lower on the PCS in comparison to younger patients $(P=0.002)$ while no significant differences in QoL scores between genotypes was found (data not shown). 
The QoL scores in relation to pain rate are depicted in Table II. With respect to the MCS, the overall score and all subscales, except for mental health, were significantly lower in patients with the highest pain rate $(P=$ 0.021). Although significantly lower scores were found on the role-physical scale $(P=0.005)$ and the general health scale $(P=0.033)$ in patients with the highest pain rate, the overall PCS was not determined by the number of admissions for painful crises $(P=0.110)$. Also, analysis by linear regression confirmed that pain rate is significantly associated with MCS and is less likely to influence the PCS (data not shown).

The prevalence of different forms of organ damage in our study population was: pulmonary hypertension (PHT): $24.5 \%$, renal failure: $3.2 \%$, microalbuminuria: $21.3 \%$, retinopathy: $31.2 \%$, iron overload: $9.6 \%$, avascular osteonecrosis: $11.7 \%$, leg ulcers: $6.4 \%$, Acute chest syndrome (ACS): $25.5 \%$, priapism: $8.5 \%$, and stroke: $4.3 \%$. Except from lower QoL scores (for the PCS) in patients with iron overload $(P=0.017)$, no association between any form of organ damage or sickle cell-related complications and QoL scores was found (Table III). Moreover, when patients with organ damage and complication were divided according the pathogenesis (hemolysis-related complication versus vaso-occlusion/ischemia-related complications), no significant differences in QoL was observed when compared with the patients without organ damage at all.

TABLE I. QoL Scores of Sickle Cell Patients

\begin{tabular}{|c|c|c|c|}
\hline & Male & Female & \\
\hline & $\mathrm{SCD}, N=32$ & SCD, $N=61$ & $P^{*}$ \\
\hline PCS & $42.5(10.9)$ & $36.9(11.9)$ & 0.000 \\
\hline Physical function & $72.5(24.2)$ & $57.4(28.0)$ & 0.000 \\
\hline Role-physical & $54.8(43.5)$ & $43.8(43.6)$ & 0.000 \\
\hline Bodily pain & $60.8(27.4)$ & $50.5(28.5)$ & 0.000 \\
\hline General health & $48.3(23.3)$ & $41.0(23.1)$ & 0.000 \\
\hline MCS & $48.4(12.6)$ & $43.9(12.1)$ & 0.023 \\
\hline Vitality & $59.5(20.8)$ & $45.4(19.3)$ & 0.000 \\
\hline Social function & $73.8(25.3)$ & $62.7(28.4)$ & 0.000 \\
\hline Role-emotional & $70.0(41.4)$ & $57.2(45.1)$ & 0.035 \\
\hline Mental health & $74.0(21.3)$ & $63.6(21.3)$ & 0.000 \\
\hline
\end{tabular}

Mean (SD).

*Mann-Whitney $U$ test.
With respect to the relation between occupation and educational level and QoL scores, the PCS was strongly associated with occupation and level of education $(P<0.001)$. The overall MCS was not related to occupation or the level of education $(P=0.206$ and $P=0.177$, respectively) (see Supporting Information Tables $\mathrm{V}$ and $\mathrm{VI}$ ). Occupation and the level of education were not different between different genotypes and were not related to pain rates.

SCD is heterogeneous in its clinical presentation with patients being continuously admitted for the management of disease-related complications at one end of the spectrum and patients rarely requiring medical care at the other [6]. Irrespective of the frequency of acute clinical complications, most patients develop accumulating organ damage throughout their lives as a result of chronic hemolytic anemia and ongoing vaso-occlusion [1]. With respect to QoL, previous studies have reported that sickle cell patients have lower QoL scores when compared with race- and age-matched controls, which were related to pain [8-10]. However, its relation to the presence of chronic organ damage has not been described before. In the present study, organ damage appeared not to be related to any of the QoL scores. If patients were grouped according the pathophysiology of their different forms of organ damage or a history of sickle cell-related complication as recently proposed by Kato et al. [11], also no relation with QoL scores was demonstrated. Surprisingly, PHT, which has been related to early mortality in SCD, was not related to QoL in our patients. This might be explained by the fact that our study population consists of patients with mild PHT (regurgitation jet flow velocity $<2.9 \mathrm{~m} / \mathrm{sec}$ ), which is generally not related to severe complaints or significantly reduced exercise tolerance.

Factors significantly associated with a reduced QoL were pain rate and social circumstances defined as educational level and occupation. Interestingly, pain rate was only associated with a reduced MCS, whereas the social circumstances of the patients were related to the PCS. These data suggest that frequent painful and unpredictable crises are an important psychological burden rather than a physical burden to sickle cell patients as has been suggested previously [12]. In contrast, social circumstances as reflected by occupation and level of education were mainly related to the PCS, suggesting that only patients in good physical performance are able to finish school and find jobs independently of the frequency of admission for painful crises. This was further supported by the finding that no correlation between the MCS and PCS was found in the sickle cell population, which is in contrast to

TABLE II. QoL in Relation to Pain Rate

\begin{tabular}{lcccr}
\hline & None $(n=25)$ & $>0<1(n=48)$ & $>=1(n=21)$ & $P^{*}$ \\
\hline PCS & $45.3(34.4-52.1)$ & $39.6(29.5-49.3)$ & $33.4(28.8-39.2)$ & $0.0(39.7-75.0)$ \\
$\quad$ Physical Function & $70.0(35.0-90.0)$ & $70.0(45.0-90.0)$ & $0.00(0.00-50.0)$ & 0.390 \\
Role-Physical & $87.5(0.0-100.0)$ & $50.0(0.0-100.0)$ & $41.0(26.5-61.0)$ & 0.005 \\
Bodily Pain & $62.0(36.5-92.0)$ & $52.0(32.0-80.0)$ & $39.5(21.3-47.0)$ & 0.102 \\
General Health & $52.0(30.0-83.3)$ & $37.0(25.0-57.0)$ & $36.7(30.4-48.2)$ & 0.033 \\
MCS & $50.6(39.3-57.6)$ & $50.8(38.3-57.1)$ & $40.0(31.3-48.8)$ & 0.021 \\
Vitality & $55.0(37.5-75.0)$ & $50.0(43.8-65.4)$ & $50.0(37.5-75.0)$ & 0.003 \\
Social Function & $75.0(56.3-100.0)$ & $75.0(50.0-100.0)$ & $0.00(0.00-100.0)$ & 0.032 \\
Role-Emotional & $100.0(8.3-100.0)$ & $100.0(33.3-100.0)$ & $56.0(52.0-68.0)$ & 0.319 \\
Mental Health & $80.0(46.0-92.0)$ & $72.0(48.0-89.0)$ & & \\
\hline
\end{tabular}

Median (IQR).

${ }^{*}$ Kruskal Wallis test.

TABLE III. QoL in Relation to Organ Damage and Sickle Cell-Related Complications

\begin{tabular}{|c|c|c|c|c|c|c|c|}
\hline \multirow[b]{2}{*}{ Manifestations } & \multirow[b]{2}{*}{$N$} & \multicolumn{2}{|c|}{ PCS } & \multirow[b]{2}{*}{$P^{*}$} & \multicolumn{2}{|c|}{ MCS } & \multirow[b]{2}{*}{$P^{*}$} \\
\hline & & Present & Absent & & Present & Absent & \\
\hline Pulmonary hypertension & 23 & $39.8(11.3)$ & $38.5(11.6)$ & 0.701 & $50.2(10.3)$ & $44.3(12.8)$ & 0.060 \\
\hline Renal failure & 3 & $28.4(14.4)$ & $39.0(11.4)$ & 0.132 & $50.3(11.1)$ & $45.2(12.4)$ & 0.466 \\
\hline Microalbuminury & 20 & $34.9(10.5)$ & $39.9(11.9)$ & 0.106 & $41.6(13.6)$ & $46.6(12.3)$ & 0.186 \\
\hline Retinopathy & 30 & $37.4(10.6)$ & $38.6(11.9)$ & 0.638 & $47.5(11.6)$ & $45.5(12.4)$ & 0.463 \\
\hline Iron overload & 9 & $30.1(8.3)$ & $39.9(11.8)$ & 0.017 & $41.4(12.4)$ & $45.9(12.4)$ & 0.348 \\
\hline Avascular osteonecrosis & 11 & $36.1(7.7)$ & $39.0(12.1)$ & 0.444 & $39.8(13.8)$ & $46.1(12.0)$ & 0.449 \\
\hline Leg ulcers & 6 & $38.5(11.9)$ & $38.6(11.7)$ & 0.966 & $40.6(7.3)$ & $45.6(12.5)$ & 0.344 \\
\hline Acute chest syndrome & 24 & $35.0(12.9)$ & $40.1(11.2)$ & 0.057 & $46.3(10.6)$ & $45.2(13.0)$ & 0.843 \\
\hline Priapism & 8 & $45.7(7.8)$ & $41.4(11.8)$ & 0.425 & $47.4(11.1)$ & $48.7(13.4)$ & 0.606 \\
\hline Stroke & 4 & $42.2(13.0)$ & $38.7(11.8)$ & 0.190 & 45.7 (16.9) & 45.5 (12.3) & 0.429 \\
\hline
\end{tabular}

Mean (SD).

${ }^{*}$ Mann-Whitney $U$ test. 
the findings of QoL assessments in healthy individuals [7]. Similar to previous findings of McClish et al. [10], we did not find a correlation between genotype and QoL scores. Also, no difference in QoL scores was observed between patients on hydroxyurea and those who are not on hydroxyurea. This might be explained by the fact that in our study population, hydroxyurea was only prescribed to reduce painful crises and the occurrence of acute chest syndrome. By reducing these complications in patients with an otherwise more severe clinical presentation, hydroxyurea may have improved the QoL. This is in line with a previous prospective study of Ballas et al. [13] who demonstrated an improved QoL with the use hydroxyurea.

Certain limitations of our study should be taken into account. First, by defining pain rate by the amount of clinical admissions, the conclusions of our study may not be extrapolated for the number of painful crises experienced at home, which have been reported to occur frequently in sickle cell patients [14]. However, previous studies have shown that pain (during a painful crises as well as chronic pain) is related to QoL in sickle cell patients $[8,10,13]$. Second, most forms of organ damage and sickle cell-related complications were only present in a relative small group of patients, which may have underpowered our study to detect an effect of specific forms of organ damage on QoL. Mild PHT, as one of the most relevant forms of organ damage that has been associated with poor prognosis, was present in $24 \%$ of all sickle cell patients and was not related to QoL.

In conclusion, the QoL scores in consecutive sickle cell patients appear to be determined mainly by pain rate and social circumstances. Despite the contribution of organ damage such as (mild) PHT on prognosis and life expectancy, cumulative organ damage does not seem to be an important determinant of QoL in SCD. In terms of clinical presentation, pain rate is the most important factor for the QoL of adult sickle cell patients.

\section{Methods}

Adult sickle cell patients visiting the Department of Hematology of the Academic Medical Centre in Amsterdam were eligible for our study. Inclusion criteria were: high-performance liquid chromatography (HPLC) confirmed diagnosis of homozygous sickle cell anemia (HbSS), sickle-C disease ( $\mathrm{HbSC}), \mathrm{HbS} \beta^{+}$-thalassemia $\left(\mathrm{HbS} \beta^{+}\right.$-thal), or $\mathrm{HbS} \beta^{0}$-thalassemia $\left(\mathrm{HbS} \beta^{0}\right.$-thal), age 18 years or older and capable of filling in a questionnaire (Dutch or English). All data were collected during a routine outpatient clinic visit.

QoL was assessed by the use of SF-36 forms. The SF-36 is a short-form health survey that has been proven to be valid and reliable in the black population [15]. It has been previously used to determine QoL in adults with SCD [16]. Briefly, it yields eight different scales (physical functioning, role limitations due to physical problems, role limitations due to emotional problems, social functioning, mental health, vitality, bodily pain, and general health perceptions) of functional health and well-being as well as psychometrically based physical and mental health summary measures. The SF-36 is a generic measure, which is not age, disease, or treatment specific. Accordingly, the SF-36 has proven to be useful in surveys of general and specific populations, comparing the relative burden of diseases [7]. All patients were asked to complete this questionnaire during a routine outpatient visit. All scale scores are linearly converted to a 0-100 scale, with higher scores indicating higher levels of functioning or well-being. We analyzed the scores of our study population and compared the data with the scores of the general healthy Dutch population [7].

Data on social circumstances represented by occupation and level of education were routinely gathered during the first routine visit for every patient. With respect to occupation patients were divided into: employed, unemployed, or student. Education level was divided into: high school or less, vocational education/community college, and tertiary education/ university.

Pain rate was defined as the number of admissions for treatment of a vaso-occlusive crisis from January 2002 until January 2007 and was determined by chart review [6]. Subsequently, three groups were arbitrarily defined: patients without, patients with $<1$ admission for painful crises per year, and patients with 1 or $>1$ admission for painful crisis per year.

Organ damage and sickle cell-related complications were assessed by systematic screening and medical record review and defined as follows: PHT: tricuspid regurgitation jet flow velocity (TRV) equal to or higher than $2.5 \mathrm{~m} / \mathrm{sec}$ in rest detected by Doppler echocardiography. PHT was considered absent with no or only trace TRV [17]. Renal failure: an estimated creatinine clearance lower than $100 \mathrm{~mL} / \mathrm{min}$ (Cockcroft and Gault). Microalbuminuria: urinary creatinine $(\mathrm{mmol} / \mathrm{L})$ to urinary albumin $(\mathrm{mg} / \mathrm{L})$ ratio higher than 3.5 for males and higher than 2.5 for females confirmed with $24 \mathrm{hr}$ urine collection with microalbuminuria higher than $30 \mathrm{mg} / 24 \mathrm{hr}$ [18]. Retinopathy: presence of at least mild nonproliferative retinopathy [19]. Iron overload: plasma ferritin level higher than $1,000 \mu \mathrm{mol} / \mathrm{L}$ (on at least three occasions during steady state) and a history of more than 20 transfused packed cells [20]. Symptomatic avascular osteonecrosis: local pain and reduced function with documented osteonecrosis of the femoral or humeral head (hip or shoulder X-ray) or a history of surgical intervention for osteonecrosis. Leg ulcers: chronic ulcers of the ankle not otherwise explained. Acute chest syndrome: defined as described by Stuart and Setty [21] occurring between January 2002 and January 2007. Priapism: spontaneous painful erection requiring hospital care. Stroke: history of stroke confirmed by magnetic resonance imaging or computerized tomography. We analyzed the relation between organ damage and QoL both for each form of organ damage or complication separate as well as for groups. Groups were divided in a group with no organ damage or sickle cell-related complications, a group with organ damage or complications due to hemolysis (leg ulcers, PHT, priapism, and stroke), or a group with organ damage related to vaso-occlusion (ACS, retinopathy, avasculair osteonecrosis, renal failure, and microalbiminuria) as proposed previously [11].

Hematological and biochemical laboratory parameters were assessed at the same visit at which the patient completed the QoL questionnaire. Fetal hemoglobin percentage ( $\mathrm{HbF} \%)$ was determined by cation-exchange HPLC and $\alpha$-thalassemia screening was performed with a multiplex PCR assay [22]. If not available, we used the results from the latest outpatient visit [23].

All numbers in the tables are medians with corresponding interquartile ranges unless stated otherwise. Difference in continuous data between groups was tested with the Mann-Whitney $U$ test. Difference in categorical data between groups was tested with the $\chi^{2}$ test or Kruskal Wallis test. $P$ values $\leq 0.05$ were considered statistically significant. Multiple linear regression analyses were performed to analyze the interaction between the different scales of the SF-36 questionnaire and pain rate. All missing data were considered missing at random. In the case that one or more questions were not answered in a specific scale of the SF-36 questionnaire, the mean value of the remaining questions on that specific scale was used for the missing items. When half or more of the questions were not answered, the results of the specific scale were discarded. Statistical analysis was performed by using SPSS 12.0.2 (SPSS, Chicago, IL).

${ }^{1}$ Department of Hematology, Academic Medical Centre, Amsterdam, The Netherlands; ${ }^{2}$ Department of Hematology and Medical Oncology, St. Elisabeth Hospital, Curaçao, Netherlands Antilles Additional Supporting Information may be found in the online version of this article *Correspondence to: Bart J. Biemond, Department of Hematology, F4-224, Academic Medical Centre, PO Box 22660, 1100 DD Amsterdam, The Netherlands E-mail: b.j.biemond@amc.uva.nl Conflict of interest: Nothing to report. Published online 13 April 2010 in Wiley InterScience (www.interscience.wiley.com). DOI: 10.1002/ajh.21731

\section{References}

1. Schnog JJ, Lard LR, Rojer RA, et al. New concepts in assessing sickle cell disease severity. Am J Hematol 1998;58:61-66.

2. Serjeant GR. The emerging understanding of sickle cell disease. $\mathrm{Br} \mathrm{J}$ Haematol $2001 ; 112: 3-18$.

3. Levenson JL, McClish DK, Dahman BA, et al. Depression and anxiety in adults with sickle cell disease: The PiSCES project. Psychosom Med 2008; 70:192-196.

4. Anie KA. Psychological complications in sickle cell disease. $\mathrm{Br} \mathrm{J}$ Haematol 2005;129:723-729.

5. Palermo TM, Riley CA, Mitchell BA. Daily functioning and quality of life in children with sickle cell disease pain: Relationship with family and neighborhood socioeconomic distress. J Pain 2008;9:833-840.

6. van Beers EJ, van Tuijn CF, Mac Gillavry MR, et al. Sickle cell disease-related organ damage occurs irrespective of pain rate: Implications for clinical practice. Haematologica 2008;93:757-760.

7. Aaronson NK, Muller M, Cohen PD, et al. Translation, validation, and norming of the Dutch language version of the SF-36 Health Survey in community and chronic disease populations. J Clin Epidemiol 1998;51:1055-1068. 
8. Anie KA, Steptoe A, Bevan DH. Sickle cell disease: Pain, coping and quality of life in a study of adults in the UK. Br J Health Psychol 2002;7:331-344.

9. Thomas VJ, Taylor LM. The psychosocial experience of people with sickle cell disease and its impact on quality of life: Qualitative findings from focus groups. Br J Health Psychol 2002;7:345-363.

10. McClish DK, Penberthy LT, Bovbjerg VE, et al. Health related quality of life in sickle cell patients: The PiSCES project. Health Qual Life Outcomes 2005;3: 50 .

11. Kato GJ, Gladwin MT, Steinberg MH. Deconstructing sickle cell disease: Reappraisal of the role of hemolysis in the development of clinical subphenotypes. Blood Rev 2007;21:37-47.

12. Booker MJ, Blethyn KL, Wright CJ, Greenfield SM. Pain management in sickle cell disease. Chronic IIIn 2006;2:39-50.

13. Ballas SK, Barton FB, Waclawiw MA, et al. Hydroxyurea and sickle cell anemia: Effect on quality of life. Health Qual Life Outcomes 2006;4:59.

14. Smith WR, Penberthy LT, Bovbjerg VE, et al. Daily assessment of pain in adults with sickle cell disease. Ann Intern Med 2008;148:94-101.

15. McHorney CA, Ware JE Jr, Lu JF, Sherbourne CD. The MOS 36-item ShortForm Health Survey (SF-36). III. Tests of data quality, scaling assumptions, and reliability across diverse patient groups. Med Care 1994;32:40-66.
16. Panepinto JA. Health-related quality of life in sickle cell disease. Pediatr Blood Cancer 2008;51:5-9

17. Gladwin MT, Sachdev V, Jison ML, et al. Pulmonary hypertension as a risk factor for death in patients with sickle cell disease. N Engl J Med 2004;350:886-895.

18. Bakker AJ. Detection of microalbuminuria. Receiver operating characteristic curve analysis favors albumin-to-creatinine ratio over albumin concentration. Diabetes Care 1999;22:307-313.

19. Wilkinson CP, Ferris FL, Klein RE, et al. Proposed international clinical diabetic retinopathy and diabetic macular edema disease severity scales. Ophthalmology 2003;110:1677-1682.

20. Files B, Brambilla D, Kutlar A, et al. Longitudinal changes in ferritin during chronic transfusion: A report from the Stroke Prevention Trial in Sickle Cell Anemia (STOP). J Pediatr Hematol Oncol 2002;24:284-290.

21. Stuart MJ, Setty BN. Sickle cell acute chest syndrome: Pathogenesis and rationale for treatment. Blood 1999;94:1555-1560.

22. Tan AS, Quah TC, Low PS, Chong SS. A rapid and reliable 7-deletion multiplex polymerase chain reaction assay for alpha-thalassemia. Blood 2001;98: 250-251.

23. Ou CN, Rognerud CL. Rapid analysis of hemoglobin variants by cationexchange HPLC. Clin Chem 1993;39:820-824.

\title{
A specific linkage between the incidence of TP53 mutations and type of chromosomal translocations in B-precursor acute lymphoblastic leukemia cell lines
}

\author{
Takeshi Inukai, ${ }^{1 *}$ Xiuru Zhang, ${ }^{2}$ Takeshi Kameyama, ${ }^{2}$ Yukiko Suzuki, ${ }^{2}$ Kazuhito Yoshikawa, ${ }^{2}$ Itaru Kuroda, ${ }^{1}$ \\ Atsushi Nemoto, ${ }^{1}$ Koshi Akahane, ${ }^{1}$ Hiroki Sato, ${ }^{1}$ Kumiko Goi, ${ }^{1}$ Kazunori Nakamoto, ${ }^{3}$ Jun-ichi Hamada, \\ Mitsuhiro Tada, ${ }^{2}$ Tetsuya Moriuchi, ${ }^{2}$ and Kanji Sugita ${ }^{1}$
}

\begin{abstract}
Chromosomal translocation plays an essential role in leukemogenesis of childhood B-precursor acute lymphoblastic leukemia (ALL) in combination with specific gene mutations. Although several reports suggest correlation of TP53 mutation with the type of chromosomal translocation in childhood B-precursor ALL, it has not been directly confirmed in a single cohort study due to the limited incidence of TP53 mutation in primary samples at diagnosis. Leukemia cell lines generally show higher incidence of gene mutations compared with primary samples. Thus, to clarify possible differences in cooperation of the p53 pathway for leukemogenesis with the type of chromosomal translocation, TP53 gene mutation was analyzed in 32 B-precursor ALL cell lines. TP53 mutation was observed in $40.6 \%$ (13 cell lines), and missense mutation of $\mathrm{R} 248 \mathrm{Q}$ was the most commonly observed ( 5 cell lines). Of note, TP53 mutation was frequently observed among MLLrearranged and $t(1 ; 19)$-positive $A L L$ cell lines, but was very rare among Philadelphia chromosome-positive and $t(17 ; 19)$-positive ALL cell lines. Although the number of samples analyzed is limited, this is the first direct observation of the correlation between the incidence of TP53 mutation and types of translocation in B-precursor ALLs, suggesting a functionally different fusion gene product in the p53 pathway for leukemogenesis.
\end{abstract}

Chromosomal translocation is one of the most important events in leukemogenesis of childhood B-precursor acute lymphoblast leukemia (ALL), and its significance in disease prognosis has been well documented. p53 is critical regulator of cell death, cell cycle progression, and DNA repair, and, recently, its critical involvement in the efficiency of induced pluripotent stem cell generation was documented [1]. Of note, TP53 mutation is widely observed in various tumors including leukemia. An early retrospective study of exons 5-8 of the TP53 gene in 50 B-precursor ALL cases demonstrated that only one case (2\%) had mutation [2], and a large retrospective study of 264 childhood B-precursor ALL cases at diagnosis demonstrated that only five cases (1.9\%) had TP53 mutation in exons $5-8$, which encode highly conserved regions during evolution [3]. The incidence of TP53 mutation in exons 4-9 among poor-outcome childhood ALL cases at diagnosis was $30 \%$ (3/10 cases) [4]. Later studies reported that TP53 mutation might be relatively frequent among $A L L$ with $M L L$-rearrangement and $t(1 ; 19)$ : the inci- dence of TP53 mutation in exons 5-9 in MLL-rearranged ALL at diagnosis was $23 \%$ ( $3 / 13$ cases) [5], and that in exons $2-11$ in $t(1 ; 19)-A L L$ at diagnosis was $10 \%$ (2/20 cases) [6]. In contrast, TP53 mutation was rare in Philadelphia chromosome (Ph1)-positive ALL: none of 15 Ph1-positive ALL cases at diagnosis had TP53 mutation in exons 2-11 [7]. Although these reports suggest correlation of TP53 mutation with the type of chromosomal translocation in childhood B-precursor ALL, it has not been directly confirmed in a single cohort study due to the limited incidence of TP53 mutation in primary samples at diagnosis. Leukemia cell lines are usually established from leukemia in progressed disease status, and, thus, generally show higher incidence of gene mutations compared with primary samples [8]. In fact, Kawamura et al. [6] reported that the incidence of TP53 mutation was increased to $80 \%$ ( $4 / 5$ cell lines) among $t(1 ; 19)$-ALL cell lines, suggesting that the incidence of TP53 mutation might be augmented in cell lines. Accordingly, ALL cell lines would be useful tools to confirm the correlation of TP53 mutation with chromosomal translocations.

To clarify the TP53 gene status in B-precursor ALL cell lines with representative chromosomal translocations, we analyzed 32 B-precursor ALL cell lines including 10 MLL-rearranged ALL [9], $6 \mathrm{t}(1 ; 19)$-ALL, 7 Ph1-positive ALL [10], and $4 \mathrm{t}(17 ; 19)$-ALL cell lines [11] using the yeast functional assay [12], which is sensitive for detecting TP53 mutation. TP53 mutation was detected in 13 cell lines (40.6\%) (Table I). The incidence of TP53 mutation in the present study is higher than that in previous reports that used primary ALL samples at diagnosis, in which TP53 mutation was identified in $\sim 2 \%$ of the cases [2,3], suggesting that acquisition of TP53 mutation might provide advantages for disease progression and/or sustained proliferation in vitro.

Among 13 cell lines with TP53 mutation, three cell lines had two types of mutations simultaneously; one cell line (KOPN36) had double mutation on the same allele, while two cell lines (KOPB26 and KOPN63) had two mutations on different alleles (Table I). The distribution of the 16 mutations identified in 13 cell lines is shown in Fig. $1 \mathrm{~A}$ and compared with that in previous reports on B-precursor ALL samples [2-7] and T-ALL samples [18,19]. Five (38.5\%) of the 13 cell lines with TP53 mutation had missense mutation of c.743 $\mathrm{G}>\mathrm{A}$ resulting in $\mathrm{p} . \mathrm{R} 248 \mathrm{Q}$, and 2 cell lines (15.4\%) had missense mutation of $c .817 \mathrm{C}>\mathrm{T}$ resulting in $\mathrm{p} . \mathrm{R} 273 \mathrm{C}$; both are well known as hotspots. Among the 16 mutations, 11 mutations were located in highly con- 
TABLE I. TP53 Gene Status in B-Precursor ALL Cell Lines

\begin{tabular}{|c|c|c|c|c|c|}
\hline Cell line & Translocation & References & Red colony (\%) & Mutation & Types of mutation \\
\hline \multicolumn{6}{|c|}{ MLL-rearranged } \\
\hline KOPN1 & $t(11 ; 19)$ & [9] & 97 & yes & c.743G > A(p.R248Q) \\
\hline KOPB26 & $t(9 ; 11)$ & [9] & 99 & yes & c.833C $>$ T(p.P278L $)+c .849 \_861 \mathrm{del}^{\mathrm{a}}$ \\
\hline KOCL33 & $t(11 ; 19)$ & [9] & 12 & no & \\
\hline KOCL44 & $t(11 ; 19)$ & [9] & 10 & no & \\
\hline KOCL45 & $t(4 ; 11)$ & [9] & 99 & yes & c.817C $>T(p . R 273 C)$ \\
\hline KOCL50 & $t(11 ; 19)$ & [9] & 99 & yes & c.817C $>T(p . R 273 C)$ \\
\hline KOCL51 & $\mathrm{t}(11 ; 19)$ & [9] & 9 & no & \\
\hline KOCL58 & $t(4 ; 11)$ & [9] & 10 & no & \\
\hline KOCL69 & $\mathrm{t}(4 ; 11)$ & [9] & 99 & yes & c.541C $>T(p . R 181 C)$ \\
\hline YAMCL95 & $t(9 ; 11)$ & & 100 & yes & c.408A $>T(p . Q 136 H)$ \\
\hline \multicolumn{6}{|l|}{$t(1 ; 19)$} \\
\hline 697 & & & 18 & no & \\
\hline KOPN34 & & & 5 & no & \\
\hline KOPN36 & & [13] & 99 & yes & c. [655C $>\mathrm{T} ; 743 \mathrm{G}>\mathrm{A}]$ p.[P219S;R248Q] \\
\hline KOPN63 & & {$[13]$} & 98 & yes & c.743G $>$ A(p.R248Q $)+c .879 \_880$ ins $^{\text {b }}$ \\
\hline YAMN90 & & & 100 & yes & c.743G > A(p.R248Q) \\
\hline YAMN92 & & & 99 & yes & c.832T $>$ G(p.L194R) \\
\hline KOPN30bi & & [10] & 12 & no & \\
\hline KOPN57bi & & [10] & 13 & no & \\
\hline KOPN66bi & & [10] & 7 & no & \\
\hline KOPN72bi & & [10] & 5 & no & \\
\hline YAMN73 & & [10] & 100 & yes & c.743G $>A(p . R 248 Q)$ \\
\hline KOPN83bi & & & 3 & no & \\
\hline YAMN91 & & [10] & 6 & no & \\
\hline \multicolumn{6}{|l|}{$t(17 ; 19)$} \\
\hline UOC-B1 & & {$[11]$} & 11 & no & \\
\hline HAL01 & & {$[11,14]$} & 3 & no & \\
\hline YCUB-2 & & {$[11,15]$} & 18 & no & \\
\hline Endo-kun & & {$[11]$} & 12 & no & \\
\hline \multicolumn{6}{|l|}{ Others } \\
\hline Reh & $t(12: 21)$ & [16] & 18 & no & \\
\hline Nalm6 & $t(5 ; 12)$ & & 19 & no & \\
\hline KOPN32 & $\operatorname{del}(17)(p 11)$ & [13] & 100 & yes & c.658 delT \\
\hline KOPN35 & $\mathrm{t}(9 ; 11)(\mathrm{p} 13 ; q 13)$ & [13] & 99 & yes & c.768C $>$ G(p.L257V) \\
\hline KOPN61 & $\mathrm{t}(\mathrm{X} ; 14)(\mathrm{p} 22 ; \mathrm{q} 22-24)$ & [17] & 13 & no & \\
\hline
\end{tabular}

${ }^{a}$ c.849_861 del CACAGAGGAAGAG.

${ }^{b}$ c.879_880 insCC, c881A.C c,884A > G c.886_887insA.

served regions. This pattern of distribution was similar to that in B-precursor ALL samples previously reported, in which 5 (18.5\%) of the 27 samples with TP53 mutation had R248Q. In contrast, R248Q mutation was reported in only one of 22 samples of T-cell ALL with TP53 mutation.

The incidence of TP53 mutation among MLL-rearranged ALL cell lines and $t(1 ; 19)$-ALL cell lines was $60 \%(6 / 10)$ and $66.7 \%(4 / 6)$, respectively, while that among Ph1-positive ALL cell lines and t(17;19)-ALL cell lines was $14.3 \%(1 / 7)$ and $0 \%(0 / 4)$, respectively (Fig. 1B). Of note, consistent with the series of clinical samples in previous reports [5-7], the incidence of TP53 mutation among MLL-rearranged and $t(1 ; 19)$-positive ALL cell lines was significantly higher than that among the other ALL cell lines including Ph1 and $\mathrm{t}(17 ; 19)$-positive ALL cell lines $(P<0.05$, chi-squared test). Although the number of cell lines analyzed is limited, this is the first direct observation in a single analysis of the correlation between the incidence of TP53 mutation and types of translocation in B-precursor ALLs. The incidence of TP53 mutation among MLL-rearranged and $t(1 ; 19)$-positive ALL cell lines observed in this study was higher than that in previous reports using clinical samples, suggesting that TP53 mutation plays a role in disease progression and/or the in vitro proliferative activity of $M L L$-rearranged and $t(1 ; 19)$-positive ALL but not necessarily Ph1 and t(17;19)-positive ALL. It should be noted that E2A-HLF chimera derived from $t(17 ; 19)$ has the potential to protect cells from apoptosis induced by activation of the p53 pathway [20], suggesting that E2A-HLF might overcome at least the proapoptotic activity of p53. Similarly, it was reported that BCR-ABL blocks apoptotic cell death induced by DNA damage without altering p53-dependent G1 arrest [21]. Thus, E2A-HLF and BCR-ABL may have the potential to overcome the pro-apoptotic activity of p53 and, thus, TP53 mutation is not necessary for disease progression. In other words, regardless of the TP53 gene status, Ph1-positive ALL and t(17;19)-ALL could be relatively resistant to therapeutic modalities that activate the p53 pathway such as irradiation. In contrast, without TP53 mutation, MLL-rearranged ALL and $t(1 ; 19)$-ALL might be relatively sensitive to therapeutic modalities that activate the p53 pathway, and, thus, TP53 mutation could be one of the prognostic factors for therapeutic outcome in these leukemias.

In conclusion, TP53 mutation was observed in as high as $40 \%$ of B-precursor ALL cell lines, but was significantly less frequent among Ph1 and $\mathrm{t}(17 ; 19)$-positive ALL cell lines. TP53 mutation might be associated with the functional significance of the fusion gene product derived from translocation in the p53 pathway.

\section{Methods}

32 cell lines established from childhood B-precursor ALL were used: 10 MLL-rearranged ALL cell lines [9] (KOPN-1, KOPB-26, KOCL-33, -44, -45, $-50,-51,-58,-69$, and YAMCL-95), $6 \mathrm{t}(1 ; 19)-\mathrm{ALL}$ cell lines (697, KOPN34, -36 [13], -63 [13], YAMN-90, and -92), 7 Ph1-positive ALL cell lines [10] (KOPN-30bi, -57bi, -66bi, -72bi, YAMN-73, -83bi, and -91), 4 t(17;19)-ALL cell lines [11] (UOC-B1, HAL01 [14], YCUB-2 [15], Endo-kun), and 5 other ALL cell lines including 1 with $t(12 ; 21)$ (Reh) [16] and 4 with others (Nalm6, KOPN-32 [13], -35 [13], and -61 [17]). Total RNA was extracted using the Trizol reagent (Invitrogen, Carlsbad, CA), reverse transcription was performed using random hexamer (Amersham Bioscience, Buckinghamshire, United Kingdom) by Superscript II reverse transcriptase (Invitrogen), and then incubated with RNase (Invitrogen). The state of the TP53 gene was tested by the yeast functional assay [12] as described previously $[22,23]$. In brief, RT-PCR amplified TP53 cDNAs were cotransfected with a linealized gap vector carrying the $5^{\prime}$ and $3^{\prime}$ ends of the gene into the ylG397 strain containing an integrated plasmid with the $A D E 2$ open reading frame under the control of TP53-responsive promoter. Yeast containing the mutant TP53 cDNA fails to transcribe ADE mRNA and formed red colonies, whereas yeast expressing the wild-type TP53 forms white colonies. Thus, the status of the TP53 gene is quantitatively analyzed by the color of colonies. When functional assay demonstrated the TP53 mutation, sequences of 
A
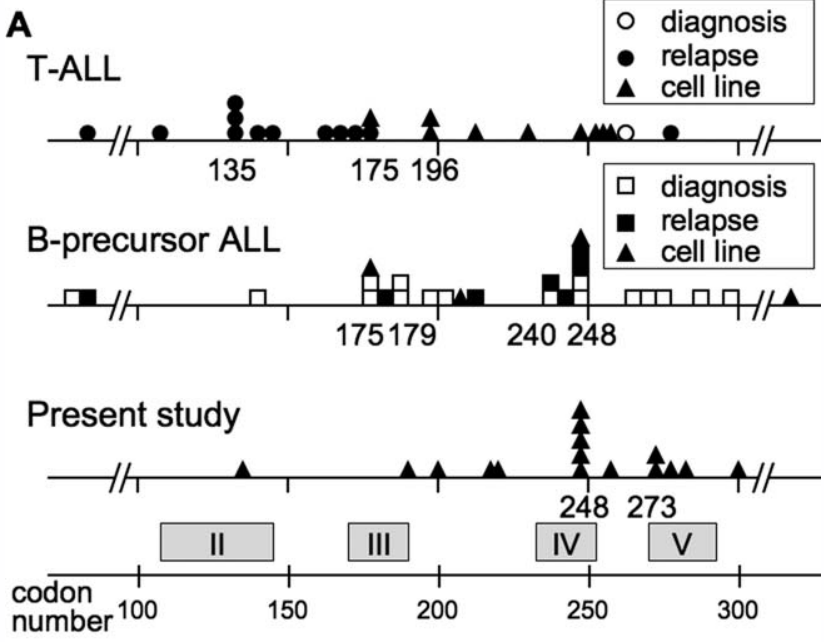

B

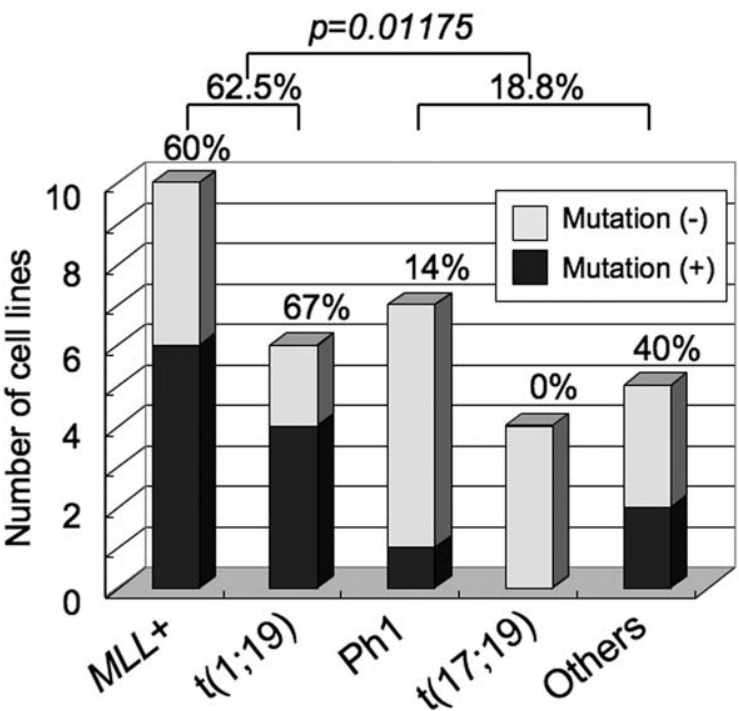

Figure 1. Codon distribution and incidence of TP53 mutation in B-precursor ALL cell lines with representative chromosomal translocations. A: Codon distribution of 16 TP53 mutations identified in the 13 B-precursor ALL cell lines in the present study is indicated at the bottom and compared with that in B-precursor ALL samples reported in the six previous studies (middle) and in T-ALL samples reported in the two previous studies (top). The number of codons in which mutation was identified in multiple samples is indicated. In the previously reported samples, open and closed symbols indicate samples at diagnosis and samples at relapse, respectively, and triangles indicate cell lines. The location of highly conserved regions (domains II, III, IV, and V) in the TP53 gene is indicated at the bottom. B: Incidence of TP53 mutation among B-precursor ALL cell lines with various chromosomal translocations is indicated. Closed and open columns demonstrate the number of cell lines with and without TP53 mutation, respectively. The $P$-value upon chisquare test between the incidence of TP53 mutation among $M L L$-rearranged and $t(1 ; 19)$-positive ALL cell lines and that among the other cell lines including Ph1 and $t(17 ; 19)$-positive ALL cell lines is indicated.

TP53 gene was analyzed. In brief, yeasts were digested with Zymolyase (Seikagaku-Kogyo, Tokyo, Japan), and TP53 expression plasmids were extracted by QIApreo (QIAGEN, Hilden, Germany) and transfected into XL-1 blue E. coli by electroporation. The extracted plasmids were processed for sequencing with a DyeDeoxy Terminator Kit (Perkin-Elmer, Urayasu, Japan).

${ }^{1}$ Department of Pediatrics, School of Medicine, University of Yamanashi Yamanashi, Japan; ${ }^{2}$ Division of Cancer-Related Genes, Institute for Genetic Medicine, Hokkaido University, Sapporo, Hokkaido, Japan;
${ }^{3}$ Bioinformatics Support Section, Center for Life Science Research, University of Yamanashi, Yamanashi, Japan 'Correspondence to: Takeshi Inukai, Department of Pediatrics, School of Medicine, University of Yamanashi, 1110 Shimokato, Chuo, Yamanashi 409-3898, Japan E-mail: tinukai@yamanashi.ac.jp Conflict of interest: Nothing to report. Published online 19 April 2010 in Wiley InterScience (www.interscience.wiley.com). DOI: 10.1002/ajh.21738

\section{References}

1. Hong $\mathrm{H}$, Takahashi $\mathrm{K}$, Ichisaka $\mathrm{T}$, et al. Suppression of induced pluripotent stem cell generation by the p53-p21 pathway. Nature 2009;460:1132-1135.

2. Fenaux P, Jonveaux P, Quiquandon I, et al. Mutations of the p53 gene in B-cell lymphoblastic acute leukemia: A report on 60 cases. Leukemia 1992;6:42-46.

3. Wada M, Bartram CR, Nakamura $\mathrm{H}$, et al. Analysis of $\mathrm{p} 53$ mutations in large series of lymphoid hematologic malignancies of childhood. Blood 1993; 82:3163-3169.

4. Marks DI, Kurz BW, Link MP, et al. High incidence of potential p53 inactivation in poor outcome childhood acute lymphoblastic leukemia at diagnosis. Blood 1996;87:1155-1161.

5. Lanza C, Gaidano G, Cimino G, et al. Distribution of TP53 mutations among acute leukemias with MLL rearrangements. Genes Chromosomes Cancer 1996;15:48-53.

6. Kawamura M, Kikuchi A, Kobayashi S, et al. Mutations of the p53 and ras genes in childhood $t(1 ; 19)$-acute lymphoblastic leukemia. Blood 1995;85: 2546-2552.

7. Nakai H, Misawa S, Tanaka S, et al. p53 Gene mutations and loss of a chromosome 17p in Philadelphia chromosome (Ph1)-positive acute leukemia. Leukemia 1993;7:1547-1551.

8. Drexler HG, Fombonne S, Matsuo Y, et al. p53 Alterations in human leukemia-lymphoma cell lines: In vitroartifact or prerequisite for cell immortalization? Leukemia 2000;14:198-206.

9. Inukai $T$, Zhang $X$, Goto $M$, et al. Resistance of infant leukemia with MLL rearrangement to tumor necrosis factor-related apoptosis-inducing ligand: A possible mechanism for poor sensitivity to antitumor immunity. Leukemia 2006;20:2119-2129.

10. Uno K, Inukai T, Kayagaki N, et al. TNF-related apoptosis-inducing ligand (TRAIL) frequently induces apoptosis in Philadelphia chromosome-positive leukemia cells. Blood 2003;101:3658-3667.

11. Akahane K, Inukai T, Inaba T, et al. Specific induction of CD33 expression by E2A-HLF: The first evidence for aberrant myeloid antigen expression in ALL by a fusion transcription factor. Leukemia 2010;24:865-869.

12. Flaman JM, Frebourg $T$, Moreau V, et al. A simple p53 functional assay for screening cell lines, blood, and tumors. Proc Natl Acad Sci USA 1995;92:39633967.

13. Nakamura M, Sugita K, Inukai T, et al. p16/MTS1/INK4A Gene is frequently inactivated by hypermethylation in childhood acute lymphoblastic leukemia with 11q23 translocation. Leukemia 1999;13:884-890.

14. Ohyashiki K, Fujieda $\mathrm{H}$, Miyauchi J, et al. Establishment of a novel heterotransplantable acute lymphoblastic leukemia cell line with a $t(17 ; 19)$ chromosomal translocation the growth of which is inhibited by interleukin-3. Leukemia 1991;5:322-331

15. Takahashi $\mathrm{H}$, Goto $\mathrm{H}$, Eunabiki $\mathrm{T}$, et al. Expression of two types of E2A-HLF fusion proteins in YCUB-2, a novel cell line established from B-lineage leukemia with $\mathrm{t}(17 ; 19)$. Leukemia 2001;15:995-997.

16. Uphoff CC, MacLeod RA, Denkmann SA, et al. Occurrence of TEL-AML1 fusion resulting from $(12 ; 21)$ translocation in human early B-lineage leukemia cell lines. Leukemia 1997:11:441-447.

17. Nakamura M, Sugita K, Inukai T, et al. Abnormalities of the p16INK4a gene in childhood B-precursor acute lymphoblastic leukemia without nonrandom translocations: Analysis of seven matched pairs of primary leukemia and corresponding cell line. Leukemia 2001;15:1136-1139.

18. Cheng J, Haas M. Frequent mutations in the p53 tumor suppressor gene in human leukemia T-cell lines. Mol Cell Biol 1990;10:5502-5509.

19. Diccianni MB, Yu J, Hsiao M, et al. Clinical significance of $p 53$ mutations in relapsed T-cell acute lymphoblastic leukemia. Blood 1994;84:3105-3112.

20. Altura RA, Inukai T, Ashmun RA, et al. The chimeric E2A-HLF transcription factor abrogates p53-induced apoptosis in myeloid leukemia cells. Blood 1998:92:1397-1405.

21. Bedi A, Barber JP, Bedi GC, et al. BCR-ABL-mediated inhibition of apoptosis with delay of G2/M transition after DNA damage: A mechanism of resistance to multiple anticancer agents. Blood 1995;86:1148-1158.

22. Kashiwazaki $\mathrm{H}$, Tonoki $\mathrm{H}$, Tada $\mathrm{M}$, et al. High frequency of $\mathrm{p} 53$ mutations in human oral epithelial dysplasia and primary squamous cell carcinoma detected by yeast functional assay. Oncogene 1997;15:2667-2674.

23. Takahashi $\mathrm{M}$, Tonoki $\mathrm{H}$, Tada $\mathrm{M}$, et al. Distinct prognostic values of $\mathrm{p} 53$ mutations and loss of estrogen receptor and their cumulative effect in primary breast cancers. Int J Cancer 2000;89:92-99. 


\title{
Clinical manifestations of combined factor V and VIII deficiency: A series of $\mathbf{3 7}$ cases from a single center in India
}

\author{
Auro Viswabandya, ${ }^{1}{ }^{*}$ Shoma Baidya, ${ }^{2}$ Sukesh C. Nair, ${ }_{1}^{2}$ Kavitha M. Lakshmi, ${ }^{1}$ Vikram Mathews, ${ }^{1}$ \\ Biju George, ${ }^{1}$ Mammen Chandy ${ }^{1}$ and Alok Srivastava ${ }^{1}$
}

We describe here the clinical manifestations of 37 patients with combined coagulation factor (F) V and FVIII deficiency, which is the commonest multiple coagulation factor deficiency state. Only a few cases are reported in the literature from India. Prolonged bleed post injury/ surgery $(62 \%)$ is the commonest manifestation in our series, and epistaxis $(19 \%)$ is rare in our patients in comparison to other series described in the literature. Although the frequency of bleeding manifestations differs among various reports, there is no evidence for increased bleeding manifestation due to combined deficiency of two coagulation factors as against a single coagulation factor. To the best of our knowledge, this is the largest series of this disorder described so far.

Combined Factor (F) V and VIII is the commonest combined hereditary coagulation factor deficiency with a prevalence of $1: 1,000,000$ [1]. It is an autosomal recessive disorder of blood coagulation [2] and the frequency of such autosomal recessive disorders increases $8-10$-folds in populations where consanguinity is common. It is caused by a defect in lectin mannose binding protein 1 (LMAN 1) gene or in multiple coagulation factor deficiency (MCFD) gene 2 [3-5]. It was initially described by Oeri et al. [6] in 1954 and so far about 150 patients have been described from around the world [711]. The largest of these studies so far, describe the clinical manifestations of this disorder in 27 patients of Iranian origin [7]. Patients who are homozygous for this combined factor deficiency state maintain a factor level between $4 \%$ and $30 \%[12,13]$. We present herewith the clinical and phenotypic data of combined FV and FVIII deficiency in a large series of 37 patients of Indian origin seen at our center.

\section{Methods}

All patients with combined FV and FVIII deficiency seen at our center over a period of 20 years, between 1988 and 2008 were included in this analysis. History of bleeding was considered significant if

i. After dental extraction bleeding persisted for more than $48 \mathrm{hr}$ or required repeat surgical intervention.

ii. Menstrual period lasted 6 days or more with history of clots and required hormonal therapy for control.

iii. Epistaxis was spontaneous and persisted even after local measures to control.

iv. Gastrointestinal bleed, presented as hematemesis or malaena.

v. Post-traumatic bleed if the bleeding was significant with minor trauma.

vi. Any other history of bleeding that required blood product support.

For hematoma, the nature of the injury and for hemarthrosis, the radiological changes in the joint were documented.

FVIII coagulant (FVIII: C) activity was measured on citrated plasma samples from these patients by one-stage APTT method while FV coagulant activity was measured by a PT based method. From 1998 till 2001, the factor assay was done by Coag-a-mate; RA4 (Organon Teknika), from 2001 till 2006 by CA-1500 Sysmex coagulometer (Sysmex, Hyogo, Japan) and from 2006 onwards by ACL Advance (Beckman Coulter). For the diagnosis of combined FV and VIII deficiency, the cut-off values for FV $(<40 \%)$ and FVIII: $C(<45 \%)$ was considered as previously described [7].

There were a total of 37 cases of combined FV and FVIII deficiency diagnosed during this time. There were $21(57 \%)$ female and $16(43 \%)$ male patients, with a mean age of 17 years (range: 1-49). Twenty-eight (76\%) out of 37 cases were born of consanguineous marriages. A family history of bleeding was present in $14(38 \%)$ cases. Nineteen patients $(51 \%)$ were symptomatic prior to 5 years of age. The mean level of FV was $12.5 \%$ (range: $5-31$ ), and the mean level of FVIII was $8.8 \%$ (range: $1-27$ ). In 11 out of $37(30 \%)$ patients both FV and FVIII levels were $10 \%$ or lower. Seven out of $37(19 \%)$ patients had both factor levels more than $10 \%$.
Nineteen patients $(51 \%)$ had one factor level above and the other below the $10 \%$ limit (five patients had FV level less than $10 \%$ and fourteen patients had FVIII level less than 10\%). Median levels of FV and FVIII around $10 \%$ was typical of the homozygous state for the combined deficiency of FV and FVIII [11-13].

Prolonged bleeding post injury/surgery was the commonest bleeding manifestation seen in $23(62 \%)$ cases. The other significant symptoms were bleeding from tooth socket in $21(57 \%)$ cases, gum bleed in $18(49 \%)$, easy bruisability in $11(30 \%)$, epistaxis in seven (19\%), hemarthrosis in five $(13 \%)$, gastrointestinal bleed in one $(3 \%)$ case. No patient had presented with intracranial bleed. Menorrhagia was seen in $6 / 9(66 \%)$ females who had attended menarche.

Our data shows that there are differences in the clinical manifestations of patients in India compared to those described in the only other large series reported so far in the literature from Iran. The clinical manifestations in our patients have been compared with that of other large series in Table I. Epistaxis $(77 \%$ and $48 \%)$ was the most common symptom among patients from Iran [7,9]. However, this occurred much less frequently (epistaxis, 19\%) in our patients. Epistaxis was also significantly less in our patients when compared to that from Israel [11]; (57\% vs. $19 \%)$. Hemarthrosis was observed in $13 \%$ of our patients though this has not been reported from the other small series reported from India [10]. Though hemarthrosis has been reported from the series published from Iran $[7,9]$, it has not been reported from that reported from Israel [11]. Bleeding following circumcision was a major feature in patient from Iran $[7,9]$. But since this is not a common practice in this part of the world, only one of our patients had presented with this symptom. Gum bleeding, which occurred in almost half of our patients was not documented in the Iranian series but was shown to be present in a smaller group of patients from India [10] and from Israel [11]. Prolonged bleeding post trauma/surgical procedure was the most frequent $(62 \%)$ symptom in our patients. Our data shows that the pattern of bleeding among patients with combined FV and FVIII deficiency in India is different from that reported from Iran and Israel, even though the mean factor levels are similar. At present, we are not able to explain the difference in clinical behavior in our patients but the change in the life style may be a factor because similar observation has also been documented from other small series India [10].

When we compared between three groups of patients (1st group: both FV and FVIII <10\%; 2nd group: both FV and FVIII levels $>10 \%$; 3rd group: either FV or FVIII $<10 \%$ ) there was no difference between different bleeding symptoms. The same has also been reported from both the series from Iran $[7,9]$. When we compared between two groups of patients (1st group: both $\mathrm{FV}$ and $\mathrm{FVIII}<5 \%$; 2nd group: both FV and FVIII $>5 \%$ ), there were no differences in the bleeding symptoms observed. This shows that presence of two defects do not make the severity of bleeding greater than that expected in patients with single coagulation defects of similar degrees.

We have reported here the clinical manifestations in 37 patients with combined FV and FVIII deficiency from India. This is the largest series in the world describing the clinical manifestations of patients with combined factor $\mathrm{V}$ and VIII deficiency reported so far. It is evident from this as well as previous studies [7,9-11] that the bleeding symptoms in combined FV and FVIII deficiency is almost similar to the deficiency of single coagulation factor. There is no clear evidence to support increased bleeding manifestations due to the combined deficiency of two coagulation factors.

In combined FV and FVIII deficiency, our knowledge about the clinical manifestation so far is based on just one or two large series published in the literature. There is a need for careful documentation of clinical data from different population to see what the profile is for large number of patients and whether there are any ethnic differences. Further molecular 
TABLE I. Comparison of Clinical Manifestations Between Our Patients and Other Large Series from Literature

\begin{tabular}{|c|c|c|c|c|c|}
\hline & $\begin{array}{l}\text { Present study } \\
\qquad(n=37)\end{array}$ & $\begin{array}{l}\text { Peyvandi et al. [7] } \\
\qquad(n=27)\end{array}$ & $\begin{array}{l}\text { Shetty et al. [10] } \\
\qquad(n=9)\end{array}$ & $\begin{array}{l}\text { Seligsohn et al. [11] } \\
\qquad(n=14)\end{array}$ & $\begin{array}{l}\text { Mansouritorgabeh } \\
\text { et al. [9] }(n=19)\end{array}$ \\
\hline $\begin{array}{l}\text { Prolonged bleed post injury/ } \\
\text { surgical procedure }\end{array}$ & $62 \%$ & $77 \%$ & $77 \%$ & $85 \%$ & $73 \%$ \\
\hline Easy bruisability & $30 \%$ & & $44 \%$ & $29 \%$ & \\
\hline Menorrhagia & $66 \%$ & $58 \%$ & $75 \%$ & $100 \%$ & $40 \%$ \\
\hline Gum bleed & $49 \%$ & & $44 \%$ & $64 \%$ & \\
\hline Haemarthrosis & $13 \%$ & $25 \%$ & $0 \%$ & $0 \%$ & $36 \%$ \\
\hline Epistaxis & $19 \%$ & $77 \%$ & & $57 \%$ & $48 \%$ \\
\hline FV: C (\%) (mean and range) & $12.5(5-31 \%)$ & $11(2-21)$ & $6.6(3-9)$ & 17 & $9.28(4-15)$ \\
\hline FVIII: C (\%) (mean and range) & $8.8(1-27 \%)$ & $13(2-22)$ & $1.6(<1-3.8)$ & 19 & $12.63(5-30)$ \\
\hline
\end{tabular}

studies to identify the causative mutations in patients with this disease will shed light on the basis for the clinical diversity seen among the patients.

\section{${ }^{1}$ Department of Hematology, Christian Medical College, Vellore, Tamil Nadu, India; ${ }^{2}$ Department of Clinical Pathology, Christian Medical College Vellore, Tamil Nadu, India ${ }^{*}$ Correspondence to: Auro Viswabandya, Department of Hematology Christian Medical College, Vellore, Tamil Nadu 632 004, India E-mail: aurov@cmcvellore.ac.in Conflict of interest: Nothing to report. Received for publication 25 February 2010; Revised 25 March 2010; Accepted 15 April 2010 Published online 21 April 2010 in Wiley InterScience (www.interscience.wiley.com). DOI: 10.1002/ajh.21741}

\section{References}

1. Peyvandi F, Duga S, Akhavan S, Mannucci PM. Rare coagulation deficiencies. Haemophilia 2002;8:308-321.

2. Nichols WC, Seligsohn U, Zivelin A, et al. Mutations in the ER-Golgi intermediate compartment protein ERGIC- 53 cause combined deficiency of coagulation factors V and VIII. Cell 1998;93:61-62.

3. Nichols WC, Seligsohn U, Zivelin A, et al. Linkage of combined factors V and VIII deficiency to chromosome $18 \mathrm{q}$ by homozygosity mapping. J Clin Invest 1982;99:596-601.
4. Girolami A, Gastaldi G, Patrssi G, et al. Combined congenital deficiency of factor V and factor VIII. Report of a further case with some considerations on the hereditary transmission of this disorder. Acta Haematol 1976; 55:234-243.

5. Zhang B, Cunningham MA, Nichols WC, et al. Bleeding due to disruption of a cargo-specific ER-to-golgi transport complex. Nat Genet 2003;34:220225.

6. Oeri J, Matter $\mathrm{M}$, Isensrhmid $\mathrm{H}$. Angeborener mangel an faktor $\mathrm{V}$ (parahaemophilie) verbunden mit echter haemophilie A bein zwei burden. Med Probl Paediatr 1954;1:575-588.

7. Peyvandi F, Tuddenham EGD, Akhtari AM, et al. Bleeding symptoms in 27 Iranian patients with the combined deficiency of factor $\mathrm{V}$ and factor $\mathrm{VIII}$. $\mathrm{Br} J$ Haematol 1998;100:773-776.

8. Mannucci P, Duga S, Peyvandi F. Recessively inherited coagulation disorders. Blood 2004:104:1243-1252.

9. Mansouritorgabeh H, Rezaieyazdi Z, Pourfathollah A, et al. Haemorrhagic symptoms in-patients with combined factors V and VIII deficiency in northeastern Iran. Haemophilia 2004:10:271-275.

10. Shetty S, Madkaikar M, Nair S, et al. Combined factor V and VIII deficiency in Indian population. Haemophilia 2000;6:504-507.

11. Seligsohn U, Zivelin A, Zwand E. Combined factor V and factor VIII deficiency in among non-Ashkenazi Jews. N Engl J Med 1981;307:1191-1195.

12. Soff GA, Levin J. Familial multiple coagulation factor deficiencies. Semin Thromb Haemost 1981;7:112-148.

13. Giddings JC, Sugrue A, Bloom AL. Quantitation of coagulant antigens and inhibition of activated protein $\mathrm{C}$ in combined factor V/VIII deficiency. $\mathrm{Br} \mathrm{J}$ Haematol 1982;52:495-502.

\title{
Expression of CD1d and presence of invariant NKT cells in classical Hodgkin lymphoma
}

\author{
Chuanhui Xu, ${ }^{1}$ Riemer de Vries, ${ }^{1}$ Lydia Visser, ${ }^{1}$ Arjan Diepstra, ${ }^{1}$ Stephan D. Gadola, ${ }^{2}$ \\ Sibrand Poppema, ${ }^{1}$ and Anke van den Berg ${ }^{1 *}$
}

We studied CD1d-restricted invariant natural killer T (iNKT) cells in classical Hodgkin lymphoma (cHL). Tumor cells stained positive for CD1d in 21/44 cHL cases, whereas in non-Hodgkin lymphoma (NHL), only 9/31 stained positive. In contrast, CD1c expression was more common in NHL. The percentage of iNKT cells in cHL cell suspensions was similar to the percentage in reactive lymph nodes and was not related to the CD1d expression status of the tumor cells. In conclusion, we found expression of CD1d in HRS cells in half of the $\mathrm{cHL}$ cases, and also observed a substantial population of iNKT cells in $\mathrm{cHL}$ cell suspensions.

Classical Hodgkin lymphoma (cHL) is a B-cell neoplasm characterized by a minority of neoplastic cells, the Hodgkin and Reed-Sternberg (HRS) cells, which are located within an extensive infiltrate of reactive cells, such as $T$ cells, B cells, plasma cells, stromal cells, eosinophils, and macrophages. The HRS cells shape their microenvironment by attracting specific favorable T cell subsets, like regulatory $\mathrm{T}$ (Treg) and T helper 2 (TH-2) cells and producing factors such as CC-chemokine ligand 17 (CCL17 or TARC), transforming growth factor (TGF)- $\beta$ and interleukin (IL)-10 [1]. Additionally, HLA class $I$ is downregulated in HRS cells in $65 \%$ of the $\mathrm{cHL}$ cases and HLA class II in $40 \%$, possibly as a strategy to escape from an effective immune surveillance [2]. All together, these factors may suppress the development of an effective antitumor response and provide a microenvironment that is favorable for the HRS cells.

Recent studies have suggested that $T$ cells restricted to nonclassical MHC class I-like CD1 molecules may be involved in immune surveillance of hematological malignancies [3-6]. CD1 molecules are nonclassical MHC class I-like molecules that present lipid antigens to $T$ cells, triggering a specific immune response. Of the five CD1 isoforms (CD1a, CD1b, CD1c, CD1d, and CD1e) expressed in human tissue, only CD1C and CD1d are expressed in $B$ cells [7]. The $T$ cell receptors (TCRs) of T cells that recognize $\mathrm{CD} 1 \mathrm{C}$ are indistinguishable from those that recognize $\mathrm{MHC}$ class I or II complexes. Most CD1c-restricted T cells appear to be TH-1-like cells that provide adaptive immunity to microbial-lipid antigens [8]. In contrast, CD1d presents lipid antigens to natural killer T (NKT) cells. The best characterized CD1d-restricted NKT cells in humans are the invariant NKT (iNKT) cells, also known as type I NKT cells. These cells are characterized by the expression of an invariant $V_{\alpha} 24 \mathrm{~J} \alpha 18$ chain paired to a semi-invariant $\mathrm{V} \beta 11$ chain [9]. Two distinct functional subsets of human iNKT cells are recognized in terms of cytokines production and cytotoxic activation. CD4- iNKT cells are more likely to be cytotoxic and produce $\mathrm{TH}-1$ type cytokines, whereas CD4+ iNKT cells are more likely to produce both $\mathrm{TH}-1$ and $\mathrm{TH}-2$ type cytokines after stimulation [10]. Several studies have shown the impor- 


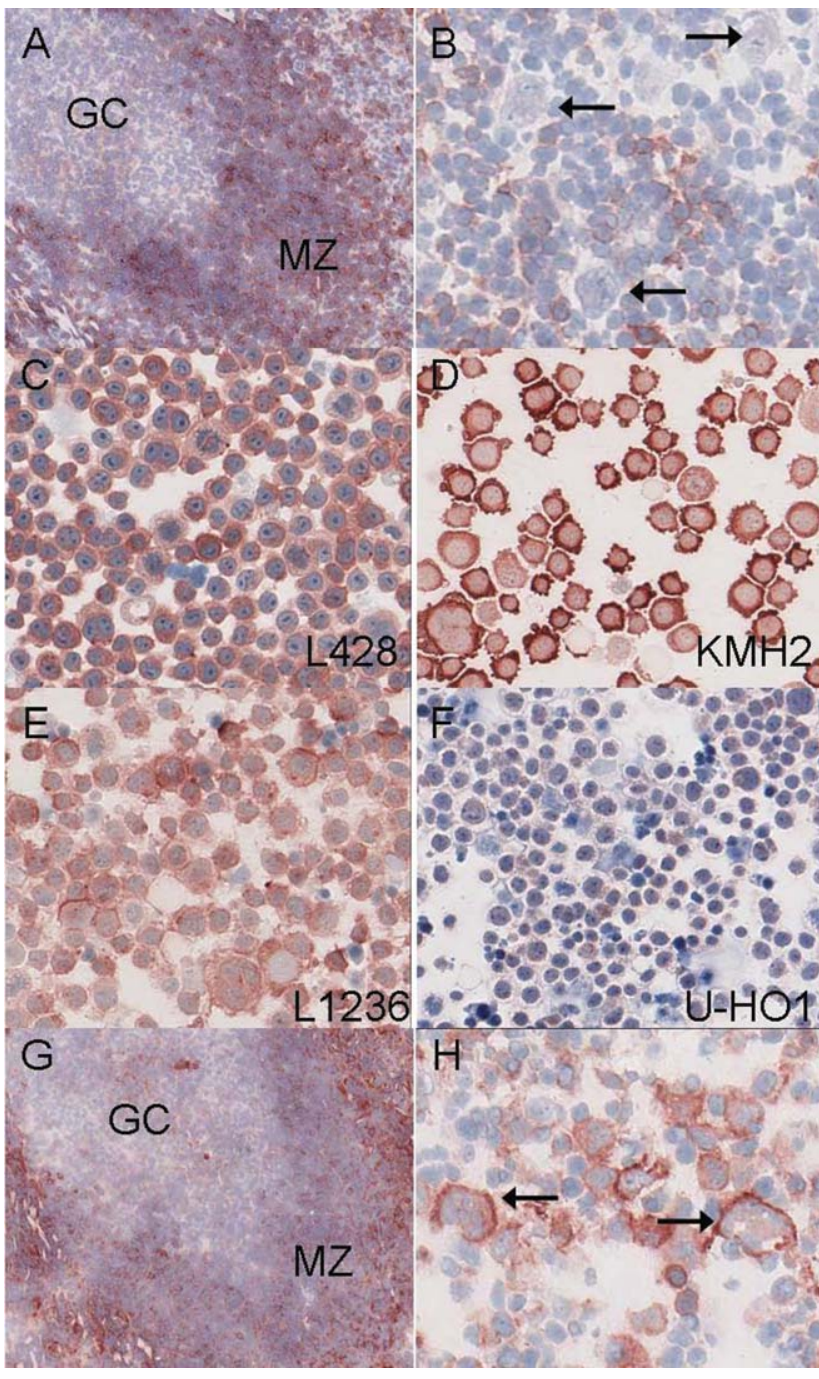

Figure 1. $\quad \mathrm{CD} 1 \mathrm{c}$ and $\mathrm{CD} 1 \mathrm{~d}$ expression in $\mathrm{CHL}$. Both CD1c and CD1d are positive in the mantle zone area and predominantly negative in the germinal center area in tonsil (A and G). Original image magnification: $\times 200$. CD1c is negative in HRS cells (arrows), but positive in reactive cells (B). CD1d is positive both in HRS cells (arrows) and reactive cells $(\mathrm{H})$. Original magnification $\times 400$. CD1d is weakly positive in $\mathrm{U}-\mathrm{HO} 1$, and strongly positive in the other three $\mathrm{cHL}$ cell lines $(\mathrm{C}-\mathrm{F})$. Original image magnification: $\times 400$. [Color figure can be viewed in the online issue, which is available at www.interscience.wiley.com.]

tance of iNKT cells in B cell malignancies [4-6]. In chronic lymphocytic leukemia (CLL), CD1d+ tumor cells loaded with $\alpha$ GalCer can activate iNKT cells and in turn induce cell death of tumor cells [4]. Malignant multiple myeloma is characterized by a reversible functional defect in iNKT cells in comparison with nonprogressive myeloma and premalignant myeloma [5]. Furthermore, iNKT cells were shown to induce effective antilymphoma responses and were essential for the survival of mice in murine lymphoma models [6]. The role of iNKT cells in the immune surveillance in $\mathrm{CHL}$ is unknown. Here, we examined the expression of CD1c and CD1d in HRS cells and tumor infiltrating cells in $44 \mathrm{cHL}$ cases, as well as in four $\mathrm{cHL}$ cell lines. Furthermore, we studied the presence of iNKT cells in cell suspensions of $10 \mathrm{cHL}$ cases.

CD1c was undetectable in CHL cell lines L428, KMH2, L1236, and U-HO1 (data not shown). In tonsil tissue, CD1c stained positive in the mantle zone (MZ) and predominantly negative in the germinal centers $(\mathrm{GC})$ of secondary lymphoid follicles (Fig. 1A) consistent with the previously reported expression pattern [11]. HRS cells in $\mathrm{cHL}$ were consistently CD1c negative in all cases (Fig. 1B), whereas 14 out of 39 non-Hodgkin lymphomas (NHL) were positive (Table I). The absence of CD1c expression in both GC B cells and HRS cells is consistent with the current assumption that HRS cells are derived from GC B cells [12]. CD1c expression has been reported in some
TABLE I. Comparison of Expression of CD1c and CD1d in $\mathrm{cHL}$ and NHL

\begin{tabular}{lccc}
\hline Lymphoma & & CD1c positive (\%) & CD1d positive (\%) \\
\hline $\operatorname{cHL}(n=44)$ & & 0 & 48 \\
& EBV + & & 42 \\
NHL $(n=39)$ & EBV - & 36 & 57 \\
& & 8 & 23 \\
& CLL $(n=13)$ & 57 & 31 \\
& $\mathrm{MCL}(n=7)$ & 67 & 14 \\
& $\mathrm{FL}(n=9)$ & 30 & 22 \\
& $\mathrm{DLBCL}(n=10)$ & & 10 \\
\hline
\end{tabular}

cHL, classical Hodgkin lymphoma; NHL, non-Hodgkin lymphoma; CLL, chronic lymphocytic leukemia; MCL, mantle cell lymphoma; $\mathrm{FL}$, follicular lymphoma; DLBCL, diffuse large $B$ cell lymphoma.

TABLE II. iNKT Cells in cHL and RLN

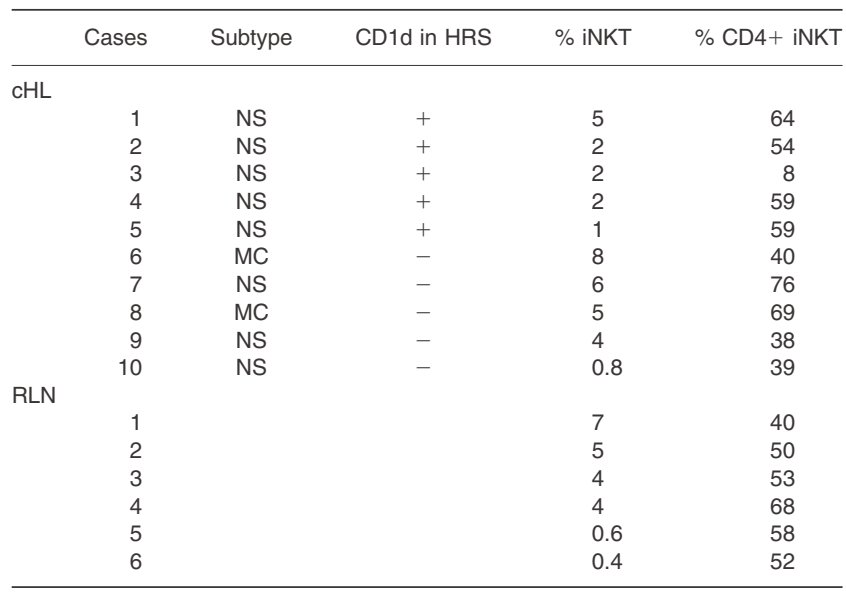

other B-cell NHL subtypes, including GC B cell derived follicular lymphoma [11]. In B-cell NHL, an inverse correlation was noticed between CD1C and the proliferative activity assessed by expression of Ki-67 [11]. This is in line with the lack of CD1c staining in GC B cells that show a high proliferation index and high CD1C expression in the MZ B cells that are in a resting state. Ki-67 was shown to be highly expressed in HRS cells [13] correlating with the lack of CD1c expression. CD1c expression was found in reactive cells in all cases with a percentage varying from a few to the vast majority, similar to the CD1c expression pattern observed in interfollicular regions of tonsil tissue.

In contrast, CD1d was detected in all four $\mathrm{cHL}$ cell lines, varying from weakly positive in $\mathrm{U}-\mathrm{HO} 1$ to strongly positive in the other three $\mathrm{CHL}$ cell lines (Fig. 1C-F). By flowcytometry, we validated that CD1d was present on the membrane in $\mathrm{cHL}$ cell lines (data not shown). In normal tonsil tissue, CD1d staining was observed mainly in the $M Z$ and showed no positive staining in the GC (Fig. 1G) consistent with the reported results [14]. CD1d was detected in HRS cells in 21 out of $44 \mathrm{cHL}$ cases (48\%) (Fig. 1H, Table I, Supporting Information Table I), showing both cytoplasmic and membranous staining. No correlation was found with EBV status and CD1d expression (Table I). CD1d was also positive in the reactive background, usually in more than half of the reactive cells. Nine of the $39 \mathrm{NHL}$ cases were positive for CD1d (23\%, Table I), i.e., in three out of $19 \mathrm{GC}$ B cell derived NHL and in six out of 20 non-GC B cell NHL (Table I, Supporting Information Table I). The CD1d expression in $\mathrm{HL}$ is remarkable since GC B cells and the majority of the GC B cell derived NHL are negative. Positivity of HRS cells indicates that these cells might have acquired CD1d expression during malignant transformation. CD1d expression has been detected in some B cell malignancies, such as CLL [4] and multiple myeloma [5]. In these B cell malignancies, iNKT cells activated by $\alpha$-GalCer loaded CD1d+ tumor cells resulted in the induction of apoptosis of the tumor cells in vitro [4,5].

Since half of the $\mathrm{CHL}$ cases were positive for CD1d in HRS cells, we further investigated the iNKT cell population in cell suspensions of $\mathrm{cHL}$ and reactive lymph node (RLN). The mean percentage of iNKT cells was $4 \%$ (range $0.8-8 \%$ ) in $\mathrm{cHL}$ and $4 \%$ (range $0.4-7 \%$ ) in RLN (Table II). iNKT cells were present at similar percentage in either CD1d positive or CD1d negative 
$\mathrm{cHL}$ cases. Two distinct iNKT subsets have been distinguished as Th1 type $\left(\mathrm{CD} 4^{-}{ }^{-} \mathrm{iNKT}\right)$ and Th2 type $\left(\mathrm{CD} 4^{+}\right.$iNKT) in terms of cytokine production and cytotoxic activation [10]. We observed a similar percentage of CD4+ iNKT cells, i.e., around $50 \%$, in $\mathrm{cHL}$ and RLN (Table II). Given the high expression of CCL17 in HRS cells of $\mathrm{CHL}$ [15] and the high expression of the CCL17 receptor, CCR4, on CD4+ iNKT cells [16], it might be speculated that especially the CD4+ iNKT cells are present in the close vicinity of HRS cells and might favor the survival and growth of HRS cells. Since it is known that the rosetting $\mathrm{CD} 4+\mathrm{CD} 26-\mathrm{T}$ cells in $\mathrm{HL}$ have several features of anergy [17], the CD1d-restricted iNKT cells might also be dysfunctional or anergic favoring HRS cells survival by escaping from an effective immunosurveillance in $\mathrm{CHL}$.

Taken together, we showed expression of CD1d in HRS cells of $\mathrm{CHL}$ cell lines and a significant proportion of $\mathrm{CHL}$ cases as well as the presence of a marked population of iNKT cells in the reactive background of CHL. The CD1diNKT cell axis might play a role in the disturbed immunoregulation in $\mathrm{CHL}$.

\section{Methods}

Patient samples and cell lines. Frozen $\mathrm{cHL}$ samples consisted of 39 cases of nodular sclerosis (NS), four cases of mixed cellularity (MC), and one case of not otherwise specified $\mathrm{CHL}$ (NOS). Frozen samples of $39 \mathrm{NHL}$ cases were used and consisted of 13 chronic lymphocytic leukemia, seven mantle cell lymphoma, nine follicular lymphoma, and 10 diffuse large B cell lymphoma cases. Cell suspensions were available of eight NS and two MC $\mathrm{cHL}$ cases. The cHL cell lines L428, KMH2, L1236, and U-HO1 [18] were cultured in RPMI-1640 medium (Lonza Walkersville, Walkersville, MD) supplemented with ultraglutamine-1, $100 \mathrm{U} / \mathrm{ml}$ penicillin/streptomycin, $10 \%$ fetal calf serum (5\% for L428) (Lonza Walkersville).

Immunohistochemistry. Immunohistochemistry was performed with monoclonal antibodies against CD1c (L161, Abd Serotec, Oxford, UK) and CD1d (NOR3.2, Abcam, Cambridge, UK) (both 1:100) on frozen cHL tissue sections and cytospins using standard laboratory protocols and appropriate positive and negative controls. Cases were defined positive when more than $50 \%$ of tumor cells showed a clear staining.

Flow cytometry. Cells $\left(1 \times 10^{6}\right)$ were stained simultaneously with PE labeled Mouse Anti-Human iNKT Cell (clone 6B11, BD Bioscience, San Jose, CA), FITC labeled anti-TCR V $\beta 11$ (clone C21, Beckman Coulter, Fullerton, CA) and CyQ labeled anti-CD4 (clone Edu-2, IQ Products, Groningen, Netherlands). A total of 100,000 lymphocytes were collected. The percentage of iNKT cells was determined by positive staining for both $6 \mathrm{~B} 11$ and $\mathrm{V} \beta 11$, and the percentage of CD4+ iNKT cells was determined by the percentage of $\mathrm{CD} 4+$ cells among the gated iNKT cells by flowcytometer (Calibur, Becton Dickinson, San Jose, CA). We used an iNKT cell clone as a positive control, and samples without primary antibody were included as a negative control. $\mathrm{CHL}$ cell lines were stained with PE labeled CD1d (clone 51.1, eBioscience, Hatfield, UK), and a IgG2b isotype control antibody, to show the presence of membrane CD1d.

${ }^{1}$ Department of Pathology and Medical Biology, University Medical Center Groningen, University of Groningen, Groningen, The Netherlands; ${ }^{2}$ Division of Infection, Inflammation and Repair, University of Southampton, Southampton General Hospital, Southampton, United Kingdom
Additional Supporting Information may be found in the online version of this article. ${ }^{*}$ Correspondence to: A. van den Berg, Department of Pathology and Medical Biology, University Medical Center Groningen, University of Groningen, PO Box 30.001, Hanzeplein 1, Groningen, 9700 RB. The Netherlands E-mail: a.van.den.berg@path.umcg.n Conflict of interest: Nothing to report. Published online 21 April 2010 in Wiley InterScience (www.interscience.wiley.com). DOI: 10.1002/ajh.21743

\section{References}

1. Poppema S. Immunobiology and pathophysiology of Hodgkin lymphomas. Hematology Am Soc Hematol Educ Program 2005:231-238.

2. Diepstra A, van Imhoff G, Karim-Kos $\mathrm{H}$, et al. HLA class II expression by Hodgkin Reed-Sternberg cells is an independent prognostic factor in classical Hodgkin's lymphoma. J Clin Oncol 2007;25:3101-3108.

3. Zheng Z, Venkatapathy S, Rao G, et al. Expression profiling of B cell chronic lymphocytic leukemia suggests deficient CD1-mediated immunity, polarized cytokine response, altered adhesion and increased intracellular protein transport and processing leukemic cells. Leukemia 2002;16:2429-2437.

4. Fais F, Morabito F, Stelitano C, et al. CD1d is expressed on B-chronic lymphocytic leukemia cells and mediates alpha-galactosylceramide presentation to natural killer T lymphocytes. Int J Cancer 2004;109:402-411.

5. Dhodapkar M, Geller M, Chang D, et al. A reversible defect in natural killer T cell function characterizes the progression of premalignant to malignant multiple myeloma. J Exp Med 2003;197:1667-1676.

6. Renukaradhya G, Khan M, Vieira M, et al. Type I NKT cells protect (and type II NKT cells suppress) the host's innate antitumor immune response to a Bcell lymphoma. Blood 2008;111:5637-5645.

7. Brigl M, Brenner MB. CD1: Antigen presentation and T cell function. Annu Rev Immunol 2004;22:817-890.

8. Sieling PA, Ochoa MT, Jullien D, et al. Evidence for human CD4+ T cells in the CD1 restricted repertoire: Derivation of mycobacteria-reactive $T$ cells from leprosy lesions. J Immunol 2000;164:4790-4796.

9. Dellabonna P, Padovan E, Casorati G, et al. An invariant V alpha 24-J alpha $\mathrm{Q} / \mathrm{V}$ beta 11 Tcell receptor is expressed in all individuals by clonally expanded CD4-CD8-T cells. J Exp Med 1994:180:1171-1176.

10. Gumperz J, Miyake S, Yamamura T, Brenner M. Functionally distinct subsets of CD1d-restricted natural killer T cells revealed by CD1d tetramer staining. J Exp Med 2002;195:625-636.

11. Smith ME, Thomas JA, Bodmer WF. CD1C antigens are present in normal and neoplastic B-cells. J Pathol 1988;156:169-177.

12. Kanzler H, Kuppers R, Hansmann ML, Rajewsky K. Hodgkin and Reed-Sternberg cells in Hodgkin's disease represent the outgrowth of a dominant tumor clone derived from (crippled) germinal center B cells. J Exp Med 1996;184:1495-1505.

13. Kim LH, Eow GI, Peh SC, Poppema S. The role of CD30, CD40 and CD95 in the regulation of proliferation and apoptosis in classical Hodgkin's lymphoma. Pathology 2003;35:428-435.

14. Exley M, Garcia J, Wilson SB, et al. CD1d structure and regulation on human thymocytes, peripheral blood $\mathrm{T}$ cells, B cells and monocytes. Immunology 2000;100:37-47.

15. Niens M, Visser L, Nolte IM, et al. Serum chemokine levels in Hodgkin lymphoma patients: Highly increased levels of CCL17 and CCL22. Br J Haematol 2008;140:527-536.

16. Kim C, Johnston B, Butcher E. Trafficking machinery of NKT cells: Shared and differential chemokine receptor expression among Valpha 24+Vbeta 11+ NKT cell subsets with distinct cytokine-producing capacity. Blood 2002;100:11-16.

17. Ma Y, Visser L, Blokzijl T, et al. The CD4+CD26-T-cell population in classical Hodgkin's lymphoma displays a distinctive regulatory T-cell profile. Lab Invest 2008;88:482-490.

18. Mader A, Bruderlein S, Wegener S, et al. U-HO1, a new cell line derived from a primary refractory classical Hodgkin lymphoma. Cytogenet Genome Res 2007;119:204-210.

\title{
Analysis of the REL, BCL11A, and MYCN proto-oncogenes belonging to the $2 p$ amplicon in chronic lymphocytic leukemia
}

\author{
Clara Deambrogi, ${ }^{1}$ Lorenzo De Paoli, ${ }^{1}$ Marco Fangazio, ${ }^{1}$ Stefania Cresta, ${ }^{1}$ Silvia Rasi, ${ }^{1}$ Valeria Spina, ${ }^{1}$ \\ Valter Gattei, ${ }^{2}$ Gianluca Gaidano, ${ }^{1}$ and Davide Rossi ${ }^{1 *}$
}

The genetic profile of chronic lymphocytic leukemia (CLL) is characterized by a pool of recurrent lesions, including trisomy 12, deletions of 13q14, 11q22-q23, 17p13, and 6q21, and $t(14)(q 32)$ translocations [1]. The aforementioned lesions can be detected by FISH and may harbor prognostic information [1]. Array-based comparative genomic hybridization (aCGH) has identified gain of multiple regions on the short arm of chromosome 2 as a recurrent CLL lesion, that contain the REL,
$B C L 11 A$, and $M Y C N$ proto-oncogenes that are involved in hematologic malignancies [2-5]. The exact prevalence of REL, BCL11A, and MYCN gains at the time of CLL diagnosis is currently unknown in consecutive series of the disease. Moreover, some studies indicate that $2 p$ gains as a whole may herald progressive and/or poor risk disease, yet the prognostic contribution of the individual genes included in the amplicon, i.e., REL, BCL11A, and MYCN, remains undefined [4-6]. The 
aim of this study was twofold: (i) characterize the prevalence of $R E L$, $B C L 11 A$, and MYCN gains in a consecutive CLL series at the time of diagnosis; (ii) define the prognostic relevance of REL, BCL11A, and $M Y C N$ gains in CLL.

The study is based on a consecutive series of 176 newly diagnosed and phenotypically typical CLL (median Matutes score: 5 ; range 4-5) [7,8], representative of all disease stages. The biological and clinical characteristics of the CLL series are reported in Table I. By FISH, gain of REL was observed in 6/176 (3.4\%) cases, gain of BCL11A in 5/176 (2.8\%), and gain of $M Y C N$ in $4 / 176(2.3 \%)$. The median percentage of nuclei harboring gains was $46.8 \%$ (range: $18.0-85.0 \%$ ) for $R E L, 66 \%$ (range: $14.0-77.4 \%$ ) for $B C L 11 A$, and $78.2 \%$ (range: $45.0-90.0 \%$ ) for $M Y C N$. The number of additional copies was 1 for REL, 1 for BCL11A, and 1 for MYCN. REL, BCL11A, and MYCN were concomitantly gained in the same clone in $4 / 176(2.3 \%)$ cases. REL and $B C L 11 A$, but not $M Y C N$, were concomitantly gained in the same clone in $1 / 176(0.5 \%)$ cases. In $1 / 176(0.5 \%)$ cases, the sole REL gene was gained.

Analysis of survival in patients with $2 p$ gains revealed that all but one patient with $2 p$ gains including MYCN have died for CLL progression or transformation to Richter syndrome (Table II). In contrast, the two patients harboring $2 p$ gains not including $M Y C N$ were alive and treatment free after a follow-up of 88 and 105 months, respectively (Table II).

On the basis of these observations, we analyzed the impact of $M Y C N$ gain on CLL presentation and outcome. By comparing biological and clinical features at diagnosis, no differences were observed between CLL with gain of $M Y C N$ compared with those devoid of such genetic lesion, with the possible exception of a higher absolute lymphocyte count in cases carrying $M Y C N$ gain $(P=0.029$; Table I).

The impact of $M Y C N$ gain on CLL prognosis was estimated by utilizing OS as a clinical endpoint. In the whole CLL cohort, after a median follow-up of 72.1 months for alive patients, 39/176 patients had died, accounting for a 5 -years OS of $84.1 \%$. By univariate analysis, CLL harboring MYCN gain at diagnosis were at increased risk of death (Events/N: 3/4; HR: $5.35 ; 95 \% \mathrm{Cl}$ 1.62-17.68; $P=0.006$; 6-years OS: $25.0 \%$; $95 \% \mathrm{Cl} 0-67.5 \%$ ) compared with CLL without $M Y C N$ gain (Events/N: 36/172; 6-year OS: 80.8\%; $95 \% \mathrm{Cl}$ 74.0-87.6\%) (Table III and Fig. 1). Other features at diagnosis associated with CLL survival by univariate analysis were those expected in a consecutive CLL series and included IGHV homology $\geq 98 \%(P=0.005),+12(P=$ 0.049), 11q22-q23 deletion $(P=0.014), 17 p 13$ deletion $(P<0.001)$, TP53 mutations $(P=0.048)$, CD38 expression $(P=0.006)$, age $>70$ years $(P<$ $0.001)$, Binet stage B-C $(P<0.001)$, and beta-2-microglobulin $>2.5 \mathrm{mg} / \mathrm{l}(P$ $=0.001$ ) (Table III).

By multivariate analysis, gain of $M Y C N$ was selected as an independent predictor of OS in this CLL cohort (HR: $4.79 ; 95 \% \mathrm{Cl} 1.31-17.39 ; P=$ 0.017 ), along with $17 \mathrm{p} 13$ deletion (HR: $2.28 ; 95 \% \mathrm{Cl} 1.01-5.15 ; P=0.045$ ), age $>70$ years (HR 3.89; 95\% Cl: $1.88-8.05 ; P<0.001)$, and Binet stage B-C (HR: 3.31; 95\% Cl 1.55-7.06; $P=0.002$ ) (Table III).

This study suggests that: (i) gains of REL, BCL11A, and MYCN occur at low frequency at CLL diagnosis; and (ii) $2 p$ gains including $M Y C N$ might have potential prognostic relevance in CLL.

Gains of REL, BCL11A, or MYCN have been reported by Chapiro et al. [5] to occur in $10 \%$ CLL, a prevalence that is higher than the $2-3 \%$ prevalence observed in our cohort. The discrepancy between our study and the study by Chapiro et al. [5] may be explained by the differences that distinguish the two CLL cohorts. Indeed, Chapiro et al. [5] analyzed REL, BCL11A, or MYCN in $86 \mathrm{CLL}$, all Binet stage B-C, at the time of treatment requirement. On the contrary, our study was based on a consecutive series of $176 \mathrm{CLL}$, that included all Binet stages and that in all cases have been analyzed at the time of diagnosis.

Some studies suggest that, in CLL, $2 p$ gains as a whole may associate with poor risk features, such as advanced stage, unmutated IGHV genes, and 17p13 deletion [4-6]. Our results are consistent with these observations and suggest that, among individual proto-oncogenes included in the $2 p$ amplicon, poor prognosis may be heralded by gain of $M Y C N$. The relevance of $M Y C N$ gain in determining CLL prognosis is also suggested by the observation that, in our cohort, the negative prognostic impact associated with gain of $M Y C N$ appears to be independent of stage at presentation, IGHV mutation status, or presence of $17 \mathrm{p} 13$ deletion. Future studies are required to validate these results in larger patient populations.

TABLE I. Biological and Clinical Characteristics and Cause of Death of the CLL Series According to MYCN Status ${ }^{\text {a }}$

\begin{tabular}{|c|c|c|c|c|}
\hline \multirow[b]{2}{*}{ Characteristics } & \multirow[b]{2}{*}{ All patients } & \multicolumn{3}{|c|}{$M Y C N$} \\
\hline & & Gain & Normal & $P$ \\
\hline \multicolumn{5}{|l|}{ Biological variables } \\
\hline IGHV homology $\geq 98 \%$ & $62 / 173(35.8 \%)$ & $3 / 4(75.0 \%)$ & 59/169 (34.9\%) & 0.132 \\
\hline Stereotyped HCDR3 & $42 / 173(24.3 \%)$ & $1 / 4(25.0 \%)$ & $41 / 169(24.3 \%)$ & 1.000 \\
\hline \multicolumn{5}{|l|}{ FISH } \\
\hline Normal & $46 / 176(26.1 \%)$ & $0 / 4$ & $46 / 172(26.7 \%)$ & 0.574 \\
\hline del13q14 & $91 / 176(51.7 \%)$ & $3 / 4(75.0 \%)$ & $88 / 172(51.2 \%)$ & 0.622 \\
\hline+12 & $36 / 176(20.5 \%)$ & $0 / 4$ & $36 / 172(20.9 \%)$ & 0.583 \\
\hline del11q22-q23 & $13 / 176(7.4 \%)$ & $1 / 4(25.0 \%)$ & $12 / 172(7.0 \%)$ & 0.266 \\
\hline del17p13 & $19 / 176(10.8 \%)$ & $2 / 4(50.0 \%)$ & $17 / 172(9.9 \%)$ & 0.058 \\
\hline del6q21 & $5 / 170(2.9 \%)$ & $0 / 4$ & $5 / 166(3.0 \%)$ & 1.000 \\
\hline$t(14)(q 32)$ & $15 / 175(8.6 \%)$ & $1 / 4(25.0 \%)$ & $14 / 171(8.2 \%)$ & 0.304 \\
\hline TP53 mutation & $18 / 160(11.3 \%)$ & $1 / 4(25.0 \%)$ & $17 / 156(10.9 \%)$ & 0.383 \\
\hline CD38 $\geq 30 \%$ & $48 / 176(27.3 \%)$ & $1 / 4(25.0 \%)$ & $47 / 172(27.3 \%)$ & 1.000 \\
\hline ZAP70 $\geq 20 \%$ & $50 / 159(31.4 \%)$ & $2 / 4(50.0 \%)$ & $48 / 155(31.0 \%)$ & 0.591 \\
\hline CD49d $\geq 30 \%$ & $68 / 161(42.0 \%)$ & $1 / 4(25.0 \%)$ & $67 / 157(42.7 \%)$ & 0.639 \\
\hline Matutes score & $5(4-5)$ & $5(4-5)$ & $5(4-5)$ & 0.987 \\
\hline \multicolumn{5}{|l|}{ Clinical variables } \\
\hline Age (years) & $69(61-76)$ & $68(63-84)$ & $68(61-75)$ & 0.578 \\
\hline Male & $92 / 176(52.3 \%)$ & $3 / 4(75.0 \%)$ & $89 / 172(51.7 \%)$ & 0.622 \\
\hline Binet stage $B-C$ & $40 / 176(22.7 \%)$ & $0 / 4$ & $40 / 172(23.3 \%)$ & 0.575 \\
\hline Splenomegaly & $27 / 176(15.3 \%)$ & $2 / 4(50.0 \%)$ & $25 / 172(14.5 \%)$ & 0.112 \\
\hline Nodal involvement & $59 / 176(33.5 \%)$ & $0 / 4$ & $59 / 172(34.3 \%)$ & 0.302 \\
\hline Lymph node size $\geq 3 \mathrm{~cm}$ & $27 / 176(15.3 \%)$ & $0 / 4$ & $27 / 172(15.7 \%)$ & 1.000 \\
\hline PB lymphocytes $\left(\times 10^{9} / l\right)$ & $10.5(5.9-19.0)$ & $22.9(16.2-123.3)$ & $10.3(5.6-18.5)$ & 0.029 \\
\hline BM lymphocytes $(\%)^{b}$ & $40(20-56)$ & $70(32-85)$ & $40(20-65)$ & 0.178 \\
\hline Diffuse BM pattern & $32 / 172(18.6 \%)$ & $2 / 4(50.0 \%)$ & $35 / 168(20.8 \%)$ & 0.203 \\
\hline Beta-2-microglobulin > $2.5 \mathrm{mg} / \mathrm{l}$ & $79 / 176(44.9 \%)$ & $3 / 4(75.0 \%)$ & $76 / 172(44.2 \%)$ & 0.327 \\
\hline LDH > ULN & $32 / 176(18.2 \%)$ & $2 / 4(50.0 \%)$ & $30 / 172(17.4 \%)$ & 0.152 \\
\hline \multicolumn{5}{|l|}{ Cause of death } \\
\hline CLL & $19 / 39(48.7 \%)$ & 1/3 (33.3\%) & $18 / 36(50.0 \%)$ & \\
\hline Infection & $5 / 39(12.8 \%)$ & $0 / 3$ & $5 / 36(13.9 \%)$ & \\
\hline Secondary cancer & $6 / 39(15.4 \%)$ & $1 / 3(33.3 \%)$ & $5 / 36(13.9 \%)$ & \\
\hline Other & $9 / 39(23.1 \%)$ & $1 / 3(33.3 \%)$ & $8 / 36(22.2 \%)$ & \\
\hline
\end{tabular}

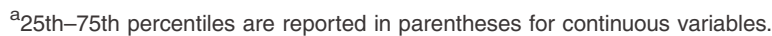

bercentage of BM lymphocytes was determined on BM biopsies.IGHV, immunoglobulin heavy chain variable gene; HCDR3, immunoglobulin heavy chain complementarity determining region 3 ; $\mathrm{PB}$, peripheral blood; $\mathrm{BM}$, bone marrow. 


\section{Methods}

Patients. The study was based on a consecutive series of 176 previously untreated CLL who presented for initial evaluation at the Division of Hematology of the Amedeo Avogadro University of Eastern Piedmont from June 1996 through June 2008. Patients provided informed consent in accordance with local IRB requirements and Declaration of Helsinki. CLL diagnosis was based on $\mathrm{NCl}$ criteria and confirmed by a flow cytometry score $>3[7,8]$.
The following biological variables were analyzed on peripheral blood mononuclear cells (PBMNC) collected at diagnosis: (i) IGHV gene homology to germline; (ii) FISH karyotype; (iii) TP53 mutations; (iv) CD38, ZAP70, and CD49d expression. Patients were managed according to $\mathrm{NCl}$ guidelines [7].

Interphase FISH. Probes used for FISH analysis were as follows: (i) LSI13 and LSID13S319 for detection of 13q14 deletion; CEP12 for detection of aneuploidy of chromosome 12; LSIp53 for detection of $17 \mathrm{p} 13$ dele-

TABLE II. Biological and Clinical Characteristics at Diagnosis of the CLL Patient with MYCN gain

\begin{tabular}{|c|c|c|c|c|}
\hline & \multicolumn{4}{|c|}{ Patient with MYCN gain } \\
\hline & Patient 1 & Patient 2 & Patient 3 & Patient 4 \\
\hline \multicolumn{5}{|l|}{ Biological variables } \\
\hline del13q14 & Positive & Positive & Negative & Positive \\
\hline Normal & Negative & Negative & Negative & Negative \\
\hline+12 & Negative & Negative & Negative & Negative \\
\hline del11q22-q23 & Negative & Positive & Negative & Negative \\
\hline del17p13 & Positive & Negative & Positive & Negative \\
\hline TP53 mutation & Unmutated & Unmutated & Mutated & Unmutated \\
\hline IGHV homology $\geq 98 \%$ & No & Yes & Yes & Yes \\
\hline CD38 $\geq 30 \%$ & No & No & No & Yes \\
\hline $\mathrm{ZAP} 70 \geq 20 \%$ & No & Yes & No & Yes \\
\hline CD49d $\geq 30 \%$ & Yes & No & No & No \\
\hline \multicolumn{5}{|l|}{ Clinical variables } \\
\hline Age & 73 & 88 & 64 & 64 \\
\hline Sex & Male & Male & Male & Female \\
\hline Binet stage & A & A & A & A \\
\hline Rai stage & III & III & 0 & 0 \\
\hline ECOG performance status & 0 & 0 & 2 & 1 \\
\hline $\mathrm{Hb}(\mathrm{g} / \mathrm{dl})$ & 10.7 & 10.4 & 12.5 & 14.1 \\
\hline Platelets $\left(\times 10^{9} / \mathrm{l}\right)$ & 113 & 108 & 146 & 202 \\
\hline Beta-2-microglobulin (mg/l) & 3.2 & 4.2 & 1.3 & 3.0 \\
\hline PB lymphocytes count $\left(\times 10^{9} / \mathrm{l}\right)$ & 155.2 & 18.1 & 27.7 & 15.6 \\
\hline BM lymphocytes infiltration percentage (\%) & 90 & 70 & 70 & 20 \\
\hline Diffuse BM pattern & Diffuse & Not diffuse & Diffuse & Not diffuse \\
\hline LDH $>$ ULN & Yes & No & No & Yes \\
\hline Splenomegaly & Yes & Yes & No & No \\
\hline Nodal involvement & Not involved & Not involved & Not involved & Not involved \\
\hline Treatment free survival (months) & 0 & 0 & 2 & 83 \\
\hline Lines of therapies & 4 & 1 & 0 & 0 \\
\hline Fludarabine refractoriness & Yes & NA & NA & NA \\
\hline Alkylator agents refractoriness & Yes & Yes & NA & NA \\
\hline Richter's syndrome transformation & Transformed & Not transformed & Not transformed & Not transformed \\
\hline Overall survival (months) & 36 & 74 & 2 & 83 \\
\hline Status & Dead & Dead & Dead & Alive \\
\hline
\end{tabular}

PB, peripheral blood; BM, bone marrow; NA, not applicable.

TABLE III. Biological and Clinical Characteristics of the CLL Series Predicting OS by Univariate and Multivariate Cox Analysis

\begin{tabular}{|c|c|c|c|c|c|c|c|c|c|}
\hline & \multirow[b]{2}{*}{ Events/patients } & \multicolumn{4}{|c|}{ Univariate } & \multicolumn{4}{|c|}{ Multivariate $^{\mathrm{a}}$} \\
\hline & & $\mathrm{HR}$ & $95 \%$ LCl & $95 \% \mathrm{UCl}$ & $P$ & $\mathrm{HR}$ & $95 \% \mathrm{LCl}$ & $95 \%$ UCl & $P$ \\
\hline \multicolumn{10}{|l|}{ Biological variables } \\
\hline$M Y C N$ gain & $39 / 176$ & 5.358 & 1.623 & 17.688 & 0.006 & 4.790 & 1.319 & 17.395 & 0.017 \\
\hline del13q14 & $39 / 176$ & 0.650 & 0.398 & 1.063 & 0.086 & & & & \\
\hline Normal & $39 / 176$ & 0.832 & 0.460 & 1.504 & 0.543 & & & & \\
\hline+12 & $39 / 176$ & 1.677 & 1.003 & 2.805 & 0.049 & & & & \\
\hline del11q22-q23 & $39 / 176$ & 2.324 & 1.182 & 4.567 & 0.014 & & & & \\
\hline del17p13 & $39 / 176$ & 3.339 & 1.829 & 6.094 & $<0.001$ & 2.289 & 1.017 & 5.151 & 0.045 \\
\hline TP53 mutation & $37 / 160$ & 2.451 & 1.007 & 5.966 & 0.048 & & & & \\
\hline IGHV homology $\geq 98 \%$ & $39 / 173$ & 2.525 & 1.318 & 4.836 & 0.005 & 1.642 & 0.790 & 3.411 & 0.184 \\
\hline CD38 $\geq 30 \%$ & $39 / 176$ & 2.475 & 1.305 & 4.694 & 0.006 & & & & \\
\hline ZAP70 $\geq 20 \%$ & $35 / 159$ & 1.011 & 0.993 & 1.029 & 0.249 & & & & \\
\hline$C D 49 d \geq 30 \%$ & $35 / 171$ & 1.687 & 0.865 & 3.290 & 0.125 & & & & \\
\hline \multicolumn{10}{|l|}{ Clinical variables } \\
\hline Age $>70$ years & $39 / 176$ & 4.290 & 2.106 & 8.740 & $<0.001$ & 3.892 & 1.881 & 8.052 & $<0.001$ \\
\hline Male sex & $39 / 176$ & 1.203 & 0.636 & 2.276 & 0.570 & & & & \\
\hline Binet stage B-C & $39 / 176$ & 3.727 & 1.963 & 7.076 & $<0.001$ & 3.316 & 1.555 & 7.069 & 0.002 \\
\hline Splenomegaly & $39 / 176$ & 4.194 & 2.191 & 8.026 & $<0.001$ & & & & \\
\hline Nodal involvement & $39 / 176$ & 2.111 & 1.059 & 4.208 & 0.034 & & & & \\
\hline Lymph node size $\geq 3 \mathrm{~cm}$ & $39 / 176$ & 3.039 & 1.444 & 6.398 & 0.003 & & & & \\
\hline PB lymphocytes > $20 \times 10^{9} / 1$ & $39 / 176$ & 1.511 & 0.772 & 2.957 & 0.228 & & & & \\
\hline BM lymphocytes > 50\% & $38 / 172$ & 2.837 & 1.375 & 5.851 & 0.005 & & & & \\
\hline Diffuse BM pattern & $38 / 172$ & 3.088 & 1.621 & 5.885 & 0.001 & & & & \\
\hline Beta-2-microglobulin > $2.5 \mathrm{mg} / \mathrm{l}$ & $39 / 176$ & 3.295 & 1.639 & 6.623 & 0.001 & & & & \\
\hline LDH $>$ ULN & $39 / 176$ & 1.911 & 0.971 & 3.762 & 0.061 & & & & \\
\hline
\end{tabular}

${ }^{\mathrm{a}}$ Events/patients = 39/173. HR, hazard ratio; LCI, lower confidence interval; UCl, upper confidence interval; IGHV, immunoglobulin heavy chain variable gene; PB, peripheral blood; BM, bone marrow. 


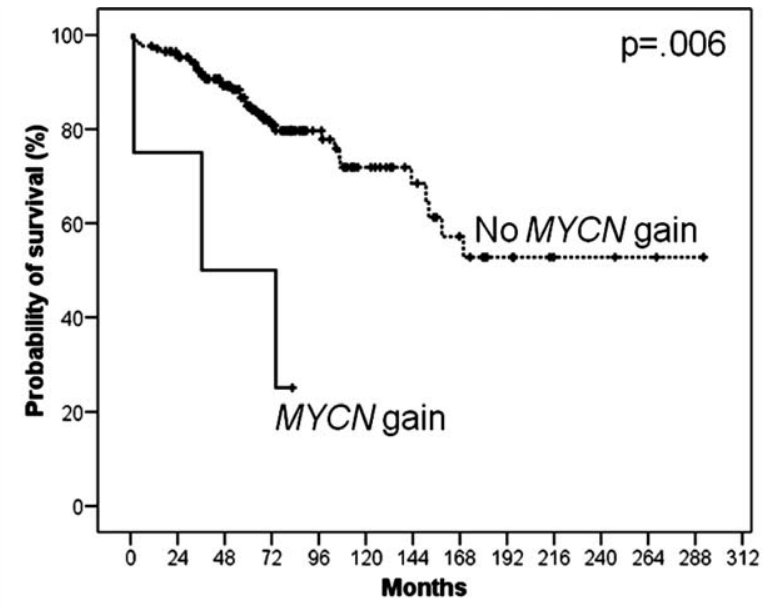

\begin{tabular}{lccc}
\hline & Events/N & 6-years OS & $\mathbf{9 5 \% ~ C l}$ \\
\hline No MYCN gain & $36 / 172$ & $80.8 \%$ & $74.0-87.6 \%$ \\
MYCN gain & $3 / 4$ & $25.0 \%$ & $0-67.5 \%$ \\
\hline
\end{tabular}

Figure 1. Kaplan-Meier curves of overall survival according to MYCN status. CLL harboring $M Y C N$ gain at diagnosis have a significantly lower survival probability compared with CLL without MYCN gain.

tion; LSIATM for detection of 11q22-q23 deletion; LSI N-MYC for detection of MYCN gain; LSI IGH dual color break-apart for detection of $\mathrm{t}(14)$ (q32) translocation (Abbott, Rome, Italy); (ii) 6q21/alpha-satellite for detection of 6q21 deletion (Kreatech Biotechnology, Amsterdam, The Netherlands); (iii) BAC clones 373L24-rel for detection of REL gain and 440P05-BCL11A for detection of $B C L 11 A$ gain. Nuclei were counterstained with $4^{\prime}, 6^{\prime}$-diamidino2-phenylindole (DAPI) and antifade, and signals were visualized using an Olympus BX51 microscope (Olympus Italia, Milan, Italy). For each probe, at least 500 interphase cells with well-delineated fluorescent spots were examined.

Analysis of IGHV rearrangements. IGHV rearrangements were amplified from genomic DNA and directly sequenced [9]. Sequences were aligned to ImMunoGeneTics (IMGT) directories, and considered mutated if homology to the corresponding germline gene was $<98 \%$.

Analysis of TP53 mutations. Mutation analysis of TP53 exons 2 through 10 was performed by DNA direct sequencing on an $A B I$ Prism 3100 automated DNA sequence analyzer (Applied Biosystems, Foster City, CA) [10].

Flow cytometry. A FACScalibur flow cytometer (Becton-Dickinson, San Jose, CA) was utilized for flow cytometric analysis. Expression of CD38, ZAP70, and CD49d was analyzed as reported [11]. Cut-off points of $30 \%$, $20 \%$, and $30 \%$ were utilized to define positivity for CD38, ZAP70, and CD49d, respectively.

Statistical analysis. Overall survival (OS) was measured from CLL diagnosis to last follow-up (censoring) or death. Categorical variables were compared by chi-square test or exact tests when appropriate. Continuous variables were compared by Mann-Whitney test. Survival analysis was performed by Kaplan-Meier method using log-rank statistics to test for significant associations. Multivariate analysis was performed by Cox proportional hazard regression. All statistical tests were two-sided. Statistical significance was defined as $P$-value $<0.05$. The analysis was performed with SPSS software v.17.0 (Chicago, IL).

\section{Author Contributions}

D.R. and C.D. designed the study, interpreted data, performed statistical analysis, and drafted the manuscript; G.G. contributed to study design, data interpretation, and drafting the manuscript; L.D.P. and M.F. collected biological and clinical data; S.C. performed FISH analysis; S.R. and V.S. performed IGHV gene and TP53 mutation analysis; and V.G. contributed to data analysis and interpretation.

${ }^{1}$ Division of Hematology, Department of Clinical and Experimental Medicine and BRMA, Amedeo Avogadro University of Eastern Piedmont and Azienda Ospedaliero-Universitaria Maggiore della Carità, Novara, Italy; ${ }^{2}$ Clinical and Experimental Onco-Hematology Unit, Centro di Riferimento Oncologico, I.R.C.C.S., Aviano, Italy

Contract grant sponsors: Progetto Giovani Ricercatori 2008, Ministero della Salute, Rome, Italy; Progetto FIRB-Programma Futuro in Ricerca 2008, Miur Rome, Italy; Ricerca Sanitaria Finalizzata, Regione Piemonte, Torino, Italy; Progetto Integrato Oncologia, Ministero della Salute, Rome, Italy; Fondazione CRT, Torino, Italy; Novara-AIL Onlus, Novara, Italy; Ministero della Salute (Ricerca Finalizzata I.R.C.C.S. and Alleanza Contro il Cancro), Rome, Italy; AIL Venezia, Pramaggiore, Italy; Ricerca Scientifica Applicata, Regione Friuli Venezia Giulia, Trieste, Italy; Associazione Franca Capurro per Novara Onlus ${ }^{*}$ Correspondence to: D. Rossi, Division of Hematology, Department of Clinical and Experimental Medicine and BRMA, Amedeo Avogadro University of Eastern Piedmont, Via Solaroli 17, 28100 Novara, Italy E-mail: rossidav@med.unipmn.it Received for publication 8 March 2010; Accepted 16 April 2010 Conflict of interest: Nothing to report. Published online 21 April 2010 in Wiley InterScience (www.interscience.wiley.com) DOI: 10.1002/ajh.21742

\section{References}

1. Döhner H, Stilgenbauer S, Benner A, et al. Genomic aberrations and survival in chronic lymphocytic leukemia. N Engl J Med 2000;343:1919-1916.

2. Schwaenen $C$, Nessling $M$, Wessendorf $S$, et al. Automated array-based genomic profiling in chronic lymphocytic leukemia: Development of a clinical tool and discovery of recurrent genomic alterations. Proc Natl Acad Sci USA 2004;101:1039-1044.

3. Pfeifer D, Pantic M, Skatulla I, et al. Genome-wide analysis of DNA copy number changes and LOH in CLL using high-density SNP arrays. Blood 2007:109:1202-1210.

4. Forconi F, Rinaldi A, Kwee I, et al. Genome-wide DNA analysis identifies recurrent imbalances predicting outcome in chronic lymphocytic leukaemia with 17p deletion. Br J Haematol 2008;143:532-536.

5. Chapiro E, Leporrier N, Radford-Weiss I, et al. Gain of the short arm of chromosome $2(2 p)$ is a frequent recurring chromosome aberration in untreated chronic lymphocytic leukemia (CLL) at advanced stages. Leuk Res 2010;34: 63-68.

6. Haferlach C, Dicker F, Schnittger S, et al. Comprehensive genetic characterization of CLL: A study on 506 cases analysed with chromosome banding analysis, interphase FISH, $\operatorname{lgV}(\mathrm{H})$ status and immunophenotyping. Leukemia 2007;21:2442-2451.

7. Cheson BD, Bennett JM, Grever M, et al. National Cancer InstituteSponsored Working Group guidelines for chronic lymphocytic leukemia: Revised guidelines for diagnosis and treatment. Blood 1996;87:49904997.

8. Matutes E, Owusu-Ankomah K, Morilla R, et al. The immunological profile of B-cell disorders and proposal of a scoring system for the diagnosis of CLL. Leukemia 1994;8:1640-1645.

9. Rossi D, Spina V, Cerri M, Rasi S, et al. Stereotyped B-cell receptor is an independent risk factor of chronic lymphocytic leukemia transformation to Richter syndrome. Clin Cancer Res 2009;15:4415-4422.

10. Rossi D, Cerri M, Deambrogi C, et al. The prognostic value of TP53 mutations in chronic lymphocytic leukemia is independent of Del17p13: Implications for overall survival and chemorefractoriness. Clin Cancer Res 2009;15:995-1004.

11. Gattei V, Bulian P, Del Principe MI, et al. Relevance of CD49d protein expression as overall survival and progressive disease prognosticator in chronic lymphocytic leukemia. Blood 2008;111:865-873. 